\title{
Dialogizität in der Predigt
}

Einer der meistdiskutierten Aspekte in Bezug auf die Predigt ist die Frage nach ihrem kommunikativ-dialogischen Charakter. Aufgrund der strukturell-formalen Eigenschaften der Predigt als Bühnenformat scheint die Frage dahingehend schnell und eindeutig beantwortbar, als dass die Predigt als vordergründig monologisches Geschehen erscheint. So beschreibt Goffman in seiner Konzeption des Bühnenformats (platform event) nicht nur eine räumlich exponierte Position einer einzelnen Person gegenüber einer Gruppe von Menschen (siehe Kapitel 14), sondern auch den Bühnen-Monolog (platform monologue; vgl. Goffman 1979:12) als charakteristisches Merkmal:

These entertainments involve long stretches of words coming from a single speaker who has been given a relatively large set of listeners and exclusive claim to the floor. [...] And when talk comes from the podium, what does the hearing is an audience, not a set of fellow conversationalists. (Goffman 1979:12)

Dass ein einzelner Sprecher zu einer Gruppe von ratifizierten Rezipierenden spricht, die selbst keinen unmittelbaren verbalen Gesprächsbeitrag produzieren, ist auch für den Wortbeitrag christlicher Predigten konstitutiv. So erhält auch in den hier untersuchten Daten der jeweilige Prediger über einen mehr oder weniger langen Zeitraum das exklusive Rederecht und spricht zu einer Gruppe zeitlich, räumlich und körperlich ko-präsenter Personen, die wiederum auf den ersten Blick ,nur' rezipierend am Geschehen beteiligt sind (siehe Kapitel 14 zur Interaktionsordnung). Im Gegensatz zu anderen Bühnenformatgattungen, wie politischen Reden, bei denen die ko-präsenten Anwesenden immer wieder aktive

Elektronisches Zusatzmaterial Die elektronische Version dieses Kapitels enthält Zusatzmaterial, das berechtigten Benutzern zur Verfügung steht https://doi.org/10.1007/978-3-658-33855-8_17.

(C) Der/die Autor(en) 2021 
Beteiligung zeigen (u. a. in Form von Klatschen oder kurzen Zwischenrufen; vgl. u. a. Atkinson 1994) bzw. explizit und implizit dazu aufgefordert werden, ist dies in Predigten meist nicht der Fall. Allerdings haben die bisherigen Analysen in der vorliegenden Arbeit bereits einen Hinweis darauf gegeben, dass die Predigt als Gesamtereignis nicht als rein monologisches Geschehen betrachtet und beschrieben werden kann, sondern sich immer wieder interaktive und dialogische Elemente zeigen. Es muss also auch hier zwischen der Predigt als Gesamtereignis und dem Wortbeitrag als spezifischem Aktivitätstyp der Gattung unterschieden werden, um ein differenziertes Bild der interaktiven Potenziale der Gattung zu zeichnen.

Sowohl in der homiletischen Tradition als auch in interaktionslinguistischen Arbeiten wird die Frage nach dem Dialog und der Dialogizität in institutionell gerahmter religiöser Kommunikation vor allem mit Blick auf den Gottesdienst gestellt. So beschreibt Gülich dialogische Sequenzen in Gottesdiensten als Teil institutionell verfestigter und geregelter Kommunikation, bei der die beteiligten Personen als ,Aktanten“ (Prediger) bzw. ,Klienten“ festgelegte „Handlungsmöglichkeiten" (Gülich 1981:421) haben und diesen innerhalb des Rituals Gottesdienst folgen. Entsprechend beschreibt sie erkennbare Sprecherwechselsequenzen zwar als wesentlichen Bestandteil von Gottesdiensten, diese seien aber lediglich ritualisierte, institutionalisierte und inszenierte Dialogelemente (vgl. Gülich 1981:441). Aufgrund dessen erschöpft sich das konversations- und interaktionsanalytische Interesse an Settings wie dem Gottesdienst und der Predigt verhältnismäßig schnell, da der enge Dialog- bzw. Interaktionsbegriff der CA wenig gewinnbringend für die Analyse erscheint. Dies führt auch dazu, dass es in der bisherigen linguistischen Forschung nur vereinzelte Studien zu den dialogischen bzw. interaktiven Strukturen in Predigten gibt. So untersucht etwa Malmström (2015) anhand schriftlicher Predigtmanuskripte und aus einer funktional-grammatischen Perspektive Frageformen in der Predigt (siehe Kapitel 4 und Abschnitt 17.3.2).

In soziologischen Arbeiten, wie der von Ruth Ayaß (1997), und in homiletischen Arbeiten wird im Gegensatz dazu ein weites Dialogverständnis in der Tradition Bachtins und seines Konzepts der Dialogizität erkennbar (vgl. Lorensen 2014:22). Dreh- und Angelpunkt sind dabei die anwesenden Personen, die die Gemeinde bilden, und die Frage ,how addressees [...] play a constitutive role in the development of the genre, as well as in the performed practice of preaching" (Lorensen 2014:22), obwohl oder gerade weil sie in der prototypischen Form der Predigt keinen eigenen (verbalen) Interaktionsbeitrag liefern.

Die nachfolgenden Betrachtungen setzen sich in der Weiter- und Engführung der bisherigen Analyseergebnisse (Kapitel 13 bis Kapitel 16) aus interaktions- und gattungsanalytischer Perspektive mit dem Thema der Dialogizität in der Predigt auseinander. Ziel ist es, die beobachtbaren Formen der Rezipientenbeteiligung 
anhand ausgewählter Beispiele authentischer Predigtsituationen aufzuzeigen und das Spannungsfeld zwischen Dialog und Monolog, in dem sich vor allem der Wortbeitrag befindet, nachzuzeichnen. In diesem Zusammenhang fragen die nachfolgenden Kapitel nach den interaktiven und dialogischen Elementen christlicher Predigten.

Im Zentrum der vorliegende Arbeit stehen sowohl ritualisierte Paarsequenzen (siehe Abschnitt 17.3.1) als auch interrrogative Sequenzen (Frage/AntwortSequenzen), bei denen in besonderer Weise eine konditionelle Relevanz aufgebaut wird (siehe Abschnitt 17.3.2). Des Weiteren betrachtet die vorliegende Untersuchung komplexe Interaktionsmomente mit der anwesenden Gemeinde (siehe Abschnitt 17.3.3), bei denen diese aktiv in die Gestaltung des Wortbeitrags einbezogen wird.

\subsection{Monolog, Dialog, Interaktion}

Um sich der Frage nach den dialogischen Potenzialen der Predigt interaktionsanalytisch zu nähern, ist zunächst eine Klärung der Begriffe ,Monolog ‘, ,Dialog ‘ und ,Interaktion“ notwendig, denn neben einem alltagsweltlichen Begriffsverständnis haben sich unterschiedliche wissenschaftliche Definitionen herausgebildet. So stehen sich vor allem zwei Konzeptionen gegenüber: a) ein weiter Dialogbegriff, der in der Tradition von Buber und Bachtin stehend als ,Dialogizität ' benannt wird, und b) ein enger Dialogbegriff, wie ihn die konversationsanalytische Tradition verfolgt. In beiden Fällen beschreibt der Begriff des Dialogs prototypisch zunächst den ,interaktive[n] Austausch von mindestens zwei Personen [...], die von Angesicht zu Angesicht, zeitlich und räumlich ko-präsent, mit verbalen, paraverbalen und nonverbalen Mitteln kommunizieren“ (Imo 2016b:341 f). Ausgehend von dieser ersten grundlegenden Definition ergeben sich jedoch schnell Abweichungen, die vor allem die Aspekte des zeitlichen Abstands zwischen den jeweiligen Gesprächsbeiträgen, die Frage nach der Ko-Präsenz und letztlich auch die Verfügbarkeit der beteiligten Individuen betreffen.

Buber vertritt in seinem Konzept der Dialogizität die sehr weite Ansicht, dass jegliche Äußerung von ihrer Natur her dialogisch sei, da sie zwischen den zwei Instanzen ,Ich“ und ,Du“ geschieht (vgl. Buber 2014:286) und das Gegenüber, d. h. die Instanz des Anderen, in jeder Äußerung mitgedacht sei. Ein bestimmendes Wesensmerkmal des Dialogs ist somit die Orientierung auf das jeweilige Gegenüber, das aus einer einzelnen Person, aber auch aus einer Gruppe von mehreren Personen bestehen kann (vgl. Buber 2014:293) und sich in der bewussten Wahrnehmung des Gegenübers sowohl physisch als auch in seiner aktualen sozialen Identität in der jeweiligen Situation (vgl. Buber 2014:170) und in der Annahme des Gegenübers als (Gesprächs-)Partner manifestiert (vgl. 
Buber 2014:293). Einen Dialog macht dann aus, dass sich beide Personen kooperativ und reziprok an der Interaktion beteiligen. Dabei erkennt Buber durchaus unterschiedliche Beteiligungsformate:

Selbstverständlich brauchen nicht alle zu einem echten Gespräch Vereinten selber zu sprechen; schweigsam Bleibende können mitunter besonders wichtig werden. Jeder aber muss entschlossen sein, sich nicht zu entziehen, wenn es etwa dem Gang des Gesprächs nach an ihm sein wird zu sagen, was eben er zu sagen hat. (Buber 2014:296)

Im Gegensatz dazu handelt es sich nach Buber um einen Monolog, wenn diese Bedingungen nicht erfüllt sind, wenn also die beteiligten Personen keine dialogische Haltung dem Anderen gegenüber einnehmen und (trotz räumlicher Ko-Präsenz) eine innerliche Abwendung vorhanden ist (vgl. Buber 2014:167). Buber bestimmt hier das Prinzip der Orientierung auf den Anderen und das Phänomen des Rezipientenzuschnitts, wie sie später von Bachtin und in der Konversationsanalyse expliziter ausgeführt werden, als einen wesentlichen Bestandteil seines Dialogkonzepts. Die Reziprozität spielt dabei eine wichtige Rolle, denn der Dialog erfordert eine wie auch immer geartete Antwort auf etwas Geäußertes (vgl. Buber 2014:168). Da alles zum Dialog werden kann, ist das Dialogische omnipräsent (vgl. dazu auch Sasse 2010:91). Buber versteht den Dialog in diesem Zusammenhang zwar auch als ein beobachtbares Phänomen vor allem aber als eine grundsätzliche Haltung bzw. Einstellung.

Da sich die Konzeptionen von Buber und Bachtin z. T. sehr ähnlich sind, gehen einige Bachtinforscher davon aus, dass sich sein Konzept der Dialogizität auf das Dialogkonzept Bubers bezieht und er dessen Denktradition weiterführt (vgl. dazu Friedmann 2001, Matveev 2015). In seiner Theorie der Dialogizität beschreibt Bachtin zunächst ebenfalls einen weiten, abstrakten Dialogbegriff, der als „(meta)theoretische Rahmung“ (Linell 2010:35; Übersetzung CD) verstanden wird und wie bei Buber in erster Linie eine grundlegende analytische Haltung gegenüber allen Formen sprachlich (sowohl mündlich als auch schriftlich) realisierter Äußerungen einschließt (vgl. Bachtin 2004:449) und Sprache als grundsätzlich dialogisch betrachtet. Der Begriff 'Dialog' bezieht sich in diesem Sinne auf ,any kind of human sense-making, semiotic practice, action, interaction, thinking or communication, as long as these phenomena are 'dialogically' (or 'dialogistically') understood" (Linell 2009:5 f; Hervorhebung im Original). Es geht also darum, ,Sprache grundsätzlich von ihrem tatsächlichen oder möglichen Potential ihrer dialogischen Wirkung her zu denken“ (Imo 2016b:338). Ob es sich bei einer Äußerung um eine dialogische Äußerung handelt oder nicht, hängt auch für Bachtin davon ab, ob der Gesprächsbeitrag auf einen Anderen, d. h. auf ein Gegenüber, hin orientiert ist (other-orientation) und in welchem Kontext die Äußerung steht. Bei der Betrachtung der Einbettung einer Äußerung in einen 
Kontext geht Bachtin von einem dynamischen Kontextbegriff aus, bei dem sich die Herstellung von Kontext und Äußerung wechselseitig beeinflusst und bedingt (Prinzip der Reziprozität; vgl. auch Imo 2016b:345; siehe Abschnitt 10.1).

A definitional point in dialogism is the assumption that human nature and human life are constituted in interrelations with 'the other', that is, in other-orientation. [...] Accordingly, dialogism denies the autonomous subject who thinks, speaks and acts in and by himself. Our actions, thoughts and utterances are imbued with interdependencies with what others have done, are doing, and could be expected to do in the future. (Linell 2009:13; Hervorhebungen im Original)

Das Gegenüber bzw. der Andere ist bei Bachtin keine passiv rezipierende Instanz, sondern ein aktiver Gesprächspartner, der zum Co-Autor wird (vgl. Bachtin 2004:452 und 455). Der Begriff des Anderen wird bei Bachtin und bei Modellen in seiner Tradition (z. B. das Modell Linells) jedoch sehr weit gefasst und schließt sowohl Personen als auch ,other systems, other dimensions of one's self, others thought texts and additional types of artifacts with 'inscriptions'" (Linell 2009:14) ein. Der ,Andere“ ist also nicht auf physisch ko-präsente Personen beschränkt, die eine unmittelbar wahrnehmbare Reaktion auf eine Äußerung zeigen, sondern umfasst auch die Auseinandersetzungen mit den Handlungen, Erfahrungen und Gedanken eines generalisierten Anderen oder auch ,nur' die ein Individuum umgebende Kultur, vor deren Hintergrund und in die hinein eine Person eine Äußerungen produziert (vgl. Linell 2009:13 und 2010:33). Relevant ist jedoch, ähnlich wie bei Buber, dass überhaupt eine Antwort gegeben wird (vgl. Bachtin 2004:455). Dies kann konkret oder abstrakt, unmittelbar oder verzögert, durch das Gegenüber wahrgenommen oder nicht wahrgenommen erfolgen (vgl. Bachtin 2004:461):

Note that interaction takes place, at least in a somewhat stretched sense, in such a seemingly solitary activity as silent reading too; the reader interacts with the printed text (and perhaps with images), with elements, parts and wholes of text. The meanings of a text result from the reader's interaction with and reconstruction of the author's construct [...]. This meaning-making does of course not just consist in a reconstruction of the author's meaning; the reader relates and reacts to the text, and develops an active responsive understanding. [...] Reading a particular text involves relating it to previous knowledge and to other texts read before ('intertextual reading'). The 'interaction' with a cognitive artefact, such as a printed text or a computer interface, is therefore a 'dialogical' activity. (Linell 2009:15f)

Strukturell gesehen ist für Bachtin vor allem der ,Wechsel der sprachlichen Subjekte“ (Bachtin 2004:458) zentral, denn dieser markiert die Grenzen einer Äußerung. Dabei unterscheidet er jedoch zwei Feinheitsgrade: den unmittelbaren Sprecherwechsel und den nicht unmittelbaren Sprecherwechsel, bei dem die 
Reaktion auf einen Gesprächsbeitrag erst nach längerer Zeit und ggf. unbemerkt vom ursprünglichen Gesprächspartner oder auch nur innerlich erfolgt (vgl. Bachtin 2004:461):

Das aktiv antwortende Verstehen des Gehörten [...] kann sich unmittelbar in einer Handlung realisieren [...], es kann auch ein vorläufig schweigendes antwortendes Verstehen bleiben (einige sprachliche Gattungen sind auch nur auf ein solches Verstehen angelegt, z.B. lyrische Gattungen), aber dabei handelt es sich sozusagen nur um ein antwortendes Verstehen mit verzögerter Wirkung: Früher oder später wird sich das Gehörte und aktiv Verstandene in nachfolgender Rede oder im Handeln des Hörers zeigen. Die Gattungen der komplexen kulturellen Kommunikation sind in der Mehrzahl der Fälle gerade auf ein solches aktiv antwortendes Verstehen mit verzögerter Wirkung angelegt. (Bachtin 2004:455)

Je nach Gattung wird, so Bachtin, zum einen ein unterschiedliches Antwortverhalten der Rezipierenden erwartbar (unmittelbar oder mit Verzögerung, sprachlich oder in Form einer Handlung, zustimmend oder ablehnend etc.) und zum anderen unterschiedlich viel Raum für unmittelbare Reaktionen gegeben. Ähnliches beschreibt auch Goffman, der unterschiedliche Beteiligungsformate in Abhängigkeit zur jeweiligen Interaktionsordnung und zur spezifischen Verteilung des Rederechts stellt:

So genießen bei Begegnungen, wo gesprochen wird, alle das Recht des Zuhörens, während das Recht zu sprechen sehr restringiert sein kann wie z.B. bei Bühnenaufführungen und großen öffentlichen Versammlungen. [...] Und in anderen Begegnungen wiederum darf eine Kategorie von Teilnehmern nur sagen: , Yes Sir ‘ und ,No Sir , oder sie ist auf die beschränkte Äußerung reduziert, die der Applaus gestattet. (Goffman 1971:101)

Das von Bachtin beschriebene zeitliche Nacheinander von Äußerungen unterschiedlicher Personen reicht so weit, dass jede Äußerung bereits dadurch dialogisch ist, dass sie sich an etwas bereits Geäußertes anschließt (dem ,,, already-said“ (of texts, traditions, past dialogues)“; Lorensen 2011:28 - wann auch immer diese Äußerung getätigt wurde) und auf noch zu tätigende Aussagen wirkt (dem ,,, notyet-said“ (listeners' verbal and embodied reactions)“; Lorensen 2011:28 - wann auch immer diese geäußert werden; vgl. dazu auch Imo 2013:41 und 2016b:346). Gerade für sekundäre sprachliche Gattungen (zu der auch die Predigt zählt) beschreibt Bachtin ein verzögertes Antwortverhalten als gattungscharakteristisch, bei dem der unmittelbare Sprecherwechsel, der für spontane alltägliche Interaktionsereignisse (in den Worten Bachtins ,primäre Gattungen') prototypisch ist, zitiert, inszeniert und als Rudimentformen wieder aufgenommen wird (siehe für primäre und sekundäre Gattungen Kapitel 7): 
In den sekundären sprachlichen Gattungen, besonders in den rhetorischen, begegnen wir Erscheinungen, die dieser unserer Auffassung zu widersprechen scheinen. Häufig stellt der Sprecher (oder Schreiber) innerhalb seiner Äußerung Fragen, antwortet selbst auf sie, erhebt Einwände gegen sich selbst und weist selbst seine eigenen Einwände zurück usw. Doch diese Erscheinungen sind nichts anderes als ein konventionelles Durchspielen der sprachlichen Kommunikation und der primären sprachlichen Gattungen. Ein solches Durchspielen ist für die rhetorischen Gattungen [...] charakteristisch, aber auch alle anderen sekundären Gattungen [...] benutzen verschiedene Formen der Einführung primärer sprachlicher Gattungen und der Beziehung zwischen ihnen [...] in die Konstruktion der Äußerung. Genau das ist das Wesen der sekundären Gattungen. (Bachtin 2004:459)

Auch Luckmann folgt einem eher weiten Dialog- bzw. Interaktionsbegriff, wenn er unter sozialer Interaktion ein Verhalten bestimmt, mit dem ein Individuum eine mehr oder weniger klare Bedeutung (ein Motiv oder ein bestimmtes Ziel) assoziiert (vgl. Luckmann 1995:175) und das sich auch in , verdeckten Formen des Handelns' wie Lesen oder Denken äußern kann (vgl. Luckmann 1995:184/FN 1). Dieses Verhalten ist dabei notwendig auf ein Gegenüber ausgerichtet und in seinem Charakter reziprok. Auch für Luckmann bildet also das wechselseitig aneinander orientierte und aufeinander bezogene (sprachliche) Handeln das wichtigste Merkmal sozialer Interaktion. Um Reziprozität herzustellen, muss das Gegenüber dann in der Lage sein, das Verhalten des anderen wahrzunehmen (vgl. Luckmann 1995:175).

Die Breite des Dialogbegriffs nach Bachtin hat vor allem von Seiten interaktionsanalytisch ausgerichteter linguistischer Forschung immer wieder zu Kritik geführt: „Wenn letztlich alles dialogisch ist, kann Dialogizität kaum noch sinnvoll als analytisches Konzept, d. h. als ein Mittel zur Schärfung von Analysen, dienen“ (Imo 2016b:340; Hervorhebung im Original). Die Kritik setzt dabei gerade daran an, dass es sich bei der Dialogizität um ,ein abstraktes sprachtheoretisches Konzept und keine praktisch anwendbare Analysekategorie“ (Imo 2016b:340) handelt. Jedoch muss die holistische Perspektive Bachtins berücksichtigt werden, der den Dialog auf unterschiedlichen Abstraktionsebenen verortet. Gerade die Ebene des unmittelbaren Wechsels und zeitlich engen Nacheinanders von Äußerungen deckt sich mit dem engen Dialogbegriff der konversationsanalytischen Forschungstradition. Diese erkennt den Dialog als zentrale Untersuchungseinheit, verengt den Begriff jedoch auf das tatsächlich beobachtbare Verhalten von Menschen in konkreten Handlungssituationen (vgl. Garfinkel 1967:1; siehe dazu auch Linell 2009:15 und Imo 2016b:340ff). ${ }^{1}$ Ein Dialog ist dann "a direct interactive encounter between two or more, mutually co-present individuals who interact by means

\footnotetext{
${ }^{1}$ Siehe zu weiteren linguistischen Dialogkonzepten die Übersicht in Imo 2016b:342-345.
} 
of some semiotic resources, such as spoken language and its accompanying body language" (Linell 2009:4; siehe in derselben Weise auch Imo 2016b:341f). Um eine deutlichere Abgrenzung zu den vorhandenen weiten Dialogbegriffen herzustellen, geht die konversationsanalytische bzw. interaktionsanalytische Forschung dazu über nicht mehr von ,Dialog ', sondern von ,Interaktion` zu sprechen. Innerhalb der Interaktionalen Linguistik und der Multimodalen Interaktionsanalyse bestehen jedoch unterschiedliche Auffassungen darüber, was die bestimmenden Kriterien von Interaktion sind. Für Imo sind es die Prinzipien der Sequenzialität, der Reflexivität und der Kontextgebundenheit (vgl. Imo 2016b:349). Interaktion wird dann definiert als ,eine sequenziell strukturierte, wechselseitige Bezugnahme aufeinander" (Imo 2016b:350). Untersuchungsgegenstand ist der unmittelbare Sprecherwechsel, der zum nächstmöglichen Zeitpunkt innerhalb der Interaktionssituation stattfindet und zu dessen Zweck mögliche übergaberelevante Punkte im Gesprächsverlauf kontextualisiert werden (vgl. Birkner et al. 2020:113). Eines der zentralen konversationsanalytischen Konzepte ist in diesem Zusammenhang das der Sequenz. Ausgangspunkt ist die Beobachtung, dass Interaktionen in der Zeit verlaufen und die einzelnen Gesprächsbeiträge (turns) in einem geordneten Nacheinander realisiert werden (vgl. Stivers 2012:191, Birkner et al. 2020:238). Immer wieder ist zu beobachten, dass spezifische Arten von Gesprächsbeiträgen in unmittelbarer Nähe zueinander und in einer typischen sequenziellen Abfolge stehen (vgl. Stivers 2012:192). Schegloff beschreibt diese Sequenztypen als (minimale) Paarsequenzen und nennt die folgenden Merkmale: „,composed of two turns, by different speakers, adjacently placed, that is, one after the other, ordered relative to one another; that is, they are differentiated into 'first pair part' (FPP) and 'second pair part' (SPP) [...], they are pair type related" (Schegloff 2007; siehe dazu auch Stivers 2012:192, Clift 2016:70, Gülich/Mondada 2008:51, Birkner et al. 2020:242f).

Paarsequenzen weisen eine besonders deutliche und starke konditionelle Relevanz auf, bei der „die erkennbare Realisierung eines ersten Paarteils einer Paarsequenz [...] die normative Erwartung [etabliert], dass im nächsten turn der entsprechende zweite Paarteil der Paarsequenz produziert wird“" (Gülich/Mondada 2008:51, Hervorhebung im Original; siehe dazu auch Stivers/Rossano 2010:4 und 2012:59f). Erwartbar ist sowohl, dass eine Reaktion auf den ersten Paarteil (EPT) erfolgt, als auch, welches Format die Äußerung des zweiten Paarteils (ZPT) hat. Typische Paarsequenzen, bei denen das der Fall ist, sind z. B. Frage/Antwort, Gruß/Gegengruß, Fokussierungsaufforderung (summons)/Fokussierungsbestätigung (answer) (vgl. Clift 2016:70, Birkner et al. 2020:244). Stivers und Rossano ergänzen diese Beobachtung, indem sie herausarbeiten, dass nicht nur die sequenzielle Position einer Äußerung als EPT für die Etablierung einer konditionellen Relevanz entscheidend ist, sondern auch die Handlung, die damit ausgeführt wird, und die Art und Weise, in der die 
Äußerung gestaltet ist, ob sich z. B. zusätzliche „response-mobilizing features“ (Stivers/Rossano 2012:67), d. h. spezielle, eine Reaktion erwartbar machende Kontextualisierungshinweise erkennen lassen.

We suggest that speakers mobilize response through the combination of multiple resources employed simultaneously: through the social action a speaker produces, the sequential position in which it is delivered and through turn-design features that increase the recipient's accountability for responding. (Stivers/Rossano 2010:4)

Auch Handlungen, die eine geringere Antwortrelevanz hervorrufen, können so als eine Antwort erforderlich machender EPT kontextualisiert werden (Stivers/Rossano 2012:64). Die konditionelle Relevanz denken die Autoren in diesem Zusammenhang skalar (vgl. Stivers/Rossano 2012:77), denn sie gehen davon aus, dass „speakers can rely on turn-design resources to increase the response relevance of a turn beyond the relevance inherent in the action performed" (Stivers/Rossano 2010:4). Als Kontextualisierungshinweise für die Produktion eines zweiten Paarteils werden laut Stivers/Rossano vor allem eine spezifische lexiko-morphologisch-syntaktische Struktur (etwa W-Fragewörter oder eine interrogative Syntax), eine spezifische Prosodie sowie das Blickverhalten und der Bezug zur epistemischen Expertise der Rezipierenden erkennbar (vgl. Stivers/Rossano 2010:8f und 2012:61, Stivers 2012). Die These von Stivers und Rossano ist dann, dass die Antworterwartung um so stärker markiert wird, je mehr „response-mobilizing turn-design features“ (Stivers/Rossano 2010:27) genutzt werden.

Für den Untersuchungsgegenstand christlicher Predigten wird dieses Modell und die Frage, mithilfe welcher Ressourcen die konditionelle Relevanz eines zweiten Paarteils kontextualisiert wird, dann relevant, wenn die Prediger in ihren Wortbeiträgen interrogative Formate äußern und markieren müssen, ob es sich dabei um eine rhetorische oder um eine echte Frage handelt, d. h. ob eine Antwort der anwesenden Personen erforderlich ist oder nicht (siehe Abschnitt 17.3.2).

Im Konzept der Sequenzialität wird bereits ein weiteres Merkmal von Interaktion erkennbar, das für Imo eine zentrale Rolle spielt und auch in den Dialogkonzepten von Buber und Bachtin sehr prominent ist: ,die Anbindung von Äußerungen an Vorgänger- und Nachfolgeäußerungen“ (Imo 2016b:349). Und auch Deppermann stellt heraus, ,dass jede Äußerung im Gespräch stets reaktive und initiative Aspekte beinhaltet" (Deppermann 2007:47; Hervorhebungen im Original). ${ }^{2}$ Anders als bei Bachtin handelt es sich im Verständnis von Imo

\footnotetext{
${ }^{2}$,Reaktiv sind Äußerungen, da sie sich zu Folge-Erwartungen, sog. ,Projektionen“, die durch vorangehende Äußerungen etabliert werden, verhalten, und da der Sprecher mit ihnen zeigt, wie er diese vorangehenden Äußerungen und die an ihn selbst gestellten Erwartungen versteht. Initiativ sind Äußerungen, da der Sprecher mit ihnen eine Handlung vollzieht, die einen neuen
} 
und Deppermann jedoch um eine mehr oder weniger unmittelbare Anbindung im Gespräch. Erweitert wird der Interaktionsbegriff der Interaktionalen Linguistik, der zunächst für verbale Interaktion und face-to-face-Situationen erarbeitet wurde, unter der Berücksichtigung medial vermittelter Interaktion mit ggf. zeitlicher und räumlicher Zerdehnung (Telefon, Radio, Fernsehen, computergestützte Kommunikation in Echtzeit wie Chat- und Email-Kommunikation etc.; vgl. Linell 2009:4 und 27f, Imo 2016b:342, Beißwenger 2016). Dies führt dazu, dass bei medial vermittelten Chats von Interaktion gesprochen wird, bei Reden, die eine ,ausbleibende Rezipientenreaktion“ (Imo 2016b:349) zeigen, jedoch nicht (vgl. Imo 2016b:349).

Im Gegensatz dazu ist für Hausendorf nicht das Merkmal der sprachlichen (unmittelbaren) Wechselseitigkeit ausschlaggebend für die Definition von Interaktion, sondern das Merkmal der Anwesenheit, d. h. die Möglichkeit wechselseitiger (visueller, auditiver, taktiler etc.) Wahrnehmung und die Herstellung von Wahrnehmungswahrnehmung (vgl. Hausendorf 2015:46). Kritisiert wird an dieser Definition von Interaktion vor allem ihre offensichtliche Fokussierung auf face-to-face Interaktionen mit ko-präsenten Beteiligten (vgl. Imo 2016b:348).

Auch nach der engeren Definition von Interaktion ist die Orientierung an und auf das Gegenüber zentral, denn ,,[z]u interagieren bedeutet in diesem Sinne, unser Gegenüber (und uns selbst) kontinuierlich in unserem eigenen Verhalten in sozial relevanter Weise zu repräsentieren“" (Schmitt/Knöbl 2014:16; siehe dazu auch Schmitt/Knöbl 2013:245f). Die Konversationsanalyse prägt in diesem Zusammenhang den Begriff des recipient design, das den ,,rezipientenspezifischen Zuschnitt[] von Äußerungen“ (Hitzler 2013:111; siehe auch Deppermann/Schmidt 2016:375) bezeichnet. Grundlage ist die Beobachtung, ,dass Äußerungen nicht lediglich in Bezug auf Inhalte organisiert, sondern auch mit Blick auf die Eigenheiten des Empfängers entworfen werden“ (Hitzler 2013:111). Damit verbunden sind Annahmen und Zuschreibungen hinsichtlich der Wahrnehmung, der Erwartungen sowie des Wissens der Interagierenden (vgl. Schmitt/Knöbl 2013:247). Mit dem Rezipientenzuschnitt verweisen die Beteiligten also nicht nur auf bestehende Annahmen über den jeweiligen Interaktionspartner, sondern es dient der „performativ[en] [...] Fremdpositionierung des Partners“ (Deppermann/Schmidt 2016:377). Die Interagierenden greifen in ihrem reziprok realisierten Rezipientenzuschnitt also auf spezifische Wissensbestände zurück und nehmen Wissensannahmen und Wissenszuschreibungen vor, die auf das Gegenüber bezogen sind und sich im situativ-lokalen Handeln niederschlagen (siehe Kapitel 16). Eine Interaktion entsteht nach Imo jedoch nur dann, ,wenn diese Adressatenorientierungen aufeinander bezogen und wechselseitig überprüft und angepasst werden können“

Gesprächszustand herstellt und selbst Folge-Erwartungen für das künftige Handeln etabliert“ (Deppermann 2007:47). 
(Imo 2016b:350). Obwohl beide mit dem Konzept der Rezipientenorientierung arbeiten, zeigen sich hier erneut die markanten Unterschiede zwischen dem weiten Dialogbegriff und dem engen Dialog- bzw. Interaktionsbegriff. ${ }^{3}$

Im Gegensatz zum Begriff des Dialogs bzw. der Interaktion ist der Gegenstand des Monologs in der interaktionsanalytischen Forschung unterrepräsentiert. Es wird lediglich auf die Möglichkeit eines multi-unit turns hingewiesen, bei dem eine der beteiligten Personen für längere Zeit das Rederecht erhält und seinen Gesprächsbeitrag über mehrere Turn-Konstruktionseinheiten (TCU) ausdehnt, wie dies z. B. bei Erzählungen (tellings) der Fall ist (vgl. Schegloff 2007:215, Clift 2016:122ff). Diese Erzählungen können mehr oder weniger ausgebaut sein. Das bedeutet jedoch auch, dass ein Monolog in ein Interaktionsgeschehen eingebettet ist und, wie jedes andere Gespräch, interaktiv hergestellt und von den beteiligten Personen wechselseitig ratifiziert werden muss.

Nach einem kurzen Exkurs zur Auseinandersetzung mit dem Thema ,Predigt und Dialog' innerhalb der homiletischen Forschung zeigen die nachfolgenden Kapitel, inwieweit methodische und begriffliche Instrumentarien der Interaktionalen Linguistik für die Beschreibung der kommunikativen Gattung Predigt auf binnenstruktureller und zwischenstruktureller Ebene fruchtbar gemacht werden können, um deren interaktive Potenziale aufzeigen zu können.

\subsection{Dialog in der Homiletik}

Die homiletische Literatur verweist auf der einen Seite darauf, dass der Dialog ein konstitutives Wesensmerkmal der Predigt sei (vgl. Esser 1958:42, Nickel 1998:19, Schwöbel 2011:158, Lorensen 2011:26) und beschreibt auf der anderen Seite deren monologische Struktur. Dies führt zu der Frage, wie die Predigt zwischen den Polen des Monologs und des Dialogs verortet werden kann. Ziel ist es, die Form des Bühnenmonologs mit dem überkonfessionellen theologischen Anspruch der Eröffnung eines Gesprächs durch und in der Predigt zusammenzubringen.

\footnotetext{
${ }^{3}$ Wie zahlreiche andere Konzepte konversationsanalytischen Ursprungs ist auch das Konzept des Rezipientenzuschnitts auf der Grundlage verbaler Interaktionsdaten (v. a. Telefongespräche) entwickelt und beschrieben worden. Im Zuge der neuen multimodalen Ausrichtung der CA sowie der Interaktionalen Linguistik, wird dieser Reduktionismus jedoch als nicht mehr zielführend kritisiert. So gibt es seit einigen Jahren den Versuch einer ,,multimodale[n] Neukonzeption“ (Schmitt/Knöbl 2014:5). Der Rezipientenzuschnitt ist dann ,,etwas ,produktähnlich 'Strukturiertes, das sich aus verschiedenen Aspekten zusammensetzt und als Ergebnis eines dynamischen Prozesses konstituiert worden ist“" (Schmitt/Knöbl 2014:96), das der wechselseitigen Überprüfung und Anpassung durch die beteiligten Interaktanten bedarf (vgl. Imo 2016b:350).
} 
Terminologisch wird in diesem Zusammenhang mehr oder weniger schlüssig zwischen ,Rede“ (Monolog) und ,Gespräch“ (Dialog) differenziert (vgl. Wollbold 2017:77). Aufgrund auch der Beobachtung, dass in der deutschsprachigen Predigtkultur call-and-response-Formate nicht prototypisch Teil des Wortbeitrags sind, hat sich die Formel von der Predigt als formal monologischem, aber intentional bzw. virtuell dialogischem Ereignis (vgl. Nickel 1998:17, Thiele 2004:30, Wollbold 2017:42), das die performative Realisierung vor (und mit) der Gemeinde erfordert (vgl. Lehnert 2010:27), herausgebildet.

Ausgangspunkt für diese Entwicklung ist eine grundlegende Perspektivverschiebung innerhalb der homiletischen Forschung, die als ,pragmatische Wende bezeichnet wird und im Zuge derer sich der Schwerpunkt vieler Arbeiten auf die Rezipierenden verlagert hat (vgl. Nembach 2002:94; siehe Kapitel 6). Dies hat zu einer Reihe von rezeptions- und wirkungsästhetischen Forschungen und Überlegungen geführt, die anhand empirischer Erhebungen (vor allem mit Fragebögen und Interviews) die Wirkung der Predigt auf die anwesenden Personen zu ermitteln suchen und nach der Wirkmächtigkeit der Wortbeiträge fragen (vgl. Daiber et al. 1980, Daiber 1991, Lütze 2006, Schwier/Gall 2008; siehe Kapitel 6). Predigten werden nun nicht mehr als ,Einbahn-Kommunikation“ im Sinne des Modells von Shannon/Weaver (1949) verstanden, in der Informationen vom Prediger ausgehend unidirektional zur Gemeinde laufen (vgl. Nembach 2002:94), sondern als Kommunikationsereignis, bei dem die Rezipierenden zu aktiven KoAutoren werden, die die Predigt mitkonstruieren (vgl. Thiele 2010, Schirmer 2013:9, Lorensen 2014:21; siehe Kapitel 6), indem sie die Worte des Predigers aufnehmen, in ihre eigenen Lebenszusammenhänge einpassen und dadurch gleichsam eine ,neue' Predigt entstehen lassen (vgl. Daiber 1991:17, Engemann 2002:146f, Lorensen 2011:27, Gaarden/Lorensen 2013). Die Rezipierenden und die biblischen Texte wirken darüber hinaus aktiv als ,Gegenüber' des Predigers, indem sie die Art und Weise des Sprechens und der Realisierung der Predigt beeinflussen, z. B. indem der Prediger die Rezipientenreaktionen antizipiert (vgl. Lorensen 2011:28) und Formen der Adressierung sowie der gesprächsrhetorischen Verfahren rezipientenorientiert gestaltet (siehe die Befunde in den Kapiteln 13 bis 16).

Vor allem die Konzeption, des Anderen' bei Buber und Bachtin als aktives Gegenüber, die Weite des angelegten Dialogbegriffs, der nicht nur als Struktur des Sprecherwechsels erscheint, sondern als übergreifende Gesprächshaltung, sowie der Gedanke eines fortlaufenden und unabgeschlossenen Prozesses der Interaktion werden in der Homiletik aufgenommen und mit Blick auf die Predigt untersucht (vgl. Lorensen 2011). Die Betrachtung ,des Anderen' hat, wie bei Bachtin angedacht, innerhalb der Homiletik vor allem zwei Richtungen: Zum einen geht es um die physisch ko-präsente Gemeinde und zum anderen um das fremde Wort Gottes als dem ,heiligen Anderen‘ (vgl. Lorensen 2011:26). Sowohl 
die Gemeinde als auch das Wort Gottes bilden für den Prediger das Gegenüber und treffen im Wortbeitrag aufeinander. Dem Prediger wurde in diesem Zusammenhang immer wieder die Rolle des Vermittlers bzw. des ,Gastgebers “ zugeschrieben, der zwischen den unterschiedlichen Agenten steht, das spannungsgeladene Aufeinandertreffen im Predigtereignis auffängt (vgl. Lorensen 2011:26f) und die Anwesenden in die aktive Auseinandersetzung mit dem Wort Gottes einlädt (vgl. Lorensen 2011:29).

Der homiletischen Forschung geht es jedoch nicht nur um die Antizipation dessen, was die Gemeinde weiß oder kennt, sondern um eine Auseinandersetzung mit deren tatsächlichen Lesarten biblischer Texte, um ein ,Lernen ' des Predigers von den Rezipierenden (vgl. Lorensen 2011:32). In diesem Zusammenhang geschieht ein Rollenwechsel z. B. in Bezug auf Wissensautorität und Erkenntnisgewinn (vgl. Lorensen 2011:32). Betrachtet man diesen Rollenwechsel als eine Art Sprecherwechsel, der unmittelbar oder mit Verzögerung erfolgen kann, wird er zu einem zentralen Punkt der Dialogizität und zu dem, was Lorensen als dialogischen Monolog bezeichnet (vgl. Lorensen 2011:32). Nimmt man zudem an, dass die Inhalte des Wortbeitrags bei den Rezipierenden nachwirken und zu späteren geistigen und körperlichen Reaktionen führen, lässt sich auch der formal monologische Charakter der Wortbeiträge mit einer dialogischen Grundauffassung vereinbaren und die Predigt als Dialog im Sinne Bachtins lesen. Die pragmatische Wende hat innerhalb der Homiletik also zu einer umfassenden Änderung in der Haltung gegenüber der Predigt und zu einer Öffnung der Disziplin für kommunikationswissenschaftliche und linguistische Einflüsse geführt (siehe Kapitel 6).

Vor allem die Sprechakttheorie nach Austin (1979) und Searle (1971 und 1976) wird innerhalb der Homiletik rezipiert und auf die Predigt angewendet (vgl. z. B. Engemann 2002:330-344). Ziel ist es, die Predigt „nicht nur als Rede schlechthin“ (Engemann 2002:138) zu beschreiben, sondern ,als ,Rede zu jemandem hin', die Situationen verändern kann" (Engemann 2002:138) und mit der Wirklichkeit konstruiert wird. Die Sprechakttheorie dient in diesem Zusammenhang dazu, den Handlungscharakter von Predigten zu dokumentieren. Als sprachphilosophisch basierte Theorie des sprachlichen Handelns gibt die Sprechakttheorie jedoch lediglich einen produzentenzentrierten Blick auf Interaktionen, da sie u. a. nach den Wirkungen fragt, die Sprechende mit einer Äußerung intendieren. Im Zuge dieser Ausrichtung stellen Austin (1979) und später Searle (1976) Gelingensbedingungen für die einzelnen Sprechakte auf und verfolgen das Ziel einer übergreifenden Sprechakttheorie, in der sämtliche Äußerungen in Sprechakten klassifiziert werden. Dafür entwickeln sie ein Kategoriensystem, das in seiner Klarheit vor allem für nicht-linguistische Disziplinen sehr attraktiv erscheint, es jedoch auch zu einem statischen Modell macht, das in der Folge stark kritisiert wurde. Besonders die Entwicklung der Theorie anhand erdachter 
und weitgehend kontextfreier Beispiele, das Verharren auf der Seite des Produzenten und die Betrachtung der individuellen Wirkungsabsichten und nicht des tatsächlichen Kommunikationsprozesses haben innerhalb der sprachwissenschaftlichen Forschung immer wieder zu scharfer Kritik geführt (vgl. Kallmeyer 1996:7, Levinson 2000:302, Linell 2009:178, Meier et al. 2019, Staffeldt 2019). Darüber hinaus wird aufgrund dieser kritisierten Aspekte auch der Mehrwert der Theorie hinsichtlich der Betrachtung dialogischer Prozesse in Zweifel gezogen. Linell ist etwa der Ansicht, dass die Sprechakttheorie eine ,monologische Pragmatik“ verkörpert:

According to that theory, speech acts are not essentially tied to its context. Rather a Searlian speech act is a decontextualized action: in theory, a speaker creates and finalizes his or her utterance (speech act), its intention, meaning and performative execution all by him- or herself. (Linell 2009:178)

Neben der Sprechakttheorie wird die Rhetorik als wissenschaftliche Disziplin mit ihren Modellen und Theorien rezipiert und nach den Möglichkeiten und Grenzen der Adaption in der Predigtarbeit gefragt. Dabei wird immer wieder der Vorwurf laut, die Hineinnahme der Rhetorik ermögliche durch die bewusste sprachliche Gestaltung der Wortbeiträge vor allem eine gezielte Manipulation und Beeinflussung der Rezipierenden (vgl. Grimmler 2011:92). Im Gegensatz dazu stehen Arbeiten, die die Potenziale der Rhetorik für die Predigt als öffentlicher Rede sehen (vgl. u. a. Otto 1976:10, Daiber 1991, Engemann 2002:290ff, Thiele 2004:15 und 36). Ziel ist es, die Wechselwirkung zwischen Form und Inhalt aufzuzeigen und zu dokumentieren, dass die Rhetorik als "Sprechhandlungstheorie“ (Koch/Schirren 2016:217) und als der Überzeugung eines Gegenübers dienende „wirkungsorientierte Kunst“ (Koch/Schirren 2016:219) gerade für die Predigt als (rezipientenorientierter) Rede funktional ist. So betrachtet Otto die „Rhetorik als Fundament einer jeden Rede, auch einer jeden Predigt" (Otto 1976:4; Hervorhebung im Original). In der Folge dieser Annäherung hat sich die rhetorische Predigtanalyse entwickelt. Diese ,konzentriert sich [...] auf die formale Gestalt der Predigt und fragt danach, welche Auswirkungen die vorgefundenen Formen und sprachlichen Faktoren für den Inhalt und nicht zuletzt für die Wirkung der Predigt haben" (Wöhrle 2006:129). Die Rhetorik ist zunächst eine genuin an sprachlichen Zeichen und auf ,sprachlich induzierte Überzeugung“ orientierte Theorie (vgl. Koch/Schirren 2016:221), die mittlerweile jedoch auch im Hinblick auf andere Ressourcen und „Verfahren von sprachlicher und visueller Persuasion" (Koch/Schirren 2016:222) hin zu einer multimodalen Rhetorik ausgedehnt wurde. Weiterhin geht es nicht mehr nur um ,die Beeinflussung anderer 
im Sinne der Änderung ihrer Anschauungen [...], sondern auch [um] die Bestätigung und Festigung von Überzeugungen und Einstellungen“ (Kallmeyer 1996:9). Innerhalb der linguistischen Tradition knüpft die Gesprächsrhetorik an gesprächsanalytische Prinzipien und Methoden an, indem sie nach Rhetorik-in-Interaktion fragt und die „Einbettung des individuellen Handelns in den Interaktionsprozess und die Auswirkung von dessen Eigenschaften wiederum auf die rhetorischen Verfahren der Interaktionsbeteiligten“ (Kallmeyer 1996:9) berücksichtigt. Diese Entwicklungen im Bereich der Gesprächsrhetorik bleiben innerhalb der theologischen Forschung jedoch weitgehend unberücksichtigt. Zudem lassen sich auch mithilfe der Rhetorik nur begrenzt dialogische Strukturen innerhalb der Predigt herausarbeiten.

Und so verlagert sich die Betrachtung der Dialogizität in Predigten weg vom eigentlichen Predigtgeschehen hin zu Kommunikationsereignissen, die 1.) der Predigt vorgelagert oder 2.) nachgestellt sind.

,Predigt als Dialog“ wird zum einen verstanden als Dialog „des Predigers mit dem Text" (vgl. Nembach 2002:38; Hervorhebungen CD). In dieser Perspektive wird der Fokus auf die Predigtvorbereitung gelegt. Der Prediger ist dann gleichfalls ein Hörender und wird sogar als erster Hörer der Predigt bestimmt (vgl. Thiele 2010:79). Das sog. , homiletische Dreieck' verweist auf die drei Faktoren, zwischen denen sich die Predigt ,in einer spannungsvollen, lebendigen Wechselwirkung" (Wollbold 2017:201) entfaltet: Text, Prediger und Hörer (d. h. Rezipierende). In anderen Arbeiten ist sogar von einem Viereck die Rede:

Jede Predigt geschieht also in einem Beziehungsviereck: Wort Gottes - Liturgie Prediger - Hörende. [...] Der Prediger zeugt von seiner Beziehung zum Wort, ist Teil des liturgischen Beziehungsgeschehens und baut Brücken zu den Hörenden. Die hörende Gemeinde schließlich ist nicht passive Empfängerin der Predigtworte und der Botschaft. Predigt als Anrede Gottes, entsteht' erst durch einen aktiven Prozess im Kopf und im Herzen der Hörenden. (Boschki 2010:223)

So ist die Predigt nicht nur der Ausdruck eines Beziehungs- und Partizipationsgeschehens zwischen Menschen, sondern auch zwischen Mensch und Gott. Engemann stellt in diesem Zusammenhang die These auf, dass die Predigt vor allem ,der Konstituierung und Pflege des Verhältnisses zwischen Gott und uns und zwischen uns untereinander" (Engemann 2002:119) diene.

Zum anderen werden Gespräche betrachtet, die im Nachgang der Predigt zwischen dem Prediger und ausgewählten Rezipierenden in kleinen Gruppen geführt werden und ein Feedback zum Wortbeitrag sowie ein Weiterdenken der Inhalte ermöglichen sollen (vgl. Nembach 2002:37; siehe dazu auch Baldwin 1984:16 
und McClure 2007:13, der dieses Vorgehen als ,kollaboratives Predigen“ bezeichnet). Vor allem der Wortbeitrag wird dadurch zum Ausgangspunkt für einen Dialog bzw. eine gemeinsame Interaktion, die wiederum neue Impulse für eine sich daran anschließende Predigt liefern soll.

Im Zusammenhang dieser zwei Perspektiven auf das Thema ,Predigt und Dia-

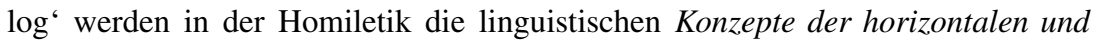
der vertikalen Kommunikation etabliert (siehe dazu auch Kapitel 4). Die vertikale Ebene umfasst die Kommunikation zwischen der Gemeinde und Gott (vgl. Koch 1992:101, Nickel 1998:20, Paul 2009:2263), und die horizontale Ebene bezeichnet die Kommunikation zwischen der Gemeinde und dem Prediger (vgl. Koch 1992:111, Nickel 1998:20, Paul 1990:35 und 2009:2263f). Paul wirft homiletischen Arbeiten in diesem Zusammenhang vor, dass sie sich zu stark auf den horizontalen Aspekt konzentrieren, den vertikalen Aspekt innerhalb der Predigt vernachlässigen und die Unterscheidung zum vertikalen Dialog nicht sauber genug herausarbeiten (Paul 1990:154f). Die Predigt befindet sich für Paul darüber hinaus , in einem Spannungsfeld von ritueller, institutioneller und alltagsweltlicher Kommunikation“ (Paul 2009:2269). Jegliche unmittelbar wechselseitige Interaktion bezeichnet er als Inszenierung spontansprachlicher Elemente (vgl. Paul 1990:153).

Damit verweist Paul auf eine dritte Perspektive auf das Thema ,Predigt als Dialog', die den tatsächlichen konkreten Wortbeitrag und dessen strukturellformale Gestaltung in den Blick nimmt. Häufig werden dann in der Homiletik jedoch lediglich neue Predigtformate, die Gespräche zwischen zwei Personen inszenieren, etwa die Dialog-Predigt, bei der zwei Prediger gleichzeitig oder nacheinander eng aufeinander bezogen den Wortbeitrag realisieren und gestalten (vgl. Esser 1958:52), untersucht. Ausgangspunkt für die Überlegungen zu neuen Wortbeitragsformaten ist die Hinterfragung der Form des Monologs, die kritische Betrachtung der Rhetorik und Fragen hinsichtlich der Funktion der Predigt als Lernprozess, die auch mit Veränderungen der Rollen von Prediger und Predigthörenden zu tun hat. So schreibt Daiber:

Der Monolog gilt als autoritätsbezogene Rede. Der Hörer will sich dieser Autorität nicht mehr ohne weiteres beugen, zudem will der Pfarrer als Prediger auch diese Autorität nicht ohne weiteres ausüben. Der Monolog [...] gilt als relativ ineffektiv, wenn von der Predigt Lernprozesse erwartet werden. Sowohl auf der kognitiven wie der emotionalen und pragmatischen Ebene wird dem Gespräch eine höhere Bedeutung eingeräumt. (Daiber 1991:203f)

Aufbauend auf diesen Beobachtungen soll nun die virtuell bzw. intentional dialogische Predigt zu einem tatsächlichen dialogischen Ereignis werden (vgl. Esser 
1958:57). Zu diesem Zweck wurden und werden seit den 1990er Jahren Alternativen zur klassischen Predigt entwickelt und getestet, die unter der Überschrift ,Dialogpredigten' firmieren:

[D]ie gleichberechtigte Rede und Gegenrede von zwei Predigern, die Entwürfe zur Predigt seitens eines exemplarischen kritischen Hörers, die Möglichkeit zu Zwischenfragen aus dem Kreis der Hörer oder auch gezielte Fragen an die Versammlung [...], eine vorgängige Befragung von Hörern oder von ausgewählten Personen und das Einbringen von deren Aussagen in die Predigt, das Einspielen von Ton- und Videosequenzen usw. (Wollbold 2017:170f)

Die neuen Formen der Predigtgestaltung sind in ihrem Erfolg jedoch nicht unumstritten und werden hinsichtlich ihres Effekts bei den Rezipierenden immer wieder in Frage gestellt (vgl. Daiber 1991:201). Zudem, so die Kritik, würden sie die Distanz ,zwischen den am Gespräch Beteiligten [d. h. den zwei Predigern; Anm. CD] und den nicht unmittelbar Beteiligten [d. h. der Gemeinde; Anm. CD] nicht überbrücken“ (Daiber 1991:201f). Ein Problem entsteht zudem, wenn die anwesenden Personen nicht mit den neuen Formaten vertraut sind und es so zu Irritationen kommt (vgl. Daiber 1991:202). Wollbold plädiert in diesem Zusammenhang dafür, alternative Predigtkonzepte in alternativen Gottesdiensten mit ,außerliturgische[r] Verkündigung“ (Wollbold 2017:170) zu nutzen und ansonsten die ,klassisch-monologische Predigt“ (Wollbold 2017:171) beizubehalten. Trotz dieser Stellungnahmen zu alternativen Predigt- bzw. Wortbeitragsformaten bleibt die kritische Haltung gegenüber der Predigt als monologischer Rede bestehen.

Bisherige Studien - sowohl innerhalb der Homiletik als auch in der Linguistik - lassen es jedoch vermissen, dass sie anhand eines Korpus authentischer Wortbeiträge herausarbeiten, welche dialogischen Strukturen tatsächlich auftreten, wie diese realisiert werden und was dies für die Diskussion über Predigt und Dialog bedeutet. Dieses Forschungsdesiderat will die vorliegende Studie in den nächsten Kapiteln bearbeiten.

\subsection{Beteiligungsformate in Predigten}

In den bisherigen Kapiteln zur multimodalen Eröffnung und Beendigung (siehe Kapitel 15) sowie zur Wissenszuschreibung und Wissensvermittlung (siehe Kapitel 16) wurden bereits erste Hinweise auf die Etablierung und Realisierung interaktiver Sequenzen gegeben. Ein zentrales Moment ist etwa die wechselseitige körperliche und blickliche Ausrichtung von Prediger und Gemeinde aufeinander (siehe Kapitel 15), die die Herstellung der typischen Interaktionsordnung 
one-face-to-many-faces mitkonstruiert und aktualisiert (siehe Kapitel 14). Die Relevanz dieser Ko-Orientierung zeigt sich u.a. in der expliziten und impliziten Rückversicherung des Predigers, dass er von den anwesenden Personen visuell und/oder akustisch wahrgenommen wird und dass ggf. sogar Wahrnehmungswahrnehmung besteht. Es konnte so bereits aufgezeigt werden, dass es nicht nur der Prediger ist, der das Predigtereignis etabliert, sondern dass es eine aktive reziproke Herstellungsleistung aller Anwesenden ist, die wechselseitig ratifiziert wird. Folgt man in diesem Zusammenhang dem Interaktionsbegriff von Hausendorf (vgl. Hausendorf 2015:46, Imo 2016b:348f; siehe Abschnitt 17.1), kann die Predigt in der hier untersuchten Gestaltung als Ereignis mit ko-präsenten Beteiligten durch die Möglichkeit wechselseitiger Wahrnehmung als Interaktionsereignis bestimmt und beschrieben werden.

Ein weiteres bereits aufgezeigtes Moment der Dialogizität ist die vom Prediger aufgestellte Annahme über vorhandene und nicht vorhandene Wissensbestände der anwesenden Personen, die in Wissenszuschreibungen münden und Ausgangspunkt für die Vermittlung und Aktualisierung unterschiedlichen Wissens ist (siehe Kapitel 16). Der Prediger muss dabei eine Mehrfachadressierung vornehmen. Dies zeigt sich u. a. auch daran, dass die Gemeinde als Wissensgemeinschaft erscheint, und dass der Prediger den Wortbeitrag nicht auf einen spezifischen, sondern auf einen generalisierten Rezipierenden hin orientiert. Speziell im Wortbeitrag wird explizit und implizit das deutlich, was die Konversationsanalyse Rezipientenzuschnitt und Bachtin sowie Linell als Orientierung auf das Gegenüber (other-orientation, Linell 2009:13) benennen. Auch aus dieser Perspektive heraus kann die Predigt also als Interaktion beschrieben werden.

Die vorliegende Arbeit widmet sich in den nachfolgenden Kapiteln der Frage, welche Beteiligungsformate speziell im (monologischen) Aktivitätstyp Wortbeitrag christlicher Predigten etabliert und ermöglicht werden. Dazu wird auf der Ebene der Zwischenstruktur mithilfe des begrifflichen und methodischen Instrumentariums der Interaktionalen Linguistik die Verteilung des Rederechts und die Etablierung unmittelbarer Redezugwechsel (turn taking) betrachtet. Ziel ist es, die im untersuchten Korpus beobachtbaren Formen der Beteiligung der anwesenden Gemeinde zu beschreiben und damit auch die interaktiven Potenziale des Wortbeitrags herauszuarbeiten.

Ziel ist es weiterhin herauszuarbeiten, welche interaktiven Bedingungen gegeben sein müssen, damit die Etablierung eines unmittelbaren Wechsels zwischen den Interaktionsbeiträgen der anwesenden Personen - und damit eines Dialogs im engeren Sinne - in christlichen Wortbeiträgen gelingt. Dazu werden die drei häufigsten Beteiligungsformate genauer vorgestellt: die minimale und ritualisierte Amen-Paarsequenz (Abschnitt 17.3.1), die Aufforderung des Predigers an die 
Gemeinde zur aktiven und unmittelbaren Reaktion (meist in Form einer Interrogativsequenz; Abschnitt 17.3.2) und die auch körperliche Miteinbeziehung der Anwesenden in den Wortbeitrag (Abschnitt 17.3.3).

\subsubsection{Die Paarsequenz,Amen'}

Mit Blick auf die institutionell eingebettete Gattung der christlichen Predigt stellt sich die Frage nach einem unmittelbaren Sprecherwechsel (turn taking) in der bisherigen Forschung vor allem vor dem Hintergrund der Stil(istik), der Ritualität und der Inszenierung typischer dialogischer Strukturen in Form von Zitaten alltäglicher Interaktionsformen bzw. dialogisch organisierter ritueller Formen (Paul 1990:153). Besonders prominent ist die ritualisierte Amen-Paarsequenz (nachfolgend auch Amen-Sequenz). Sie ist spezifisch für religiöse Kommunikation und historisch gesehen bereits Teil der Durchführung des Synagogalgottesdienstes (vgl. Trepp 1992:281). Sie besteht sowohl im ersten als auch im zweiten Paarteil aus der „religious formulaic expression“ (Wharry 2003:208) „Amen“. Der aus dem Hebräischen übernommene Begriff ,,signalisiert insbesondere in liturgischem Kontext die Zustimmung des Sprechers. [...] Es bestätigt, dass etwas Ausgesprochenes als gewiss und zuverlässig erkannt und anerkannt wird, etwa im Sinn von ,so sei es““ (Rösel 2013). Neef bezeichnet den Gebrauch des ,Amen“ „geradezu als Markenzeichen christlicher Existenz über alle Konfessionsgrenzen hinweg. Leben im Glauben ist Leben im Horizont des ,Amen “ (Neef 2008:363).

Im Gegensatz zur Predigtkultur afroamerikanischer Gemeinden, bei denen das ,Amen' innerhalb des Wortbeitrags von der Gemeinde ohne vorherige Aufforderung durch den Prediger als Bewertung, Zustimmungsmarkierung und Kommentar auf die Äußerungen des Predigers realisiert wird (vgl. Wharry 2003), ist die sequenzielle Einbettung und die Verteilung zwischen EPT und ZPT in den hier untersuchten Predigten deutlich festgelegt. In der Regel formuliert der Prediger ein ,Amen' als ersten Paarteil und die Gemeinde reagiert ebenfalls mit einem ,Amen' als zweitem Paarteil. Innerhalb der untersuchten Wortbeiträge wurde die Amen-Paarsequenz, bis auf eine Ausnahme, an spezifischen verfestigten und z. T. liturgisch vorgegebenen Stellen innerhalb der Predigt initiiert und durchgeführt:

- am Ende des Kanzelgrußes (Abschnitt 15.1.4, Beispiel 7),

- am Ende des Kanzelsegens (Abschnitt 15.2.1, Beispiel 15),

- im Anschluss an die Lesung des biblischen Textes und des Textsegens (Abschnitt 15.1.5, Beispiel 12),

- als Abschluss eines Gebets (zu Beginn oder am Ende des Wortbeitrags; Abschnitt 15.1.4 und 15.2.1) oder 
- als Beendigungssignal für den Wortbeitrag (Abschnitt 15.2, Beispiel 14).

Die Amen-Sequenz dient damit in allen Fällen als ritualisierte Beendigungsmarkierung und als Übergang zu einer darauf folgenden Aktivität, etwa dem Beginn des Wortbeitrags oder dem nächsten Teil des Gottesdienstes (z. B. ein Lied oder die Abkündigungen). Die Initiierung der Sequenz geht in den hier untersuchten Fällen immer vom Prediger aus. So ist er es, der den ersten Paarteil produziert und damit das Rederecht für die minimale Reaktion eines „Amen“ abgibt. Die anwesenden Personen bestätigen diese ritualisierte Paarsequenz, indem sie das übergebene Rederecht nicht über die Produktion des „Amen“ als zweiten Paarteil hinaus in Anspruch nehmen und das Rederecht so unmittelbar im Anschluss wieder an den Prediger zurückgeben. Wie bereits in den Kapiteln zur Eröffnung und Beendigung der Predigt herausgearbeitet wurde (siehe Abschnitt 15.1 und 15.2), handelt es sich bei der Amen-Sequenz zwar um eine Sequenz, die spezifisch für religiöse Kommunikation, jedoch gerade in christlichen Predigten nicht obligatorisch ist. In den untersuchten katholischen und freikirchlichen Predigten wurde an keiner der fünf beschriebenen Positionen eine Amen-Sequenz realisiert.

Darüber hinaus wurde in einer der untersuchten Freikirchen innerhalb des Wortbeitrags eine Amen-Sequenz initiiert, bei der der Prediger die Gemeinde zu einer Bestätigung bzw. zu einem Bekenntnis aufforderte. Dieses Format der Sequenz kam dem, was Wharry (2003) als call-and-response-Format beschreibt, am nächsten. 
Beispiel51: Wer mir zustimmt sagt Amen

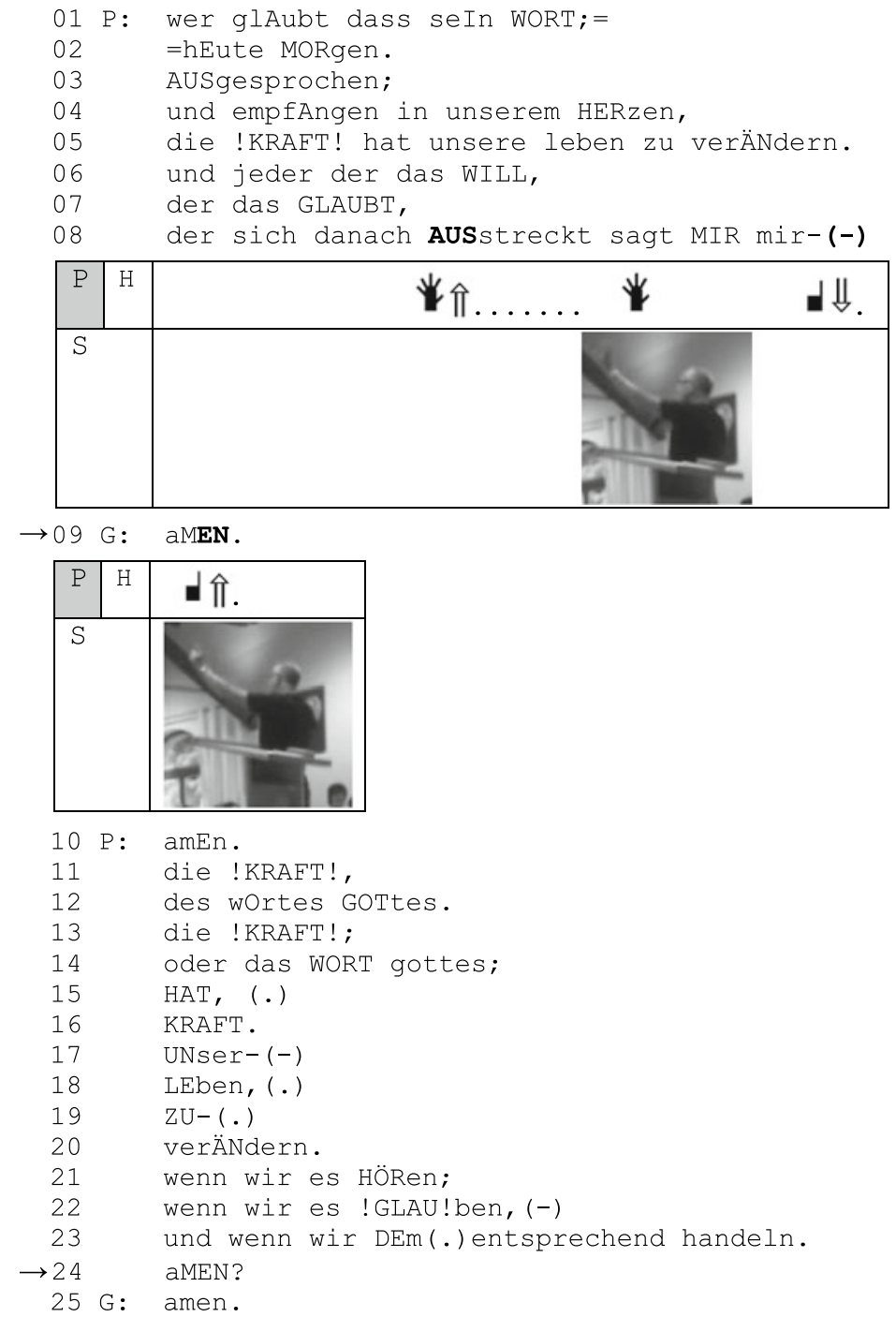


In diesem Beispiel elizitiert der Prediger eine Reaktion der anwesenden Personen, indem er mehrere Amen-Sequenzen initiiert (Z.9/10 und Z.24/25). Das „Amen“ ist vor allem in der ersten Sequenz eine Zustimmung, Bestätigung und ein Bekenntis der Gemeinde zu der Glaubenshaltung, die zuvor vom Prediger aktualisiert wurden (wer glAubt dass seIn WORT; hEute MORgen. AUSgesprochen; und empfAngen in unserem HERzen, die !KRAFT! hat unsere leben zu verÄNdern, Z.1-5). Im Anschluss daran fordert der Prediger die Gemeinde auf, das Bekenntnis laut auszusprechen (und jeder der das WILL, der das GLAUBT, der sich danach AUSstreckt sagt MIT mir, Z.6-8). Dadurch konstruiert er eine Glaubensgemeinschaft unter den anwesenden Personen. Der Prediger benennt nach der Formulierung der Glaubensgewissheit zunächst die Art und Weise, in der sich die anwesenden Personen unmittelbar im Wortbeitrag beteiligen sollen (sagt, Z.8). Visuell koordiniert er, wann die Gemeinde ihren Interaktionsbeitrag produzieren soll: auf die erste Silbe von „AUSstreckt“, streckt der Prediger seinen linken Arm in die Höhe ( MIT mir“ wieder zurück ( ل) und streckt ihn bei dem ,aMEN“ der Gemeinde wieder aus ( $\Uparrow$ ). Der Prediger gibt darüber hinaus nicht an, mit welchen Worten die Gemeinde ihren Gesprächsbeitrag produzieren soll. Auffällig ist, dass in diesem Auszug die Gemeinde den ersten Paarteil produziert (Z.9) und der Prediger, entgegen seiner Ankündigung, es gemeinsam zu sprechen (Z.8), erst im Anschluss daran ein „aMEN“ (Z.10) und damit den zweiten Paarteil realisiert. Dies macht auch deutlich, dass der Prediger zuschreibt, dass die Gemeinde weiß, dass sie nicht mit ,ja', ,halleluja ${ }^{\star}$ etc. reagieren soll und dass diese Form der Beteiligung in dieser Gemeinde bekannt ist.

Während in der ersten Amen-Sequenz (Z.8-10) verbale, vokale und visuelle Ressourcen genutzt werden, um zu kontextualisieren, dass das Rederecht abgegeben wird, sind es in der zweiten Amen-Sequenz (Z.24-25) vor allem verbale und vokale Ressourcen, die vom Prediger eingesetzt werden. Der Prediger produziert den ersten Paarteil in Form eines „aMEN?“ (Z.24) mit steigender Intonation am TCU-Ende und Betonung der zweiten Silbe. Zudem gibt er damit verbal vor, wie der zweite Paarteil zu erfolgen hat. Dies setzt eine konditionelle Relevanz für eine Reaktion der anwesenden Personen frei und die Gemeinde reagiert entsprechend (Z.25). Auch das Raumverhalten des Predigers unterscheidet sich im Verlauf der zwei Amen-Sequenzen. Während er bei der ersten Sequenz näher an die Gemeinde herantritt (Abb. 17.1), steht er bei der zweiten Sequenz neben dem beweglichen Rednerpult und hat seinen linken Arm auf dem Pult abgestützt (Abb. 17.2), setzt also zur Kontextualisierung seiner Erwartung einer Reaktion der 


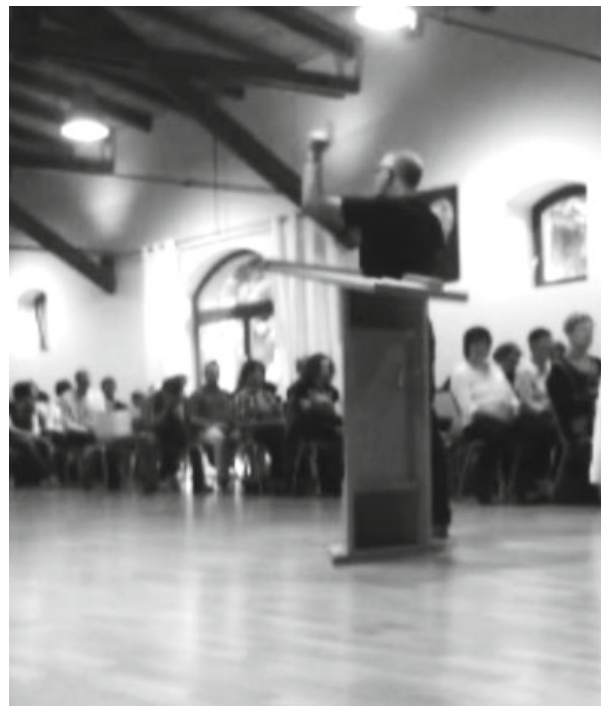

Abb. 17.1 erste Amen-Sequenz

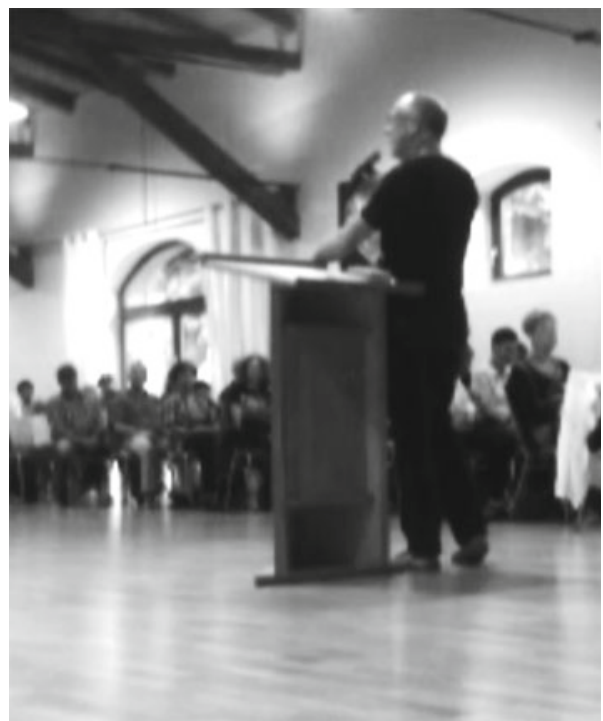

Abb.17.2 zweite Amen-Sequenz 
Gemeinde weniger gestische und proxemische Ressourcen ein als in der ersten Sequenz.

Während Wharry (2003) vor allem die Funktion von Zwischenrufen und unmittelbaren verbalen Reaktionen der Gemeinde als Diskursmarker, ,Platzhalter', Markierung unterschiedlicher Aktivitäts- und Handlungstypen oder als rhythmisches Stilmittel beschreibt und herausarbeitet, wird z. B. die Amen-Sequenz in den hier untersuchten Daten neben ihrem Gehalt als interaktionsstrukturierende rhetorische und ritualisierte Formel, als Mittel der Identitätskonstruktion gebraucht, indem Zustimmungen zu Glaubensgewissheiten eingefordert werden und darüber eine Wissens- und Glaubensgemeinschaft unter den anwesenden Personen hergestellt wird.

Im Gegensatz zu Predigtkulturen, in denen die unmittelbare verbale Beteiligung der anwesenden Personen ein ritueller und erwartbarer Teil innerhalb des Wortbeitrags ist (z. B. afro-amerikanische Predigten, vgl. Wharry 2003), findet sich die Sequenz in den hier untersuchten Predigten deutschsprachiger, christlicher Predigten hauptsächlich in den Aktivitätstypen der (verbalen) Eröffnung und Beendigung. Zudem ist es der Prediger und nicht die Gemeinde, der das ,Amen' als ritualisierte religiöse Wendung initiiert und damit eine Reaktion der anwesenden Personen elizitiert. Gleiches gilt auch für die Etablierung anderer call-and-response-Formate wie Interrogative. Das nachfolgende Kapitel zeigt, wie diese im Wortbeitrag christlicher Predigten etabliert und durchgeführt werden und welche interaktiven Ressourcen die Prediger einsetzen, um eine Reaktion der anwesenden Personen einzufordern. In diesem Zusammenhang zeigt sich, dass in den hier untersuchten Predigten Fragen eine schwächere konditionelle Relevanz für eine Antwort etablieren als in alltäglicher Interaktion und dass die Prediger auch aufgrund des institutionellen Charakters der Gattung und der typischen Interaktionsordnung (siehe Kapitel 13 und 14) zusätzliche interaktive Arbeit leisten müssen, um einen unmittelbaren Sprecherwechsel herbeizuführen.

\subsubsection{Interrogativsequenzen}

Neben der ritualisierten Amen-Sequenz treten in den Wortbeiträgen der hier untersuchten christlichen Predigten weitere Beteiligungsformate auf. Eine dieser Formen sind Interrogative. Die Sequenz Frage/Antwort ist eine der prototypischen Paarsequenzen, bei der der erste Paarteil (Frage) i. d. R. eine starke konditionelle Relevanz des zweiten Paarteils (Antwort) erzeugt (vgl. u. a. Stivers/Rossano 2010 und 2012; siehe Abschnitt 17.1). 
In der theolinguistischen Forschung zu dialogischen Strukturen in Predigten gelten Fragen als zentrale, Dialogizität erzeugende kommunikative Struktur (vgl. Malmström 2015:252). Auf der Grundlage der empirisch-quantitativen Auswertung eines Korpus von Predigtmanuskripten anglikanischer, katholischer und baptistischer Predigten unterscheidet Malmström die auftretenden Interrogative auf drei Ebenen:

- bezüglich des Wirklichkeitsbezugs, zwischen Fragen, die das subjektive Empfinden oder den kognitiven Zustand der Anwesenden betreffen (,internal states of affairs“, Malmström 2015:256), und Fragen, die die historische oder gegenwärtige Wirklichkeit betreffen (,external states of affairs“, Malmström 2015:256),

- bezüglich des Grades der Referenz auf und den Grad der Involviertheit der anwesenden Personen, zwischen inkludierenden Fragen (u. a. markiert durch den Gebrauch der Pronomen , du ${ }^{6}$ und ,wir') und nicht-inkludierenden Fragen (vgl. Malmström 2015:256),

- bezüglich der Antwortmöglichkeiten und der morpho-syntaktischen Realisierung, zwischen offenen und geschlossenen Fragen, Alternativfragen, Deklarativsatzfragen und Rückversicherungssignalen/tag questions (vgl. Malmström 2015:258).

Den Grad der Dialogizität einer Predigt macht er u. a. davon abhängig, wie viele Fragen ein Prediger im Verlauf seines Wortbeitrags produziert und ob der Prediger häufiger geschlossene oder offene Fragen stellt, da bei letzteren vermeintlich eine größere Involviertheit der anwesenden Personen erreicht wird (vgl. Malmström 2015:258). Im Zuge seiner Untersuchung arbeitet Malmström unterschiedliche Funktionen von Interrogativen in Predigten heraus: Die Gemeinde in die Predigt und deren Thema einzubeziehen und in einen Dialog zu involvieren, den Prozess der Exegese eines Bibeltextes zu strukturieren und die anwesenden Personen in diesem Prozess zu leiten, die Anwesenden als ko-präsente Beteiligte zu würdigen, Antizipation mit dem Gesagten herzustellen, unterschiedliche Meinungen gegenüberzustellen und schließlich die Prediger selbst sowohl als Lehrende als auch als Lernende zu positionieren (vgl. Malmström 2015:252 und 263-268).

In der linguistischen Forschung wird bezogen auf die morpho-syntaktische Struktur, die Illokution und die prosodische Gestaltung vor allem zwischen Entscheidungsinterrogativen (Ja-Nein-Fragen; polar interrogatives) und Ergänzungsinterrogativen (W-Fragen bzw. Informationsfragen) unterschieden (vgl. Clark 2012:81, Lohnstein 2013:52, Reis 2013:105). Hinzu kommen weitere Formen, die jedoch nicht als prototypische Fragen gelten: Alternativfragen, Echo-Fragen 
und assertive Fragen bzw. Deklarativsatzfragen. Hinsichtlich des Verhältnisses zwischen Frage und Antwort wird bei allen Typen bestimmt, dass eine Antwort erforderlich ist, die Frage aber jeweils einen anderen Antwortraum eröffnet. So geben Entscheidungsinterrogative einen „binären Alternativraum“ (Lohnstein 2013:51) zwischen den Antworten ,ja und ,nein“ vor, und Ergänzungsinterrogative eine Auswahl aus einer Alternativmenge (vgl. Lohnstein 2013:53). Als interaktive Kontextualisierungshinweise für Fragen und Elizitierungsressourcen für eine Antwort wurden in bisherigen Studien neben unterschiedlichen syntaktischen Markierung (Verbstellung, Nutzung von Fragewörtern etc.) und prosodischen Markierungen (steigende oder fallende Intonation) auch Hinweise auf eine bestehende epistemische Asymmetrie (,recipient-tilted epistemic asymmetry“, Hayano 2012:397) zwischen den Interagierenden sowie das Blickverhalten der beteiligten Personen beschrieben (vgl. Stivers/Rossano 2010 und 2012, Hayano 2012:396, Stivers 2012; siehe Abschnitt 17.1).

In ihrer Funktion als stilistische Satzfiguren werden schließlich rhetorische Fragen untersucht. Im Gegensatz zu den bisher vorgestellten Interrogativformen werden sie vor allem bezogen auf die Relevanz einer Antwort als Frage definiert, ,auf die keine Antwort erwartet wird, weil die Antwort evident ist - die Formulierung der Frage impliziert schon die Antwort" (Kolmer/Rob-Santer 2002:87), d. h. es wird auf morpho-syntaktischer Ebene ,ein Fragesatz realisiert, aber keine Fragehandlung ausgedrückt" (Fernandez Bravo 1995:123). Als rhetorisches Element z. B. einer Rede zielen sie nicht auf die Überwindung eines Wissensdefizits auf Seiten der Fragenden, sondern auf die ,aktive[] geistige[] Mitarbeit“ (Kolmer/Rob-Santer 2002:87) der Adressierten ab. De Ruiter charakterisiert rhetorische Fragen als ,persuasive argument dressed up as a superfluous information request" (de Ruiter 2012:3). Von ihrer formalen Struktur ähnelt die rhetorische Frage demnach Informationsfragen, setzt aber nicht deren Relevanz zur Vermittlung der erfragten Information frei, sondern macht den entsprechenden zweiten Paarteil überflüssig bzw. nicht erwartbar. Studien, die den Definitionsfokus auf diesen Aspekt gerichtet haben, können dann weiter herausarbeiten, dass jeder Fragetyp, der sich an syntaktischen Elementen festmachen lässt, auch als rhetorische Frage realisiert werden kann, und die Rhetorizität einer Frage vor allem durch den situativen Kontext bedingt wird (vgl. Fernandez Bravo 1995:126).

Rhetorische Fragen werden als Stilmittel verstärkt in Interaktionsereignissen mit vordergründig monologischer Rederechtsverteilung eingesetzt (vgl. Sadok 2012:103). Ruth Ayaß arbeitet für das mediale Verkündigungsformat „Wort zum Sonntag" mit nicht ko-präsenten Beteiligten heraus, dass rhetorische Fragen dort ein wesentlicher Bestandteil sind (vgl. Ayaß 1997a:185). Als entscheidendes 
Moment beschreibt sie in diesem Zusammenhang, dass die Sprecher des Wortes zum Sonntag systematisch turnübergaberelevante Punkte (TRPs) produzieren, indem sie nach der Frage Pausen lassen:

Pausen, die nach einem solchen ,possible completion point ' gelassen werden, eröffnen [...] den Rezipienten hypothetisch eine Stelle, an der sie den Redezug übernehmen und ihrerseits das Wort ergreifen können. Die Pausen indizieren eine Redezugvakanz, als würde der Sprecher dem Rezipienten nahelegen, auf die Frage wenigstens gedanklich zu antworten. (Ayaß 1997a:186)

Dies sieht Ayaß als Indiz für die ,,interaktive Qualität“ (Ayaß 1997a:186) von rhetorischen Fragen im Wort zum Sonntag. Darüber hinaus identifiziert sie aufgrund der häufig auftretenden Bündel rhetorischer Fragen die Funktion der präventiven Verstehenssicherung (Аyaß 1997a:187). Obwohl keine unmittelbare Wechselrede stattfindet, und damit das prägnanteste Merkmal eines Dialogs im engeren Sinne nicht vorhanden ist, schreibt Ayaß dem Wort zum Sonntag ein interaktives Potenzial zu. Das Dialogverständnis von Ayaß tendiert an dieser Stelle also deutlich stärker hin zu einem weiten Dialogbegriff, wie ihn Bachtin annimmt.

Malmström wiederum unterscheidet in seiner Studien zu Fragen in Predigten nicht zwischen, echten' Fragen und rhetorischen Fragen, da seiner Untersuchung schriftlicher Predigtmanuskripte zufolge ,virtually no sermon questions are asked to elicit information that is unknown by the preachers [...]; there is no ,elicitation " proper because sermon listeners typically do not answer back" (Malmström 2015:261). Dies lässt Malmström zu dem Schluss kommen, dass alle Interrogative in Predigten rhetorische Fragen seien: ,they are questions to which no answer is expected, and they are included because the preacher is after some 'effect"' (Malmström 2015:261). Interrogative haben seiner Meinung nach also keine interaktive, sondern lediglich eine stilistische Funktion.

Im Gegensatz dazu treten in den hier untersuchten Predigten in ihrem interaktiven Vollzug unter ko-präsenten Beteiligten nicht nur rhetorische Fragen auf, die keine Relevanz einer Antwort aufbauen, und Interrogative mit verzögerter (gedanklicher) Antworterwartung, sondern auch Fragen mit einer hohen Antworterwartung. Es können in diesem Zusammenhang spezifische interaktive und für die Gattung konstitutive Formen beschrieben werden (vgl. Tabelle 17.1). Die Befunde Malmströms müssen also aufgrund der empirischen Daten in der vorliegenden Arbeit revidiert werden. 
Tabelle 17.1 Antwortearwartung Interrogative in Predigten

\begin{tabular}{|l|l|l|l|}
\hline \multicolumn{2}{|c|}{ Grad der Antworterwartung } & Grad der Rhetorizität & Form des Interrogativs \\
\hline a) & keine Antworterwartung & hohe Rhetorizität & $\begin{array}{l}\text { Fragen, bei denen keine Antwort relevant } \\
\text { gesetzt wird (Fragen ohne Antwort) }\end{array}$ \\
b) & $\begin{array}{l}\text { geringe (unmittelbare) } \\
\text { Antworterwartung }\end{array}$ & Fragen mit stark verzögerter Antwort \\
\hline c) & $\begin{array}{l}\text { hohe mittelbare } \\
\text { Antworterwartung }\end{array}$ & mittlere Rhetorizität & $\begin{array}{l}\text { Fragen mit innerlicher (gedanklicher) Ant- } \\
\text { wort }\end{array}$ \\
\hline d) & $\begin{array}{l}\text { hohe unmittelbare } \\
\text { Antworterwartung }\end{array}$ & geringe Rhetorizität & Fragen, die der Prediger selbst beantwortet \\
& & Fragen, die die Gemeinde beantworten soll \\
\hline
\end{tabular}

Der Prediger kann Interrogative formulieren, die aufgrund der Gattungskonventionen und der eingesetzten Kontextualisierungshinweise keine Antworterwartung aufbauen. Diese Fragen sind als rhetorische Fragen beschreibbar, die entsprechend eine hohe Rhetorizität aufweisen. Sie sind jedoch nicht der häufigste Fall in den untersuchten Wortbeiträgen. Frequenter sind hingegen Interrogative mit hoher Rhetorizität, die aber eine geringe (unmittelbare) Antworterwartung aufbauen. Hier markiert der Prediger, dass er eine Antwort erwartet, diese jedoch erst verzögert erfolgen soll - im Nachgang des Gottesdienstes. Ein dritter Typ sind Fragen mit einer hohen mittelbaren Antworterwartung. Der mittlere Grad an Rhetorizität entsteht dadurch, dass der Prediger eine Antwort auf seine Frage erwartet, diese jedoch innerlich bzw. gedanklich, aber zeitnah, noch innerhalb der Prediger oder des Gottesdienstes, erfolgen soll. Schließlich sind in dem hier untersuchten Korpus Interrogative mit hoher unmittelbarer Antworterwartung erkennbar. Sie weisen eine geringe Rhetorizität auf. Es können dabei Fragen unterschieden werden, auf die der Prediger selbst den zweiten Paarteil produziert, d. h. die Antwort gibt und Fragen, die von der Gemeinde durch einen visuellen oder auch verbalen Interaktionsbeitrag beantwortet werden sollen. Bis auf wenige Ausnahmen (ein katholischer Wortbeitrag und ein freikirchlicher Wortbeitrag) wurden die Fragen der Gruppe a), b) und c) in jedem der untersuchten Wortbeiträge erkennbar. Sie können allein auftreten oder in Interrogativbündeln. Das nächste Beispiel zeigt ein solches Fragenbündel, das der Prediger am Ende seines Wortbeitrags direkt an die Anwesenden adressiert (Z.2-3). 
Beispiel 52: Persönlich überdenken

01 P: wenn dich dAs nicht verändert weIß ich nicht was sich verändern SOLL. (--)

$\rightarrow 02{ }^{\circ} \mathrm{hh}$ und die frAge IST,

03 die wir euch heute STELlen?

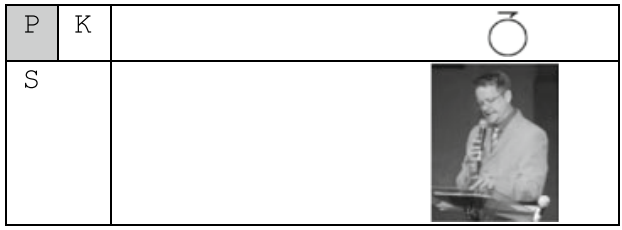

$\rightarrow 04{ }^{\circ}$ hh lässt du dich auf diese be!GNA!digung EIN?=

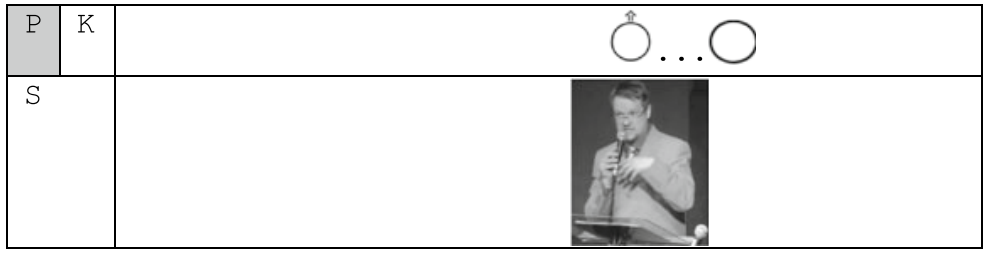

05 =auf diese FRETheit?

06 lässt du dich !RES!cuen, (----------)

\begin{tabular}{|l|l|c|}
\hline$P$ & $K$ & $0 . .0$ \\
\hline$S$ & & \\
& & \\
& & \\
\hline
\end{tabular}

07 oder lebst du weiter mit den verNARbungen; (-)

\begin{tabular}{|l|l|l|l|}
\hline $\mathrm{P}$ & $\mathrm{K}$ & $\mathrm{O} . \mathrm{O}$ & \\
\hline $\mathrm{S}$ & & & \\
& & & \\
& & & \\
\hline
\end{tabular}




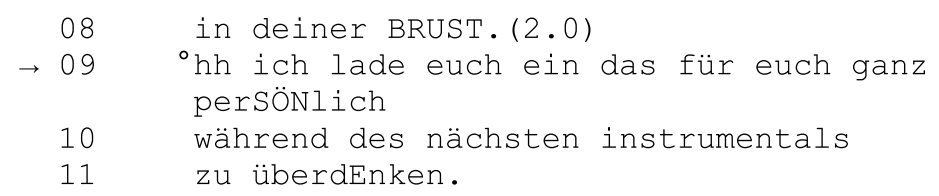

Der Prediger kontextualisiert die Entscheidungsinterrogative (lässt du dich auf diese be!GNA!digung $\operatorname{EIN} ?=((\ldots))$ oder (.) lebst du weiter mit den verNARbungen; (-) in deiner BRUST, Z.4-8) als Fragen, auf die er eine Antwort verlangt, die jedoch nicht unmittelbar, sondern verzögert und zunächst innerlich erfolgen soll, indem er eine Handlungsempfehlung ausspricht, die er in diesem Fall durch die Rahmung als Einladung kontextualisiert (ich lade euch ein das für euch ganz perSÖNlich während des nächsten instrumentals zu überdEnken, Z.9; siehe Abschnitt 16.6). Mit seinen Fragen (Z.4-8) fasst der Prediger seinen Wortbeitrag auch inhaltlich zusammen: seine Ausführungen darüber, dass die anwesenden Personen, wenn sie an Gott glauben, gerettet und begnadigt sind, befreit vom Zwang, durch eigene Taten Rettung zu erfahren (siehe Abschnitt 16.3.5, Beispiel 41). Die damit verbundenen moralischen Implikationen, dass auf der Grundlage von biblischen Überlieferungen und Glaubensgewissheiten ein gerettetes Leben besser ist als ein Leben ohne Gott, werden mit den Fragen gleichfalls aktualisiert und auf mögliche zukünftige Handlungen hin ausgedehnt. Abhängig davon, wie die Antwort der anwesenden Personen ausfällt, können sie im Anschluss an ein Musikstück mit dem Prediger zusammen ein Gebet sprechen, um die getroffene Entscheidung zu bekräftigen (nicht im Transkript). Dass es sich in diesem Beispiel um Interrogative mit einer mittleren Rhetorizität und hoher mittelbarer Antworterwartung handelt, kontextualisiert der Prediger nicht nur verbal durch die Angabe, wann die Antwort erfolgen soll (bei dem der Predigt folgenden Musikstück), sondern auch visuell. Während er das erste Interrogativ äußert (Z.4) hebt er auf die stark betonte Silbe von

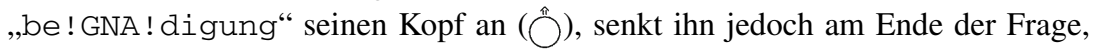
d. h. am möglichen übergaberelevanten Punkt (Z.6) wieder ab ( $\left.\bigcirc^{\Perp}\right)$. Obwohl er eine Pause produziert, in der grundsätzlich die Möglichkeit für eine Antwortproduktion bestehen würde, blockiert der gesenkte Kopf und damit der angewendete Blick, dass der Prediger Reaktionen der Gemeinde (visuell) wahrnehmen könnte. Ein ähnliches Verhalten zeigt der Prediger auch beim zweiten Interrogativ (Z.7-8). Auch hier senkt er den Kopf am Ende der Frage nach unten und wendet damit seinen Blick ab. Visuell verhindert der Prediger damit eine mögliche turn-Übergabe. 
Fragen mit hoher oder mittlerer Rhetorizität sind nicht nur eine von den Predigern genutzte Praktik, um Beteiligung zu suggerieren, sondern auch, um Verbindungen zwischen einem Bibeltext und der Lebenswirklichkeit der anwesenden Personen herzustellen und so z. B. die überzeitliche Gültigkeit biblischer Texte herauszuarbeiten. Das nachfolgende Beispiel aus einem Jugendgottesdienst verdeutlicht, wie eng die in dieser Arbeit beschriebenen Verfahren und Praktiken miteinander verzahnt und aufeinander bezogen sein können und dass auch Interrogative mit hoher Rhetorizität in diesem Zusammenhang realisiert werden. Der Prediger führt seinen Wortbeitrag zum Thema Zweifeln in Form einer Dialogpredigt durch (siehe Abschnitt 17.4). Textliche Grundlage ist die biblische Geschichte des Jüngers Thomas. 


\section{Beispiel 53: Vergessen}

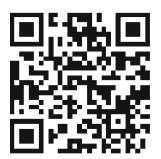

288 lobe den Herrn meine SEele.=

289 =und vergiss nicht was er dir gutes geTAN hat.

290 das ist eine LEbenswahrheit.

291 das NICHT zu vergessen.

$292{ }^{\circ}$ hh im Alten testament haben MENschen, (-)

293 nach einer eInschneidenden gotteserFAHrung,

294 alTäRE gebaut.(-)

295 sie haben si sch ein rIese (.) STEINhaufen irgendwohin gestellt, (-)

296 gEgen das verGESsen.

297 haben dort NAmen gegeben, (-)

298 haben dort das als heiligen ORT äh-

299 deklaRIERT,

300 dass auch generationen noch danach WUSsten-

301 dA hat GOTT-

302

303

304

gAnz konkret in die gescHICHte eingegriffen.

'hh heute würde man dazu DENKmal sagen.

305

ein ORT-

306

307

der zum geDENKen,

und zum DANKen.

308

aufFORdert. (-)

${ }^{\circ} \mathrm{h}$ jetzt kommst DU ins spiel.

$\rightarrow 309$

310

wAs machst DU? (--)

311

um die kleInen und großen beGEGnungen-

312

die dU mit gott HAST,

$\rightarrow 313$

314

NICHT zu vergessen.

315

was machst DU?

316

317

318

wo baust dU ein ! DENK!mal.

319 (2.0) lerne vielleicht ein Lied oder einen

was dich immer wieder an GOTT erinnert.(1.5)

was sind deine DENKmäler,

ich will dir MUT machen,

SCHREIbe dir dinge AUF. bibelvers AUSwendig,

320 der dich an EIne bestimmte gottesbegegnung erInnert. 
Am Ende seines Wortbeitrags vermittelt der Prediger, nachdem er einen Bibeltext zitiert hat (Z.288-289), Bibeltextwissen in Bezug auf die Erinnerungskultur des Alten Testaments $\left({ }^{\circ} \mathrm{hh}\right.$ im ALten testament haben MENschen nach einer EINschneidenden gotteserfahrung, (-) alTÄRE gebaut, Z.292-302). Durch die Bildung einer Analogie $\left({ }^{\circ} \mathrm{hh}\right.$ heute würde man dazu DENKmal sagen, Z.303; siehe Abschnitt 16.4) zeigt er zugleich die überzeitliche Gültigkeit der biblischen Schilderungen auf. Dies wird zusätzlich dadurch verstärkt, dass er die Gemeinde direkt adressiert $\left({ }^{\circ} \mathrm{h}\right.$ jetzt kommst DU ins spiel, Z.308) und eine Folge von Interrogativen mit hoher Rhetorizität, aber dennoch einer verzögerten Antworterwartung produziert (WAS machst DU? (--) um die KLEInen und grOßen begegnungen die DU mit gott hAst, NICHT zu vergessen. (1.5) was machst DU? wo baust DU ein ! DENK!mal. was dich immer wieder an GOTT erinnert. (1.5) was sind deine DENKmäler, Z.309-316). Im Anschluss an diese Fragen gibt der Prediger schließlich Handlungsoptionen, wie die persönliche Erinnerungskultur jedes Einzelnen aussehen könnte (ab Z.317-319; siehe Abschnitt 16.6, Beispiel 50). In diesem kurzen Auszug nutzt der Prediger die Vermittlung von Bibeltextwissen, intertextuelle Verweise, Analogiebildungen, die Formulierung von Handlungsoptionen und Fragen mit hoher Rhetorizität, um eine biblische Begebenheit nicht nur zu veranschaulichen, sondern auch um die überzeitliche Gültigkeit und die Relevanz für die Gegenwart aufzuzeigen. An diesem Beispiel zeigt sich im Zusammenspiel all dieser Praktiken der rekonstruktiv-prospektive Charakter, der für die hier untersuchten Predigten herausgearbeitet werden konnte: Im Rückblick auf alte biblische Texte (hier: die Erinnerungskultur im AT und die Geschichte des zweifelnden Jüngers Thomas im NT) wird in der Parallelisierung mit aktuellen, gegenwärtigen Zusammenhängen (hier: der Prediger schreibt der anwesenden Gemeinde zu, dass sie Glaubenszweifel kennt und bereits persönliche Begegnungen mit Gott hat - wie die thematisierten biblischen Personen) der überzeitliche Charakter biblischer Texte und auf deren Grundlage das Potenzial für zukünftige Handlungen aufgezeigt (hier: die Aufforderung des Predigers in der Entwicklung einer persönlichen Erinnerungskultur in Zeiten des Zweifels an göttlichen Zusagen festzuhalten).

Fragen, die für den Moment des Wortbeitrags eine hohe oder mittlere Rhetorizität haben, d. h. auf die eine unmittelbare Reaktion ausbleibt, erscheinen als Elemente eines weiten Dialogbegriffs im Sinne Bachtins, bei denen unklar bleibt, wie stark die konditionelle Relevanz ist, die sie auslösen, denn die Antworterwartung erstreckt sind nicht auf eine unmittelbar (verbal) wahrnehmbare Reaktion der 
Rezipierenden, sondern auf ein innerliches Antworten bzw. eine erst später erfolgende Reaktion. Der zweite Paarteil ist damit lediglich in einer anderen Form realisiert bzw. suspendiert, nicht aber irrelevant. Es handelt sich damit nicht um eine rhetorische Frage im engeren Sinne. Interrogative dieses Formats können an allen Stellen innerhalb des Wortbeitrags realisiert werden und erstrecken sich syntaktisch sowohl auf Ergänzungsinterrogative, wie in Beispiel 53 (WAS machst DU? wo baust DU ein ! DENK!mal.), als auch auf Entscheidungsinterrogative, wie in Beispiel 52 (lässt du dich auf diese be!GNA!digung ein?=).

Betrachtet man beide Auszüge (Beispiel 52 und 53) mit dem Begriff der Dialogizität, wie Bachtin ihn gebraucht (siehe Abschnitt 17.1), zeigt sich auch im rekonstruktiv-prospektiven Charakter von Predigten ein dialogisches Merkmal. Denn für Bachtin entsteht ein Dialog gerade auch dadurch, dass eine Äußerung an etwas bereits Geäußertes anschließt (der biblische Text) und gleichzeitig auf zukünftige Handlungen wirkt und diese ermöglicht (in diesem Beispiel die Aufforderung, sich an Gotteserfahrungen zu erinnern). Alle hier untersuchten Predigten zeigen diesen retrospektiv-prospektiven Charakter und damit ein dialogisches Potenzial.

Fragen können zudem vom Prediger selbst beantwortet werden. Er produziert dann sowohl den ersten als auch den zweiten Paarteil der Sequenz und kontextualisiert, dass er keine Antwort seitens der Gemeinde erwartet. Einen solchen Fall verdeutlicht das nachfolgende Beispiel aus einer ökumenischen Sonntagspredigt: 
Beispiel 54: Was ist also der Glaube

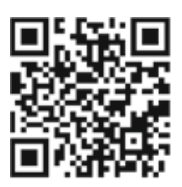

$\rightarrow 01 \mathrm{P}:$ was Ist also der GLAUbe? (----------)

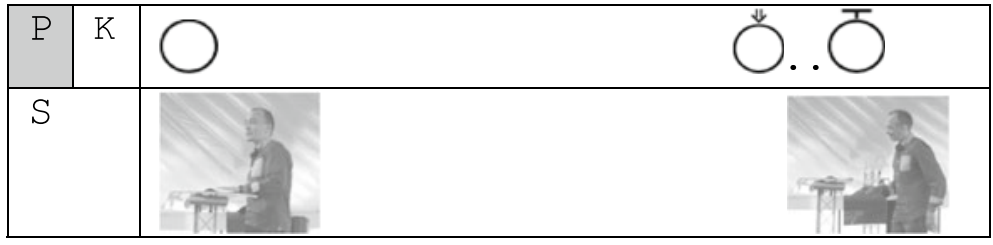

02 er ist die GRUNDlage; (.)

03 Unserer HOFfnung. (----)

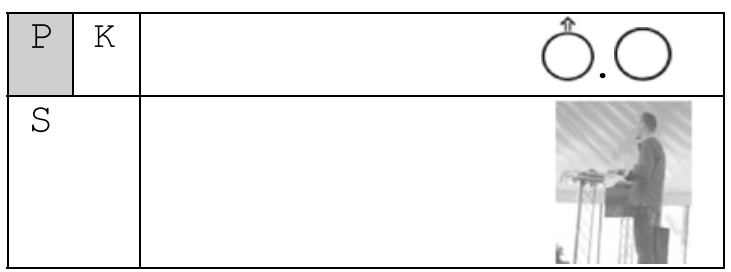

04 ein !WISS!EN um !WIRK!lichkeit.

05 die man NICHT sieht. (-)

$06<<$ dim> ein wIssen um !WIRK!lichkeit,

07 die man NICHT sieht.>

Der Prediger äußert hier zu Beginn seines Wortbeitrags ein Ergänzungsinterrogativ mit steigender Intonation am TCU-Ende, W-Fragewort und einer daran anschließenden Pause (was Ist also der GLAUbe?, Z.1). Aufgrund dieser morpho-syntaktischen, prosodischen und sequenziellen Kontextualisierungshinweise handelt es sich nach Abschluss des Interrogativs um einen möglichen übergaberelevanten Punkt (TRP). Dieser wird jedoch weder vom Prediger noch von der Gemeinde als solcher behandelt. Ein Grund dafür ist das Blickverhalten des Predigers. Während er bei der Formulierung der Frage in die Gemeinde blickt $(\bigcirc, \mathrm{Z} .1)$, wendet er diesen in der sich anschließenden Pause ab, indem er den Kopf senkt ( $\oplus^{\circ}$ ) und schaut auf die auf dem Rednerpult liegende Bibel. Nicht nur die gattungstypische Interaktionsordnung kontextualisiert hier, dass es 
sich um ein Interrogativ ohne Antworterwartung aus der Gemeinde handelt, sondern zusätzlich das Blickverhalten des Predigers. Denn obwohl die Pause eine Reaktion der Anwesenden möglich machen würde, verhindert der gesenkte Kopf die Wahrnehmung etwaiger Meldungen. Der Prediger beginnt dann den ZPT auf seine Frage zu realisieren (er ist die GRUNDlage; (.) Unserer HOFFnung, Z.2-3). Währenddessen hebt er den Kopf wieder an $(\hat{\bigcirc}, Z .3)$ und setzt seine Antwort fort (ein wIssen um WIRKlichkeit. die man NICHT sieht, Z.4-5). Dadurch, dass er nicht nur den EPT, sondern auch den ZPT realisiert, initiiert der Prediger einen, wie Ayaß es benennt, ,fingierten FrageAntwort-Dialog“ (Ayaß 1997a:195). Dieser wird von den Predigern nicht nur genutzt, um Wissen zu vermitteln, sondern auch dazu, den Wortbeitrag zu strukturieren, indem sie Fragen stellen, die sie im Verlauf der Ausführungen und anhand von biblischen Texten beantworten. Gerade wenn es um die Auseinandersetzung mit zuvor gelesenen Bibeltexten geht, nutzen einige Prediger die Frage, Was heißt $d a s^{\varsigma}$, um Erklärungen und Auslegungen einzuleiten und damit die Antwort auf diese Frage zu geben, indem sie z. B. den Text veranschaulichen und als nicht vorhanden zugeschriebene Wissensbestände vermitteln.

Vor allem in Wortbeiträgen im Rahmen spezieller Zielgruppengottesdienste (z. B. Jugendgottesdienste, Familiengottesdienste und Lobpreisgottesdienste) und alternativer Gottesdienste nutzen die Prediger die Möglichkeit, Interrogativsequenzen zu initiieren, bei denen die Erwartung einer unmittelbaren Reaktion der anwesenden Personen kontextualisiert wird. Dass die direkte Wechselrede ein mögliches, aber häufig nicht erwartbares und zudem interaktiv nicht unproblematisches Element des Wortbeitrags ist, zeigt sich in den nachfolgenden Beispielen vor allem daran, dass die Prediger einen hohen interaktiven Aufwand betreiben, um das geäußerte Interrogativ als Frage mit geringer Rhetorizität und hoher unmittelbarer Antworterwartung zu kontextualisieren. Bedingt wird dies durch den Charakter der kommunikativen Gattung Predigt als Bühnenformat mit einer Interaktionsordnung one-face-to-many-faces und der Übergabe des Rederechts an den Prediger. Diese Merkmale konkurrieren mit der Struktur von Frage/Antwort-Sequenzen und verlangen von den Predigern u. a. den Einsatz morpho-syntaktischer und prosodischer sowie visuell-leiblicher Kontextualisierungshinweise. 
Beispiel 55: Ihr dürft hier mitmachen

134 P: weiß nicht ob ihr euch daran erINnern könnt? (-)

135 als MOse? (1.5)

136 die zehn gebote von gott (.) emPFING?

$\rightarrow 137$ was ist pasSIERT; $=$

138 =als er zuRÜCKgekommen ist,

139 als er auf dem BERG war?
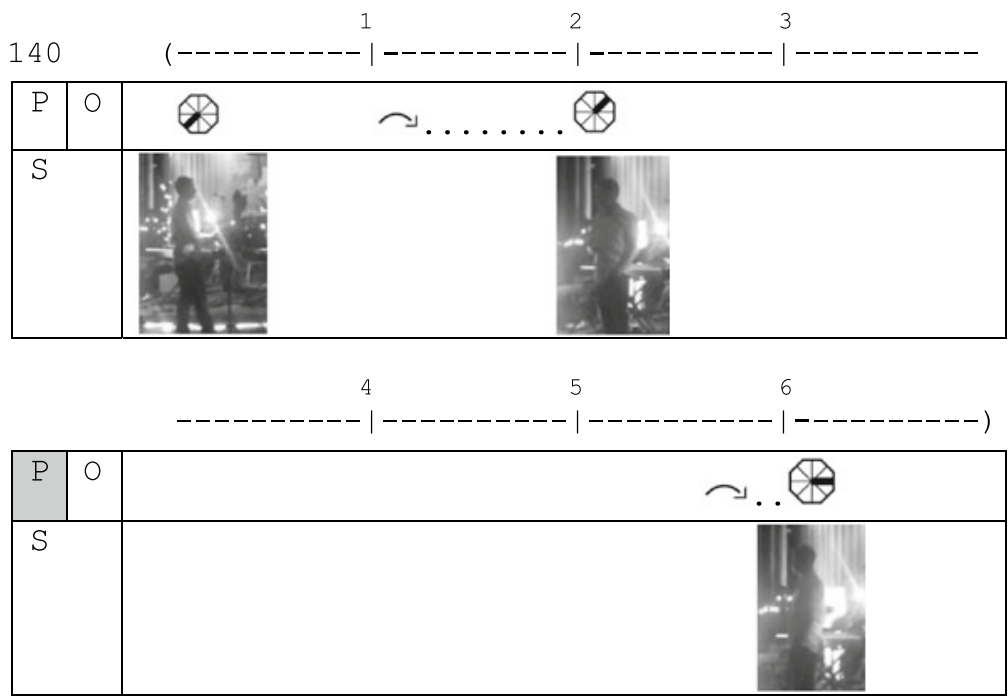

$\rightarrow 141$ irgendjemand schon mal die geschichte geHöRT?

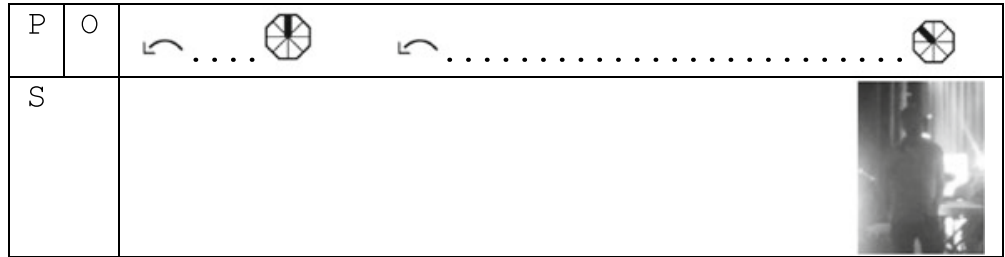

142 G: <<p>ja:?> 


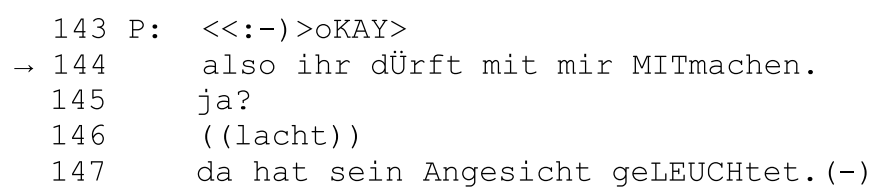

In diesem Auszug aus dem Wortbeitrag einer Predigt, die im Rahmen eines ökumenischen Lobpreisgottesdienstes gehalten wurde, setzt der Prediger Bibeltextwissen über eine Episode aus dem Alten Testament (Mose erhält von Gott die 10 Gebote) relevant. Zunächst produziert er die epistemischrhetorische Formulierung ,weiß nicht“"(Z.134), mit der er seinen niedrigen epistemic stance hinsichtlich der Zugänglichkeit zum Territorium der Erinnerung der anwesenden Personen herausstellt (weiß nicht ob ihr euch daran erINnern könnt?, Z.134; siehe Abschnitt 16.2). Im Anschluss daran benennt er den Wissensbestand, den er verhandelt (135-136) und aktualisiert dazu einige Elemente aus der entsprechenden biblisch tradierten Erzählung. Dass es sich bei der Konstruktion ,ich weiß nicht " um eine Prä-Sequenz zu einer Frage mit hoher unmittelbarer Antworterwartung (was ist pasSIERT; als er zuRÜCKgekommen ist, als er auf_dem BERG war?, Z.137-139) handelt, markiert der Prediger durch die steigende Intonation am TCU-Ende (Z.134-136). Mit der Frage selbst prüft er, inwiefern das Wissen über den biblischen Text bei den anwesenden Personen vorhanden ist oder nicht. Zusätzlich zur intonatorischen Markierung nutzt der Prediger vor allem visuell-leibliche Kontextualisierungshinweise, indem er seine Körperausrichtung ändert und sich in einer halben Drehung von links nach rechts den anwesenden Personen zuwendet (von zu Z Z z 140) und den Blick konstant suchend in die Gemeinde richtet. Parallel dazu verändert er mit seiner Körperorientierung auch den Distanzraum, denn er bewegt sich von seinem Predigtort weg und auf die Gemeinde zu. Hinzu kommt dann die morpho-syntaktische Gestaltung als Ergänzungsinterrogativ, das ebenfalls mit steigender Intonation realisiert ist. An dieser Stelle hat der Prediger bereits sechs unterschiedliche Kontextualisierungshinweise produziert, die darauf verweisen, dass es sich um eine Frage mit hoher unmittelbarer Antworterwartung handelt:

- der Verweis auf die epistemische Expertise der Rezipierenden und auf die Unzugänglichkeit des Territoriums der Erinnerung für den Prediger (,ich weiß nicht'),

- die Produktion einer Äußerung mit expliziter Fragesyntax als Ergänzungsinterrogativ (W-Ausdruck in Erstposition, Verb-Zweit-Stellung),

- ein steigender Intonationsverlauf, 
- lange Pausen, die einen TRP anzeigen,

- die Zuwendung und das Halten des Blicks auf die anwesenden Personen,

- die Verringerung der räumlichen Distanz zur Gemeinde.

Auf die ausbleibende Reaktion, d. h. das Fehlen eines zweiten Paarteils (Z.140) reagiert der Prediger mit einer weiteren Frage, die den grundsätzlichen Wissensstand der anwesenden Personen über die Erzählung von Mose und den 10 Geboten thematisiert (irgendjemand schon mal die geschichte geHÖRT?, Z.141). Dabei wendet er sich körperlich wieder der linken Seite der Gemeinde zu ( gerichtet. In diesem Fall produzieren einige der Anwesenden einen ZPT, indem sie die Frage mit „ja:?“(Z.142) beantworten. Mit seiner zweiten Frage liefert der Prediger eine erste mögliche Erklärung für das Ausbleiben des ZPT der ersten Frage: die Unkenntnis der thematisierten biblischen Erzählung auf Seiten der Rezipierenden. Da die Wissensannahme des Prediger zumindest für einen Teil der Gemeinde als zutreffend bestimmt wird, verortet der Prediger den Grund für die fehlende Reaktion auf die erste Frage auf interaktiver Ebene. Dieses expliziert er mit einem Metakommentar, der eine geänderte bzw. abweichende Interaktionsordnung etabliert (also ihr dÜrft mit mir MITmachen, Z.144). Damit interpretiert der Prediger das Handeln der Anwesenden nicht als Dokumentation von Nichtwissen, dass nämlich die Geschichte rund um die 10 Gebote unbekannt ist, sondern als Unklarheit bezüglich der Interaktionsordnung und die Interpretation der von ihm etablierten Frage als Frage mit niedriger Antwortrelevanz. Schließlich beantwortet der Prediger die Frage selbst (da hat sein Angesicht geLEUCHtet, Z.147) und produziert damit den ZPT der Ausgangspaarsequenz.

Neben den bisher gezeigten reaktionselizitierenden Ressourcen haben die Prediger darüber hinaus die Möglichkeit, durch die Benennung und das Anzeigen der Art und Weise, in der die Antwort erfolgen soll, zu kontextualisieren, dass sie eine Reaktion der anwesenden Personen auf eine zuvor geäußerte Frage erwarten. Mit hohem interaktivem Aufwand und unter Nutzung verschiedener interaktiver Ressourcen verdeutlicht der Prediger im nachfolgenden Auszug aus einer Dialogpredigt, bei der sich zwei Prediger am Predigtort befinden und gemeinsam den Wortbeitrag gestalten, die Erwartung einer unmittelbaren Reaktion auf seine Frage. Das Transkript beginnt mit dem Ende eines längeren Redebeitrags von Prediger 1 (P1), der die Antwort auf eine vorausgegangene Frage von Prediger 2 (P2) ist. P1 gibt das Rederecht schließlich wieder an P2 ab, der in seinem Redebeitrag die Aussagen von P1 bewertet und innerhalb seines turns eine Frage produziert. Um anzuzeigen, dass diese Frage eine echte Frage an die Gemeinde ist, nutzt der Prediger neben verbalen und vokalen Ressourcen auch visuelle Kontextualisierungshinweise. 


\section{Beispiel 56: Meldet euch kurz}

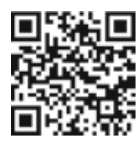

142 P1: wenn (.) wenn wir wÜssten was jeder in seinem HERzen hat.=

143 =aber dann denk ich auch am ENde; (-)

144 sOll_n_s alle SEhen.

145 soll doch jeder SEhen;

146 sollen meine gedAnken alle hier (.) angeBEAMT sein;

147 WEIL-

$148{ }^{\circ} \mathrm{h}$ jEsus sieht_s doch sowiesO.

149 warum soll ich vor jemandem etwas verbErgen was jesus am ende DOCH sieht.(-)

150 und es KOMMT doch'

151 also-

152 ich will ja-(-)

153 wie steht ICH vor IHM.

154 es kommt doch nicht drauf an wie ich vor ANderen stehe.(1.5)

155 P2: also es gibt für und WIder für dich.

\begin{tabular}{|c|c|c|}
\hline $\mathrm{P} 1$ & 0 & $\theta d$ \\
\hline & $\mathrm{K}$ & \\
\hline P2 & 0 & $\varepsilon$ \\
\hline & K & \\
\hline S & & \\
\hline & & \\
\hline & & \\
\hline
\end{tabular}

157 P1: <<p>SEHR. >

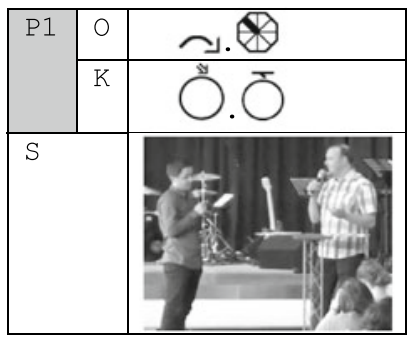


158 P2: wir können ja mal kUrz einen TEST machen.

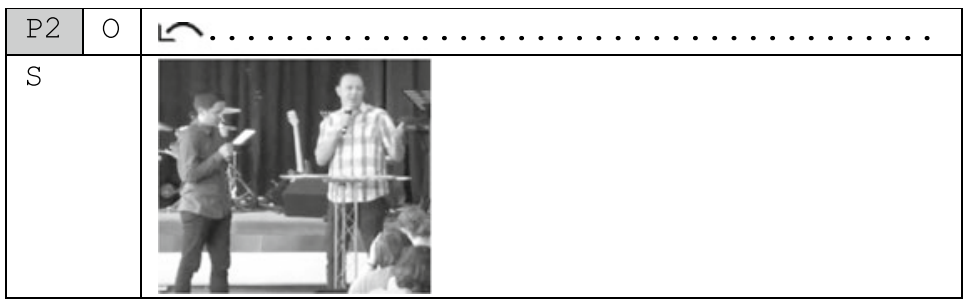

$\rightarrow 159$ wEr ist daFÜR,

\begin{tabular}{|l|l|l|}
\hline P2 & O & Q \\
\hline S & & \\
& & \\
\hline
\end{tabular}

160 wir sollen ab jetzt immer ALles sehen,

161 wenn (.) wir uns Angucken,

162 <<all>alle gedAnken geFÜHle, >

$\rightarrow 163$ mEldet euch KURZ,

\begin{tabular}{|c|c|c|}
\hline $\mathrm{P} 1$ & $\mathrm{M}$ & ـ...8 \\
\hline P2 & $\mathrm{H}$ & \\
\hline$S$ & & \\
\hline
\end{tabular}

164 okay wir sind zu DRITT.

165 P2: [( (lachen))

$166 \mathrm{G}:$ [ ( (lachen))

\begin{tabular}{|l|l|l|}
\hline P2 & H & v. \\
\hline
\end{tabular}

167 P1: okay. 
Die zwei Prediger sind zu diesem Zeitpunkt des Wortbeitrags körperlich aufeinander ausgerichtet ( $)$ und Z.156) und stehen damit seitlich zur Gemeinde. Inhaltlich verhandeln sie den Zugang unterschiedlicher Instanzen (Gott vs. Menschen) zu Wissensterritorien wie Gedanken und Gefühlen und das utopische Szenario, dass alle Menschen die Gedanken einer anderen Person sehen können. Nachdem P1 seine Meinung zu diesem Thema geäußert hat (Z.142-155), den Kopf senkt ( $\bigcirc^{\ominus}$ ) und sich körperlich von P1 abwendet, übernimmt P2 den turn und gibt die Frage an die Gemeinde weiter. Dazu wendet er sich in seiner körperlichen Orientierung den anwesenden Personen zu $(\curvearrowleft$, Z.158 und $\bigoplus$, Z.159) und produziert ein Entscheidungsinterrogativ, ob das in den Augen der anwesenden Personen erstrebenswert wäre (wEr ist daFÜR, wir sollen ab jetzt immer ALles sehen wenn (.) wir uns Angucken <<all> alle gedAnken geFÜHle, , Z.159-162). Dass es sich um eine Frage mit direkter Antworterwartung handelt kontextualisiert der Prediger zum einen durch die syntaktische Struktur, die hier steigende Prosodie und vor allem durch den verbalen Metakommentar, der angibt, auf welche Art und Weise die Antwort produziert werden soll (mEldet euch KURZ, Z.163). Zusätzlich zu diesen verbalen und vokalen Kontextualisierungshinweisen hebt der Prediger selbst seine linke Hand (*介, Z.162) und visualisiert damit zusätzlich die Art der unmittelbaren Beteiligung der anwesenden Personen. Gleichzeitig ist sein Blick suchend auf die Gemeinde gerichtet. Als adäquate Antwort der Gemeinde erscheint hier sowohl das Heben der Hand, dass die positive Bewertung und Zustimmung für den gemachten hypothetischen Vorschlag signalisiert, als auch das Ausbleiben einer Meldung. Letzteres interpretiert der Prediger als Ablehnung, was sein Metakommentar verdeutlicht (okay wir sind zu DRITT, Z.163). In dem darauffolgenden Lachen der anwesenden Personen senkt P1 seine Hand wieder ab (I, Z.166). Der Prediger nutzt hier also fünf verschiedene Kontextualisierungshinweise, um anzuzeigen, dass sein Interrogativ eine hohe unmittelbare Antwort verlangt: 
- die Produktion einer Äußerung mit expliziter Fragesyntax als Ergänzungsinterrogativ (Verb-Erst-Stellung),

- ein verbaler Metakommentar zur Art und Weise der Antwortproduktion,

- die Etablierung langer Pausen, die Raum für die Antwortproduktion lassen,

- die Zuwendung und das Halten des Blicks auf die anwesenden Personen,

- die visuelle Anzeige der Art und Weise der Antwort (Heben der Hand)

In vielen Fällen verändern die Prediger zusätzlich die Struktur des Interaktionsraums, indem sie den Abstand zwischen sich und der Gemeinde zumindest andeutungsweise verringern. Abhängig vom Predigtort haben die Prediger einen größeren oder kleiner Spielraum, dies zu tun. Nutzen sie ein bewegliches Pult, besteht die Möglichkeit, ihre Ausgangsposition hinter dem Pult zu verlassen, um das Pult herumzugehen und sich der Gemeinde zu nähern. Auf einer Kanzel ist der Bewegungsfreiraum des Predigers ungleich begrenzter. Aber auch dort nutzen Prediger Ressourcen des Blicks und der Körperorientierung zur Anzeige des Suchens von sich meldenden Personen und bewegen sich dabei ebenfalls, auf die Gemeinde zu'. Sie lehnen sich nach vorn und richtet den Blick auf die vor ihnen sitzende Gemeinde. In den meisten Fällen fordern die Prediger die anwesenden Personen zu einer visuellen Beteiligung durch Handzeichen auf. In einigen alternativen evangelischen Sonntagsgottesdiensten elizitieren die Prediger jedoch auch verbale Reaktionen auf eine gestellte Frage, wie das nachfolgende Beispiel zeigt. 


\section{$\underline{\text { Beispiel 57: Sagt mal }}$}

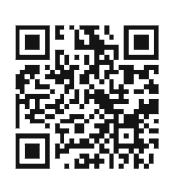

072 P: und heute ist erster adVENT.(2.0)

073 erster adVENT.

074 ANkunft. (2.0)

075 eine zeit die mit wArten zu TUN hat.

076 (ne wir ham) da vorne die erste kArze`(.)

077 erste !KER! ze!BRENnen, =

078 =und wir warten auf die <<all>zwEite dritte VIERte>;

079 und auf WEIHnachten;

$\rightarrow 080 \quad{ }^{\circ}$ hh WOrauf;

081 wArten wir Eigentlich;

082 im adVENT.(2.0)

$\rightarrow 083 \quad$ SAGT mal.

$084 \mathrm{~K} 2:<<$ p $>$ auf weihnachten>.

$085 \mathrm{P}$ : auf WEIHnachten.

086 warUm warten wir auf WEIHnachten.(3.0)

$087 \mathrm{~K} 2:<<\mathrm{p}>\mathrm{jEsus}$ geBURTStag. (.)

088 jEsus seine geBBURT.>

089 P: auf den gebUrtstag von JEsus.

090 da DENken wir dran.

091 aber worauf WARten; (.)

$092 \quad j A$ ?

$093 \mathrm{K3}:(\quad)$

$094 \mathrm{P}: \mathrm{jA}$.

095 geNAU.

096 jEsus ist geBOren.

$097<$ <all>jEsus hat geBURTStag weihnachten>.

098 das FEIern wir weihnachten.

099 das stIMMT.

$100{ }^{\circ}$ hh aber wir wArten in der adventszeit $\mathrm{NOCH}$ auf etwas.

$\rightarrow 101$ worAuf_denn NOCH; (--)

$\rightarrow 102 \quad \mathrm{SACH}$ màl.

103 K4: geSCHENke.(1.0)

104 P: auf geschEnke wart mer AUCH.

$105 j \mathrm{ja}$. 


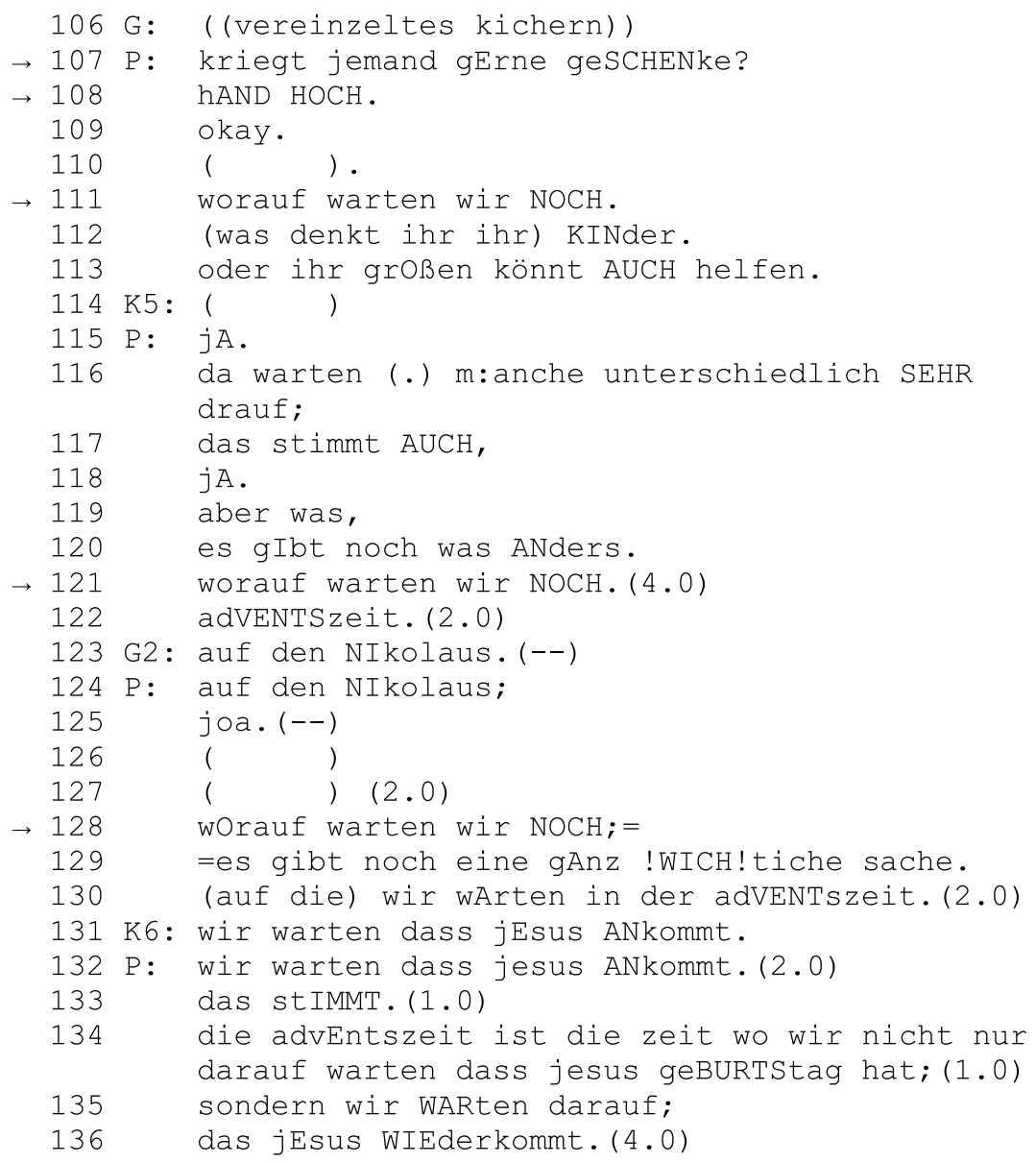

Zunächst übersetzt der Prediger $(\mathrm{P})$ den Begriff des Advent mit „ANkunft“ (Z.74) und führt das Thema des Gottesdienstes (,Warten') mit dieser Übersetzung zusammen (eine zeit die mit wArten zu TUN hat, Z.75). Davon ausgehend formuliert er einen EPT (WOrauf wArten wir EIgentlich im adVENT, Z.80-82), der als Ergänzungsinterrogativ das Religionswissen der anwesenden Personen relevant setzt. Nach einer längeren Pause (Z.80), in der bereits die Möglichkeit zur Produktion eines ZPT besteht, aber keine Reaktion erfolgt, benennt der Prediger die Art und Weise, in der die Frage beantwortet werden soll: diesmal nicht in Form eines Handzeichens, sondern eines verbal 
geäußerten Beitrags der Gemeinde (SAGT mal, Z.84). Damit kontextualisiert er zusätzlich zu den Hinweisen der morpho-syntaktischen Struktur und der Pause, dass es sich um eine Frage mit unmittelbarer Antworterwartung handelt. Es folgt denn auch eine längere Sequenz, in der vor allem die anwesenden Kinder antworten (K2 bis K5) und die Antworten vom Prediger bewertet werden. Er reklamiert dabei immer wieder, dass das Geäußerte zwar grundsätzlich richtig sei, aber noch nicht seiner Antworterwartung entspräche, da er die Frage nach jeder Antwort wiederholt:

- warUm warten wir auf WEIHnachten. (Z.86)

- auf den gebUrtstag von JEsus. da DENken wir dran. aber worauf WARten; (.) (Z.89-91)

- aber wir wArten in der adventszeit NOCH auf etwas. worAuf denn NOCH; (Z.100-101)

- wOrauf warten wir NOCH. (Z.111)

- es gIbt noch was ANders. worauf warten wir NOCH. (4.0) (Z.120-121)

- wOrauf warten wir NOCH; es gibt noch eine gAnz !WICH!tige sache. (Z.128-129)

Insgesamt sechs Mal re-etabliert der Prediger so seine Frage und zeigt damit auch an, dass es sich nicht nur um eine Frage mit hoher Antwortrelevanz handelt, sondern dass auch eine bestimmte inhaltliche Antwort erwartet wird und dass es bei der Frage nicht um die Überwindung eines Wissensdefizits des Predigers geht, sondern um die Abfrage eines bestimmten Wissensbestandes auf der Seite der Gemeinde. Ähnlich der Frageformen in schulischen LehrLern-Kontexten handelt es sich hier um eine known-answer-question, d. h. um eine Frage, deren Antwort dem Prediger bereits bekannt ist. Schließlich gibt eines der Kinder (K6) eine adäquate Antwort (Z.129), die der Prediger wiederholt und die ausgebaute Version des ZPT produziert (die adVENTSzeit ist die zeit wo wir nicht nur darauf warten dass jesus geBURTStag hat; 1.0$)$ sondern wir WARten darauf; das JEsus wiederkommt, Z.132-134). Mithilfe von vier Praktiken macht der Prediger deutlich, dass es sich bei seiner Frage (Z.80) um einen ersten Paarteil handelt, der einen zweiten verlangt:

- Interrogative Syntax

- Pausengestaltung

- Wiederholung und mehrfache Re-etablierung der Frage 
- Benennung der Art und Weise der Antwortproduktion

Die Prediger fragen auf diese Weise nicht nur Religionswissen ab, sondern vor allem das Bibeltextwissen der anwesenden Personen. So fordert der Prediger dieses Wortbeitrags die Gemeinde zu einem späteren Zeitpunkt dazu auf, biblische Erzählungen zu benennen, in denen es um das Thema ,Warten' geht (nicht im Transkript). Durch die Formulierung eines Ergänzungsinterrogativs konstruiert der Prediger in besonderer Weise eine Wissensgemeinschaft, da er der Gemeinde zuschreibt, dass sie mit den biblischen Geschichten in einer Weise vertraut ist, die es ihr erlaubt seine Frage zu beantworten. Der Prediger verweist damit auch auf die epistemische Expertise der anwesenden Personen.

Die gezeigten Auszüge machen deutlich, dass die Gattung der Predigt grundsätzlich Sequenzen mit unmittelbarem Wechsel der Interaktionsbeiträge zulässt und dass es vor allem Gattungstraditionen und die Gewohnheiten der anwesenden Personen sind, die die Etablierung von nicht-ritualisierten Paarsequenzen behindern bzw. erschweren. So zeigen die untersuchten Wortbeiträge, dass es in den meisten der hier untersuchten Gemeinden unüblich ist, dass die anwesenden Personen einen aktiven verbalen oder visuell-leiblichen Beitrag innerhalb des Wortbeitrags produzieren, und auf eine vom Prediger geäußerte Frage antworten ohne, dass eine Kontextualisierung der Antworterwartung erfolgt ist. Dies führt dazu, dass die Gemeinde Interrogative vor allem als Fragen mit hoher Rhetorizität und niedriger bzw. keiner Antworterwartung Seitens des Predigers interpretiert. Will der Prediger als Person mit aktivem Rederecht und der Hoheit, dieses Rederecht abzugeben und zu verteilen, tatsächlich dialogische Sequenzen mit unmittelbarem Wechsel der Interaktionsbeiträge etablieren, so bedarf es dazu immer wieder eines erhöhten kommunikativen Aufwands unter Einsatz verbaler, vokaler und visueller Ressourcen, um die Antworterwartung des Predigers zu kontextualisieren und eine wahrnehmbare Reaktion der anwesenden Personen zu elizitieren. In dem untersuchten Korpus wurde dieses Beteiligungsformat 40 Mal von acht verschiedenen Predigern in insgesamt 14 der 65 Predigten realisiert. Es handelte sich dabei um Jugendgottesdienste, alternative evangelische Gottesdienste und ökumenische Lobpreisgottesdienste.

Während Stivers/Rossano (2012) für Fragen in (englischsprachigen) Alltagsinteraktionen neben der sequentiellen Positionierung vier weitere typische antwortelizitierende Praktiken herausarbeiten (interrogative Syntax, steigende Intonation, Blickverhalten und den Verweis auf die epistemische Expertise des Gegenübers; vgl. Tabelle 17.2), werden in der institutionell gerahmten Gattung der Predigt neun unterschiedliche Praktiken der Antwortelizitierung auf verbaler, vokaler und visuell-leiblicher Ebene erkennbar. 
Tabelle 17.2 Antwortelizitierende Reccourcen

\begin{tabular}{|l|l|l|}
\hline $\begin{array}{l}\text { Ressourcen- } \\
\text { ebene }\end{array}$ & \multicolumn{1}{|c|}{$\begin{array}{c}\text { Alltagsinteraktion } \\
\text { (nach Stivers/Rossano 2010 und } \\
\text { 2012) }\end{array}$} & \multicolumn{1}{|c|}{$\begin{array}{c}\text { Wortbeitrag christlicher } \\
\text { Predigten }\end{array}$} \\
\hline verbal & $\begin{array}{l}\text { interrogative Syntax (Fragepartikel, } \\
\text { Satzbau, Rückversicherungssignale/ } \\
\text { tag questions } \text { etc.) }\end{array}$ & $\begin{array}{l}\text { interrogative Syntax (W-Fragewör- } \\
\text { ter, Fragepartikel, Satzbau etc.) }\end{array}$ \\
\cline { 3 - 3 } & & $\begin{array}{l}\text { Metakommentare (z.B. Benennung } \\
\text { der Antwortart) }\end{array}$ \\
\cline { 3 - 3 } & interrogative Prosodie & Wiederholung der Frage \\
\cline { 3 - 3 } & Bokal & Blickverrogative Prosodie \\
\hline visuell & & Pausen \\
\cline { 3 - 3 } & & $\begin{array}{l}\text { Anzeige der Antwortart (z.B. Mel- } \\
\text { den) }\end{array}$ \\
\cline { 3 - 3 } & & Reduzierung der räumlichen Distanz \\
\hline epistemisch & $\begin{array}{l}\text { Verweis auf epistemische Expertise } \\
\text { des Rezipierenden }\end{array}$ & $\begin{array}{l}\text { Verweis auf epistemische Expertise } \\
\text { des Rezipierenden }\end{array}$ \\
\hline
\end{tabular}

In den untersuchten Wortbeiträgen wurde auf verbaler Ebene eine interrogative Syntax mit z. B. W-Fragewörtern erkennbar (wEr ist daRÜR,warUm warten wir auf WEIHnachten), aber auch verbal realisierte Metakommentare (mEldet euch KURZ, SAGT mal), in denen die Prediger angeben, auf welche Art und Weise der Interaktionsbeitrag der anwesenden Personen erfolgen soll. In einigen Fällen wurden die Fragen mehrfach wiederholt. Auch das kontextualisiert, dass es sich um eine Frage mit geringer Rhetorizität und hoher (unmittelbarer) Antworterwartung handelt. Auf vokaler Ebene konnten für die vorliegenden Daten sowohl eine für Interrogative typische Prosodie als auch längere Pausen, die Raum für die eingeforderte Antwort lassen, herausgearbeitet werden. Besonders prägnant sind jedoch die Kontextualisierungshinweise mithilfe visuell-leiblicher Ressourcen. Hier spielen vor allem das Blickverhalten und das visuelle Anzeigen der Antwortart eine zentrale Rolle. Darüber hinaus reduzierten viele Prediger die räumliche Distanz, indem sie ihre körperliche Positionierung zur Gemeinde veränderten, wenn eine Frage eine hohe Antworterwartung hatte. Schließlich wurde auch in den untersuchten Wortbeiträgen der Verweis auf die epistemische Perspektive der Rezipierenden als Ressource zur Elizietierung eines unmittelbaren Interaktionsbeitrags der anwesenden Personen eingesetzt, indem z. B. Bibeltextwissen und Erfahrungswissen relevant gesetzt wurde. 
Ähnlich wie dies Stivers/Rossano in ihren Studien für Alltagsinteraktionen aufzeigen, nutzen auch die Prediger in den untersuchten Wortbeiträgen nicht nur eine antwortelizitierende Ressource, sondern mehrere. In den hier untersuchten Fällen waren das immer eine interrogative Syntax, längere Pausen und der (suchende) Blick in die Gemeinde. Diese Kontextualisierungshinweise werden häufig mit anderen Ressourcen kombiniert. Tabelle 17.3 gibt an, wann die einzelnen Elizitierungselemente eingesetzt wurden und wie häufig.

Tabelle 17.3 Sequenzielle Organisation Fragen in Wortbeiträgen

\begin{tabular}{|l|l|c|}
\hline Sequenzposition & \multicolumn{1}{|c|}{ Elizitierungselement } & $\begin{array}{c}\text { Anzahl im } \\
\text { Corpus }\end{array}$ \\
\hline \multirow{2}{*}{ Prä-Element } & Ankündigung der Frage & 2 \\
\cline { 2 - 3 } & Metakommentar zur Antwortweise & 1 \\
\hline EPT & Ergänzungs- oder Entscheidungsinterrogativ & 40 \\
\hline \multirow{5}{*}{$\begin{array}{l}\text { Antwort- } \\
\text { elizitierung }\end{array}$} & Metakommentar zur Antwortweise & 12 \\
\cline { 2 - 3 } & Visuelles Anzeigen der Antwortart (Melden) & 5 \\
\cline { 2 - 3 } & Blickzuwendung/ suchender Blick & 40 \\
\cline { 2 - 3 } & Pause & 40 \\
\cline { 2 - 3 } & Wiederholung und Erweiterung der Frage & 2 \\
\cline { 2 - 3 } & Reduzierung der räumlichen Distanz & 4 \\
\hline ZPT & Verbale oder visuell-leibliche Reaktion der Gemeinde & 34 \\
\hline Expansion & Kommentar des Predigers zur Antwort & 12 \\
\hline
\end{tabular}

In den untersuchten Wortbeiträgen werden insgesamt 40 InterrogativSequenzen mit einem ersten Paarteil (EPT) und einem zweiten Paarteil (ZPT) und hoher unmittelbarer Antwortrelevanz als Ergänzungs- oder Entscheidungsinterrogativ realisiert. Diese wurden morpho-syntaktischen als Fragen erkennbar. Da sich auf der verbalen und vokalen Ebene Fragen mit hoher Rhetorizität (niedrige Antworterwartung) und niedriger Rhetorizität (hohe Antworterwartung) nicht voneinander unterscheiden, reichen dieser Kontextualisierungshinweis nicht aus, um eine Reaktion der Gemeinde zu elizitieren. Daher nutzen die Prediger zusätzliche reaktionsmobilisierende Ressourcen und Praktiken. Die wichtigsten sind längere Pausen und die Zuwendung des Blicks in die Gemeinde im Anschluss an den EPT. Dies war in allen 40 Fällen erkennbar. 
Die auffälligste und zweithäufigste Praktik zur Kontextualisierung einer Frage mit unmittelbarer Antworterwartung ist die Benennung der Art und Weise, in der der ZPT produziert werden soll. In den untersuchten Wortbeiträgen forderten die Prediger in 13 Fällen entweder zu einer visuellen Reaktion auf (,meldet euch mal", ,mal melden“; ,meldet euch kurz", „Hand hoch") oder zur Produktion eines verbalen Gesprächsbeitrags (,sagt mal“, „lasst uns mal zusammentragen“). Die Angaben dazu, wie die Reaktion zu erfolgen hat, wird sowohl vor der Frageformulierung (in einem Fall) als auch im Anschluss daran gegeben (in 12 Fällen). Visuell unterstützt wird dies häufig dadurch, dass der Prediger die Antwortart visualisiert, indem er die Hand hebt (in 5 Fällen). In zwei Fällen reichte dieser visuelle Verweis aus, um eine Reaktion der Gemeinde zu elizitieren. Fragen mit hoher Antworterwartung können zu jedem Zeitpunkt des Wortbeitrags produziert werden und setzen vor allem Erfahrungen, Einstellungen und Empfindungen der anwesenden Personen relevant. Sie verweisen damit auf B-events, d. h. auf Wissensbestände, die im Erfahrungsbereich und im Wissensterritorium der Gemeinde liegen und auf die der Prediger keinen Zugriff hat. Darüber hinaus werden auch Religionswissen und Bibeltextwissen abgefragt. In diesem Zusammenhang werden Fragen mit niedriger Rhetorizität nicht nur dazu genutzt rhetorisch-didaktische Alternativen zum monologischen Wortbeitrag zu liefern, sondern auch zur Konstruktion einer Wissensgemeinschaft und zur Überprüfung der vom Prediger gemachten Wissensannahmen und -zuschreibungen. Dies steht wiederum in einem engen Zusammenhang mit der Art und Weise der Wissensvermittlung im Wortbeitrag (siehe Abschnitt 16.3.1, u. a. Beispiel 27). Grundsätzlich erscheint es, dass die Nutzung bestimmter elizitierender Ressourcen davon abhängt, wie ,trainiert" die Gemeinde darauf ist, Interrogative mit hoher unmittelbarer Antworterwartung wahrzunehmen. Eine Abhängigkeit von der Konfession oder dem Anlass konnte nicht festgestellt werden. ${ }^{4}$

Eine unmittelbare Beteiligung der anwesenden Personen am Wortbeitrag kann jedoch nicht nur durch Fragen mit hoher unmittelbarer Antworterwartung geschehen, sondern auch, indem eine oder mehrere Person(en) aus der Gemeinde zu Mitspielern werden. Dabei greift der Prediger noch stärker in die typische Interaktionsordnung des Wortbeitrags ein. Wie dies in den untersuchten Wortbeiträgen realisiert wurde, zeigt das folgende Kapitel.

\footnotetext{
${ }^{4}$ Vom Anlass der Predigt scheint lediglich abhängig zu sein, ob überhaupt Interrogative mit hoher unmittelbarer Antworterwartung realisiert werden. Grundsätzlich kann aber in jeder Predigt, egal ob reguläre Sonntagspredigt oder Jugendgottesdienst, das Format der Interrogative mit hoher Antworterwartung auftreten.
} 


\subsubsection{Anwesende Personen als Mitspieler im Wortbeitrag}

Wie es bereits in Beispiel 43 (Abschnitt 16.4) erkennbar wurde, können ausgewählte Personen zu einem Teil des Wortbeitrags werden, indem der Prediger sie zu sich bittet, um die thematisierten Aspekte zu verdeutlichen oder im Bibeltext beschriebene Personen darzustellen. Dieses Beteiligungsformat wurde im untersuchten Korpus in drei Wortbeiträgen von drei unterschiedlichen Predigern realisiert. Es handelte sich dabei um einen Lobpreisgottesdienst, einen alternativen evangelischen Gottesdienst und einen Jugendgottesdienst. Im nachfolgenden Auszug aus einem in einem Zelt stattfindenden Jugendgottesdienst bittet der Prediger eine einzelne Person zu sich auf die Bühne. Der Prediger nutzt das Beteiligungsformat, um einen zuvor vorgelesenen Bibeltext und die darin gemachten Aussagen für die Anwesenden anschaulich zu machen. Er setzt sich in seinem Wortbeitrag mit der Geschichte von Paulus und Silas auseinander, die in einem Gefängnis sitzen und Gott loben (Apg.16,22-25). Zunächst vermittelt der Prediger Bibeltextwissen über die göttliche Berufung der biblischen Protagonisten und Glaubenswissen indem er den überzeitlichen Charakter und die überzeitliche Gültigkeit des Textes herausstellt und verweist intertextuell auf weitere Bibelstellen, die diese Glaubensgewissheit stützen (,es ist die gleiche Berufung, die du auch hast. Und die ich habe. Jesus spricht sie aus - in Johannes fünfzehn"). Um die biblisch tradierte Berufung zu verdeutlichen, bittet er eine der anwesenden Personen zu sich. Die Erklärung des Predigers besteht in der Erzählung einer Begebenheit zwischen ihm und seiner Frau. Der nach vorn gekommene Junge nimmt dabei die Position der Ehefrau ein. Während der Prediger die Erzählung beginnt, steht der Junge neben ihm auf der Bühne und wartet, bis der Prediger ihn schließlich zu einem aktiven Gestalter des Wortbeitrags macht. 


\section{Beispiel 58: Rücken an Rücken}

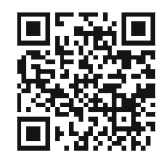

120 P: als wir vor eInigen JAhren, (-)

121 unterwEgs gewesen SIND, =

122 =silVESter?(---)

123 haben wir (.) mEnschen getroffen die auch so verrückt SIND;

124 wie Ihr und wie wie ICH; (-)

125 also die was mit jEsus am HUT haben; =

126 =und-(.)

127 da so ihr LEben; (-)

128 damit verBRINGen,

129 und an einem Abend wo wir uns getroffen HAben

130 und geBEtet haben,

131 hat (.) eIner aus dieser RUNde

132 über UNS, =

133 =über unserer ART, =

134

135

136

137

=wie wir unsere (.) LIEbesbeziehung;

Leben sollen. (-)

ein BILD ausgesprochen.

und ZWAR hat er-=

$\rightarrow 138$

139

=und dafür BRAUCH ich dich jetzt?

140

äh (.) er hat geSAGT wir zwei sollen;

141

äh (.) MENschen sein-

142

die rücken an RÜcken stehen.

ich bitt dich mal dass du dich mit deinem

rÜcken an mich STELlst.

143 so rIchtig FEST.

144 hier SO,

145 [kann man sich richtig RANlehnen?

$146 \mathrm{G}: \quad[($ (lachen) )

147 P: rücken an RÜcken.

148 er hat gesagt geht so durch das leben.

149 immer rücken an RÜcken.

150 wenn der eIne sich DREHT? (--)

151 dreht der Andere sich MIT. 
Der Prediger führt zunächst auf die eigentliche Inszenierung hin, indem er eine persönliche Geschichte rekonstruiert (Z.120-137). Innerhalb dieses Narrativs visualisiert er das Erzählte schließlich (ich bitt dich mal dass du dich mit deinem rÜcken an mich STELlst. so rIchtig FEST, Z.142-143). In diesem Fall ist es keine Begebenheit aus einem biblischen Text, die veranschaulicht wird (im Gegensatz zu Beispiel 43), sondern eine Metapher, die der Prediger vermittelt, um den Begriff der Berufung für die anwesenden Personen nachvollziehbar zu machen. Das Beteiligungsformat des gemeinsamen Vorspielens ist in diesem Wortbeitrag damit Teil der Handlung der Auslegung und Veranschaulichung des biblischen Textes. Nachdem dies abgeschlossen ist, setzt sich der Junge wieder zu den anderen Anwesenden und der Prediger fährt mit seinem Wortbeitrag fort. Dies ist der typische Fall: Eine Person aus der Gemeinde wird vom Prediger für einen begrenzten Zeitraum zu sich zum Predigtort geholt (vgl. dazu auch wieder Beispiel 43). Eine Ausnahme zeigt das nachfolgende Beispiel aus einem alternativen Gottesdienst einer evangelisch-lutherischen Gemeinde, der von der Gemeinde selbst als ,Der andere Gottesdienst " bezeichnet wird. Charakteristisch dafür ist eine veränderte Liturgie, die Integration moderner Lobpreislieder und die interakive(re) Gestaltung des Wortbeitrags. Auffällig ist vor allem die deutliche Orientierung auf die anwesenden Kinder. Der Prediger eröffnet die Predigt zunächst in der prototypischen Weise mit dem in der Gottesdienstordnung aufgeführten liturgischen Kanzelgruß, einer Aufforderung zum stillen Gebet, das durch die Textlesung beendet wird, und dem Textsegen, der mit einer Amen-Sequenz abgeschlossen wird (Z.1-15; siehe Kapitel 13 und Abschnitt 15.1.4). Dazu steht der Prediger in diesem Fall nicht auf einer Kanzel, sondern in freier Orientierung im vorderen Teil des Altarraums am Übergang zum Kirchenschiff. 
Beispiel 59: Drei Schwestern

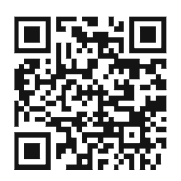

01 P: gnade sei MIT euch;

02 und frlede von gott unsrem VA:ter;

03 und von dem hErrn jesus CHRIStus.(-)

04 Amen. (--)

05 lAsst uns in der STILle; (.)

06 BEten.(15.0)

07 gott nAhe zu sein (.) ist mein GLÜCK, (--)

08 oder wie es LUther übersetzte-

09 ! A !er.

10 dAs ist meine FREUde;

11 dass Ich mich zu gott HALte.

12 der herr sEgne sein WORT;

13 an uns ALlen. (-)

14 Amen. 
$15 \mathrm{G}: \quad<<\mathrm{pp}>$ Amen. $>(2.0$

$\rightarrow 16$ P: habt ihr auch märchen so GERne.

\begin{tabular}{|c|c|c|}
\hline $\mathrm{P}$ & 0 & $\theta$ \\
\hline & $\mathrm{K}$ & \\
\hline S & & \\
\hline & & \\
\hline & & \\
\hline
\end{tabular}

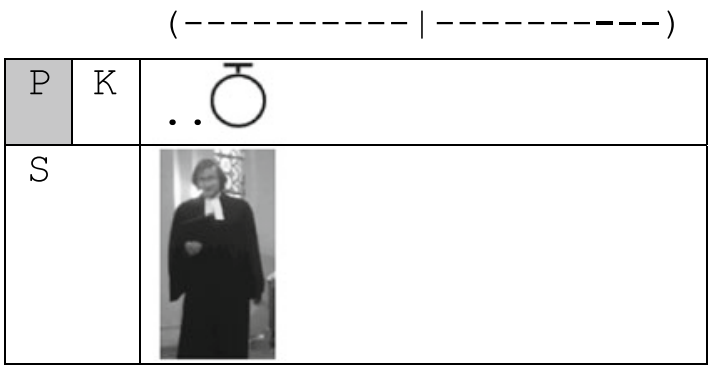

17 dann erzëHL ich einfach mal eins.(---)

18 es wAren einMAL drei-

19 drei geschWISter.(---)

20 sagen wir drei SCHWEStern. (1.5)

21 und die DREI-

22 sie STRITten sich.(--)

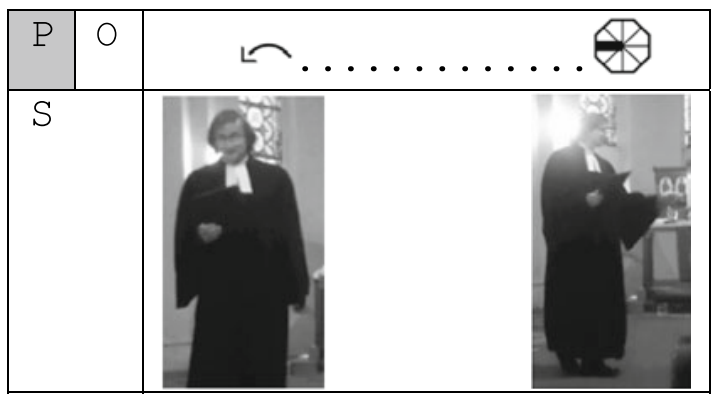


$\rightarrow 23<<$ pp $>$ habt ihr gesCHWISter?>

$24 \mathrm{KN}: \mathrm{JA}:::$ : :

25 P: [STREItet ihr euch?

$26 \mathrm{KN}: \mathrm{JA}::$ :

27 G: ((Gemurmel)) (---------1--------)

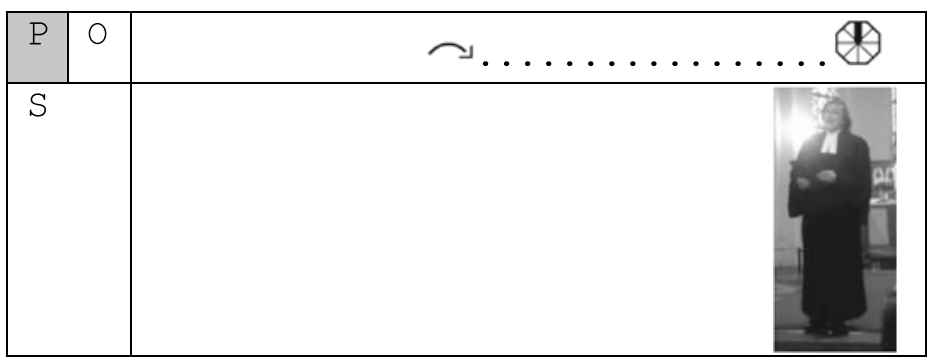

28 P: normAlerweise STREIten sich geschwister.

29 das ist KLAR.

30 die eIne schwester HIEß-(--)

31 TRAU (.)mir. (1.5)

32 TRAUmir.

33 die zweIte schwester HIEß-(-)

34 hAb (.) ANgst;

35 G: ((verweinzeltes Gekicher))

$36 \mathrm{P}$ : und die drItte schwester HIEß-

$37<$ <melodisch, gedehnt>ich weIß NICHT>; (2.0)

38 TRAUmir war ein,

39 FRÖHliches mädchen.

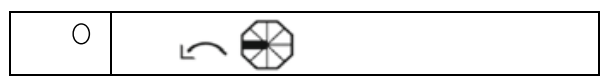

$\rightarrow 40 \quad<<\mathrm{p}>$ wEr ist von euch FRÖHlich?>(1.5)

$41<<$ p $>$ gut $>$. (2.0)

42 trAumir war ein FRÖHliches mädchen.=

43 =sieht man doch auf den ersten BLICK. 
Nach der liturgischen Eröffnung der Predigt (Z.1-15) beginnt der Prediger seinen Wortbeitrag mit einer Frage, die trotz einer interrogativen Syntax als Entscheidungsinterrogativ und der Etablierung einer langen Pause (habt ihr auch märchen so GERne. (2.0), Z.16) nur eine sehr geringe Antworterwartung etabliert. Dies liegt vor allem daran, dass der (suchende) Blick in die Gemeinde als wichtigster Kontextualisierungshinweise (siehe Abschnitt 17.3.2) fehlt, denn der Prediger senkt kurz vor der Beendigung der Frage seinen Kopf nach unten $\left(\bigcirc^{\Perp}, \mathrm{Z} .16\right)$ und wendet damit den Blick von den anwesenden Personen ab. Da er eine präferiert positive Antwort auf die Frage zuschreibt, kündigt er die Erzählung eines Märchens an (dann erZÄHL ich einfach mal eins, Z.17) und beginnt dieses mit der Märchenformel „es wAren einMAL“(Z.18). Kurz nach der Einführung der Märchenprotagonisten (Z.18-22) wendet sich der Prediger vom Großteil der Gemeinde ab und den im Altarraum sitzenden Kindern zu (ட und $\&$ Z.22). An diese adressiert er zwei Entscheidungsinterrogative mit hoher Antworterwartung (habt ihr geSCHWISter?, Z.23 und STREItet ihr euch?, Z.25), der die Kinder folgen und jeweils einen ZPT produzieren, indem sie verbal und durch Handzeichen antworten (Z.24 und Z.26). Im Anschluss daran wendet sich der Prediger wieder der Gemeinde zu ( $\mathbb{Q}, \mathrm{Z} .27)$. In dieser Position charakterisiert er die Märchenprotagonisten weiter (Z.30-39). Schließlich wendet er sich wieder den Kindern zu (Z.39) und wählt nach einer Frage mit hoher Antworterwartung (Z.40) eines aus, das er zu sich holt. Sie ist das erste von drei Mädchen, die im weiteren Verlauf des Wortbeitrags jeweils eine der vom Prediger vorgestellten Märchenprotagonistinnen verkörpern und die Geschichte spielen, während der Prediger sie erzählt. Dabei stehen sie die gesamte Zeit im Altarraum der Kirche, der in diesem Fall den Predigtort bildet.

Wie in den Beispiel 43 und 58 fragt der Prediger auch hier nicht nach dem Namen des Kindes, sondern adressiert es unmittelbar mit dem Rollennamen (trAumir war ein FRÖHliches mädchen. sieht man doch auf den ersten BLICK, Z.42-43). Nach den Mädchen bittet er nach einiger Zeit auch noch einen Mann aus der Gemeinden nach vorn, der ebenfalls eine der Figuren verkörpert und damit auch Teil der Geschichte und Teil des Wortbeitrags wird. Der Prediger verlässt dazu seinen Predigtort im Altarraum und geht den Mittelgang der Kirche entlang bis zu dem Mann, den er auswählt und zu sich und den Kindern bittet. Auch dieser Mann wird unmittelbar und ohne metakommunikativen Übergang in die Märchenfigur überführt. Während der Prediger seine Erzählung fortsetzt bleibt der Mann zunächst unterhalb der Altarstufen 
stehen und beginnt dann in einem kleinen Kreis zu laufen und damit die vom Prediger beschriebene Handlung der Figur auszuführen. Am Ende des Wortbeitrags zieht der Prediger zunächst eine Parallele zwischen den Handlungen der Märchenprotagonisten und den anwesenden Personen und schließt inhaltlich mit dem Verweis auf Gott und der Wiederholung des Predigttextes. Die Mädchen und der ausgewählte Mann bleiben den gesamten Wortbeitrag, bis zu dessen Beendigung mit dem Segen, neben dem Prediger stehen und sind dann auch Teil des auf die Predigt folgenden Liedes im Altarraum. Der Prediger bricht die prototypische Struktur des Wortbeitrags hier zum einen dadurch auf, dass er eine Geschichte erzählt und zum zweiten dadurch, dass er dazu vier Personen aus der Gemeinde als Darsteller zu sich holt und mit ihnen gemeinsam eine theatrale Inszenierung gestaltet.

In dem untersuchten Korpus ließen sich die Beteiligungsformate der ritualisierten Amen-Sequenz, der Frage-Antwort-Sequenz mit unterschiedlichen Antworterwartungen und das Format des gemeinsamen szenischen (Nach)Spielens herausarbeiten. Besonders das (Nach)Spielen und Fragen mit unmittelbarer Antworterwartung wurden vor allem in Predigten mit spezieller Zielgruppen- oder Themenausrichtung (Jugendgottesdienste, alternative Gottesdienste, Lobpreisgottesdienste) erkennbar. Dies zeigt, dass die kommunikative Gattung der Predigt auch innerhalb des Wortbeitrags für dialogische Sequenzen im engeren Sinne offen ist und sich so z. T. sowohl enge als auch weite Dialogizität in ein und demselben Wortbeitrag erkennen lassen. Gerade Interrogative mit hoher unmittelbarer Antworterwartung bedürfen in den hier untersuchten Wortbeiträgen zu ihrer Etablierung eines erhöhten kommunikativen Aufwands, d. h. die Prediger nutzen mehrere Ressourcen (verbal, vokal und visuell). Während die beschriebenen Beteiligungsformate dennoch den Wortbeitrag mehr oder weniger deutlich in seiner typischen Interaktionsordnung aufrechterhalten bzw. nur kurzzeitig aufbrechen, ist dies bei Dialogpredigten vermeintlich anders. Das nächste Kapitel widmet sich abschließend diesem Predigttrend. 


\subsection{Dialogpredigt}

In der homiletischen Diskussion zum Thema ,Predigt und Dialog' wird das Format der Dialogpredigt immer dann genannt, wenn es um die Herstellung hoher Dialogizität auf horizontaler Ebene geht. Die Dialogpredigt zeichnet sich vor allem dadurch aus, dass zwei Prediger zeitgleich den Wortbeitrag gestalten und sich gemeinsam am Predigtort aufhalten. Diese Dialogizität zwischen den beteiligten Predigern, die zudem keine spontane ist, sondern eine vorbereitete, inszenierte Dialogizität, sagt jedoch noch nichts darüber aus, ob sich auch die Beteiligungsformate mit der Gemeinde ändern und erhöhte Dialogizität entsteht. In diesem Kapitel sollen zwei unterschiedliche Realisierungsformen von Dialogpredigten betrachtet werden: die klassische Form, die durch die unmittelbare Wechselrede zweier Prediger gekennzeichnet ist, und eine zweite Form, bei der ein Prediger in zwei unterschiedlichen Rollen agiert und dadurch Dialogizität inszeniert.

Das nachfolgende Beispiel zeigt zunächst die erste Form, bei der sich zwei Prediger zeitgleich am Predigtort befinden (Abb. 17.3) und den Wortbeitrag gemeinsam gestalten, indem sie in einen Austausch treten, sich gegenseitig Fragen stellen, diese wechselseitig beantworten (siehe Beispiel 34, 50 und 60) und so Gedanken in Bezug auf das Thema des Wortbeitrags und einen biblischen Text äußern.

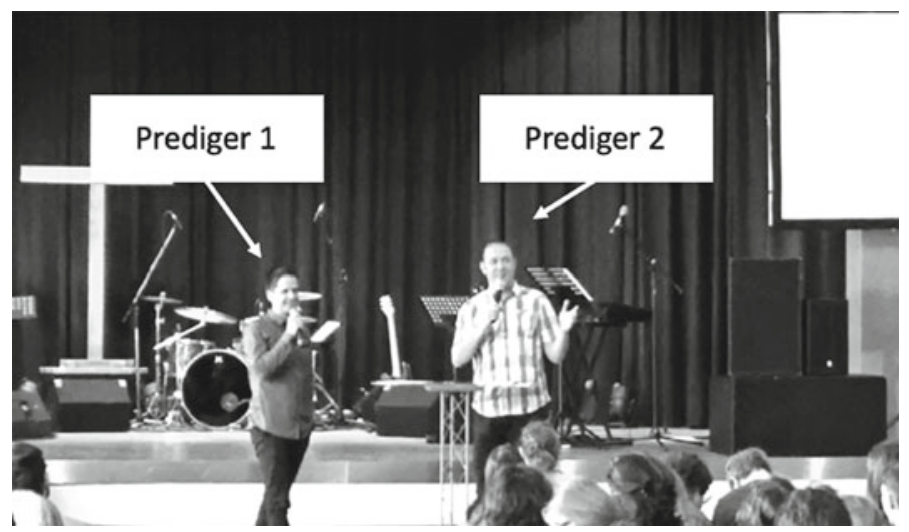

Abb. 17.3 Dialogpredigt 
Der Wortbeitrag wurde im Rahmen einer ökumenischen Jugendgottesdienstpredigt gehalten. Der Gottesdienst findet in einem Raum statt, der nicht spezifisch auf die Durchführung von Gottesdiensten ausgerichtet ist, sondern auch für andere Veranstaltungen wie Konzerte und Vorträge genutzt wird. Erkennbar ist eine Bühne, auf der Instrumente aufgebaut sind, und ein dieser festen Bühne vorgelagerter Bereich, der von den Gottesdienstmitarbeitern hergerichtet wurde. Auf diesen leicht erhöhten Podesten befindet sich der Predigtort, der aus einem beweglichen Pult besteht. P1 und P2 haben sich an diesem Pult positioniert und ihre Wortbeitragsmanuskripte darauf abgelegt. Während P1 Zettel gebraucht, nutzt P2 ein Tablet. Beide Prediger halten Mikrophone in der Hand. Die anwesenden Personen erscheinen als ratifizierte Rezipierende. Dies zeigt sich nicht nur in sprachlich realisierten Adressierungen, sondern vor allem an der Körperorientierung der Prediger. So wechseln sie beständig zwischen der Ausrichtung aufeinander und zur Gemeinde. Dies soll nachfolgend anhand einiger Sequenzen nachgezeichnet werden. Prediger 2 (P2) hat zunächst von einem alltäglichen Ereignis berichtet und damit das Thema eingeleitet. Es folgt die Frage an Prediger 1 (P1), ob dieser ebenfalls schon die Erfahrung gemacht hat, zwischen äußerem Schein und innerer Herzenshaltung zu stehen. Daraufhin erzählt P2 von Erlebnissen eines ihm bekannten Mannes und berichtet im Anschluss daran von eigenen Erfahrungen. An dieser Stelle setzt das nachfolgende Beispiel an. 
Beispiel 60: Bestimmung

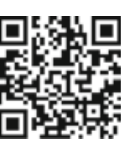

226 P1: ${ }^{\circ} \mathrm{h}$ es beginnt IMmer;

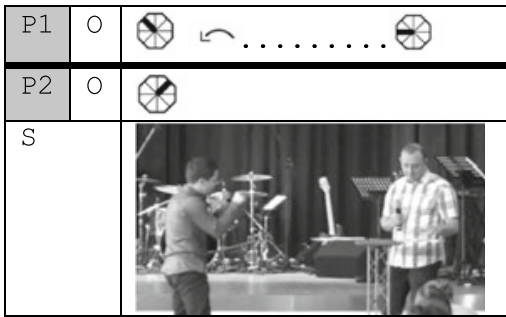

227 mit_nem gedanken in deinem HERzen;

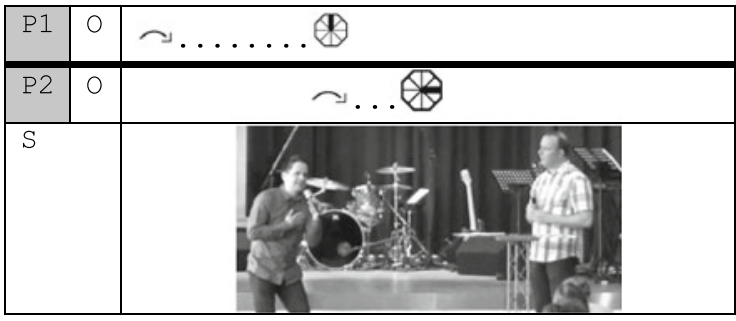

228 den du dort wOhnen LÄSST; (-)

229 und der dort (.) seine KREIse ziehen kann.

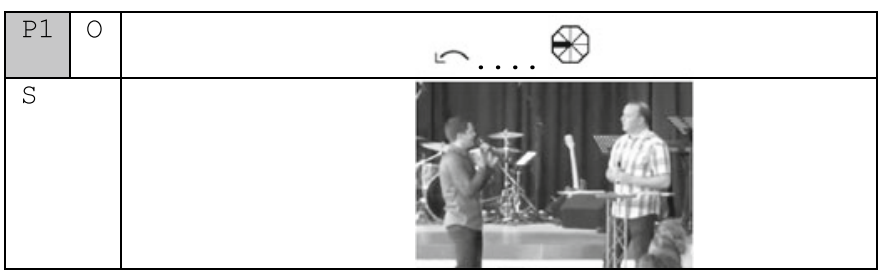

$230{ }^{\circ} \mathrm{h}$ und Endet ! IMM!er.

231 es endet Immer mit deiner bestimmung.

232 mit der mit dem wIe du LEBST;

233 was dein lEben AUSfüllt.

234 was ist deine bestIMmung.

235 kannst du_s auf den PUNKT bringen?

236 wenn dieses gesetzt STIMMT; (-)

237 dass es Immer mit der bestimmung ENdet;

238 wAs ist eigentlich deine bestiMmung. 
Während seines Redebeitrags bewegt sich P1 relativ stark und entfernt sich immer wieder auch vom Predigtort. Dabei wechselt er zwischen einer Orientierung auf P2 ( $\mathbb{Z}$, Z.226) zu einer Orientierung auf die Gemeinde ( $\mathbb{Q}$, Z.227),

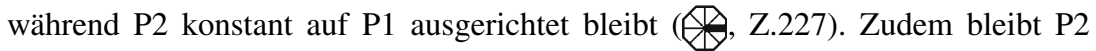
direkt am Pult stehen. Während P1 spricht, gibt P2 keine Rückmeldesignale durch Nicken oder verbale Äußerungen. Die Prediger zeigen damit unterschiedliche Bewegungs- und Raumnutzungsmuster. Dass der sprechende Prediger während seines Beitrags sich der Gemeinde zuwendet und der nicht sprechende Prediger seitlich zur Gemeinde steht, ist ein Muster, das sich durch die Predigt zieht. Während P1 spricht, ist er durch seine starke Bewegung körperlich sowohl zu P2 als auch zur Gemeinde orientiert und öfnet dadurch die Situation zu einer triadischen Interaktion. Kurz bevor er seinen Redebeitrag beendet und das Rederecht an P2 abgibt (wAs ist eigentlich deine beSTIMmung, Z.238) wendet er sich wieder P2 zu ( zwischen P1 und P2 wieder hergestellt ist. Damit wird deutlich, dass die Frage an P2 adressiert ist und dieser den turn übernehmen soll. P2 produziert daraufhin nicht nur einen zweiten Paarteil, indem er Bibeltextwissen vermittelt (siehe Beispiel 34, Abschnitt 16.3.3), sondern verändert auch seine körperliche Ausrichtung, indem er sich unmittelbar nach der turn-Übernahme von P1 ab- und der Gemeinde zuwendet. 
Beispiel 61: Hinweisschild 回risin

240 P2: ich DENK-(-)

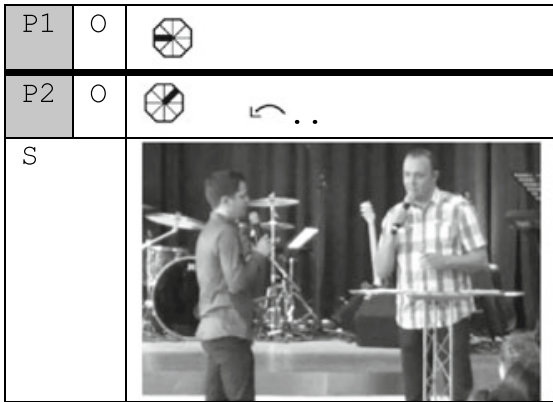

241 an den Anfang der BIbel?

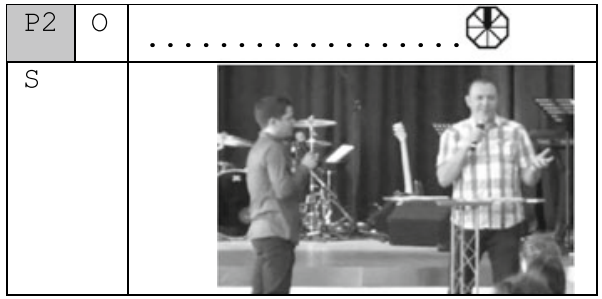

242 da gibts mal so_ne AUSsage; (-)

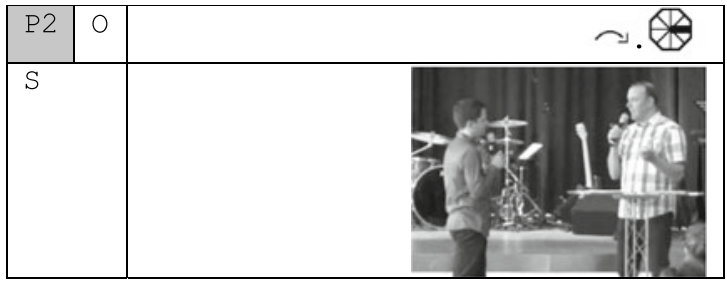

243 die hat mir geholfen das so_n bisschen so zu verSTEHen.

$244{ }^{\circ} \mathrm{h}$ da steht dass wir geschAffen sind als (.) BILD.

245 GoTtes.

246 oder ebenBILD;

247 so a_als gegenÜber.= 


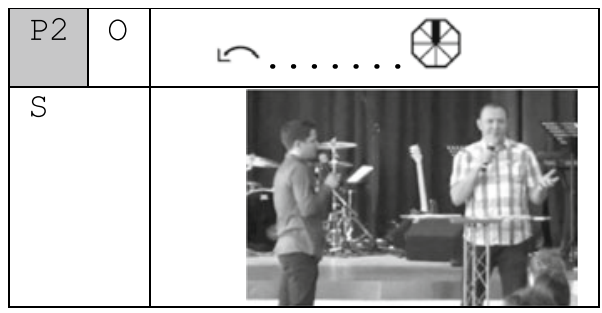

$((\ldots))$

264

und so geSEhen;

265

h* das wär_ne krasse geschichte.

266 wenn wIr solche saLEMS sind;

267

ja?

268

also- $(-)$

269

wir sollen-

270

als kInder GOTten;

271

in dieser WELT, (-)

272

so ein hInweisschild auf GOTT sein.

273

wir sollen etwas von der SCHÖNheit;

\begin{tabular}{|c|c|c|}
\hline P2 & O & $\frown \ldots . . . .8$ \\
\hline$S$ & & \\
\hline
\end{tabular}

274 und etwas von dem charAkter GoTtes;

275 WIEderspiegeln.

276 ! FÜR! ihn (.) LEben.=

277 =ein HINweisschild auf ihn sein.

278 das ist ne KRASse, (-)

279 ein krAsser AUFtrag. (-)

280 aber ich dEnk das ist unsere besTIMmung. 
Nachdem P2 das Rederecht von P1 übernommen hat, wendet er sich von diesem $\mathrm{ab}$ und der anwesenden Gemeinde zu ( $\curvearrowleft$ und $\mathbb{7}$, Z.240). P1 wiederum nimmt eine ähnliche Position wie zuvor P2 ein, denn er ist auf P2 ausgerichtet und steht somit seitlich zur Gemeinde ( $\$$ Z, Z.240). Dies Position verändert er während des Redebeitrags von P1 nur einmal, um auf seine Notizen zu schauen. P2 wiederum ist während seines Redebeitrags die meiste Zeit auf die Gemeinde ausgerichtet und adressiert an sie die Antwort, die er auf die Frage von P1 gibt. Erst kurz bevor er das Rederecht wieder an P1 übergibt, wendet sich P2 diesem deutlicher und länger zu ( $(\mathbb{D})$, ab Z.273). Während P1 relativ bewegungslos dasteht, bewegt sich P2 in seiner Orientierung zwischen dem Mitprediger und der Gemeinde. Er zeigt damit ein ähnliches Muster wie zuvor P2. Dieser kurze Auszug kann nur andeuten, dass sich die Prediger im Verlauf ihres Wortbeitrags wechselseitig das Ticket für relativ lange Redebeiträge geben, in denen der sprechende Prediger sich von dem anderen Prediger ab- und der Gemeinde zuwendet. Dabei zeigt sich anhand der verbalen und visuellen, vor allem körperlichen Ausrichtung auf die Gemeinde, dass diese nicht nur bystander und damit Betrachtende der Inszenierung und Performanz zwischen den Predigern ist oder diese zufällig wahrnimmt. Vielmehr ist die Gemeinde ein wesentlicher Bestandteil dieser Predigt und bildet damit das Interaktionsensemble mit. In diesem Zusammenhang wird auch deutlich, dass der unmittelbar vollzogene Sprecherwechsel zwischen den Predigern nicht die Häufigkeit oder die Form von Beteiligungsformaten der Gemeinde erhöht, denn bis auf eine Frage mit hoher Antworterwartung, die von P2 an die Gemeinde gerichtet wird (siehe Abschnitt 17.3.2, Beispiel 56), werden die anwesenden Personen nicht direkt in den Wortbeitrag einbezogen. Die Interrogativsequenz ist darüber hinaus - so legen es die Ergebnisse der vorgenommenen Untersuchung nahe - weniger dem Format der Dialogpredigt geschuldet als dem Charakter des Gottesdienstes als Jugendgottesdienst (siehe Abschnitt 17.3.2).

Eine abgewandelte Form der Dialogpredigt zeigt der nächste Auszug, ebenfalls aus einer Jugendgottesdienstpredigt. In diesem Beispiel realisiert nur ein Prediger den Wortbeitrag, wechselt jedoch währenddessen in unterschiedliche Personenrollen. Dies markiert er nicht nur verbal und vokal, sondern vor allem visuell, indem er eine räumliche Veränderung seiner Position vornimmt. Die Predigt realisiert er in einer Kirche, nutzt jedoch nicht die vorhandene Kanzel, sondern hält seinen Wortbeitrag von einem beweglichen Pult aus (nachfolgend als, erster Predigtort' bezeichnet; Abb. 17.4). Zusätzlich zu diesem Predigtort hat er daneben ein weiteres bewegliches Pult aufgebaut, zu dem er wechselt, wenn er von der Rolle des Predigers in die Rolle eines Zweiflers und damit in die Rolle einer biblischen Figur (Thomas) wechselt (nachfolgend als ,zweiter Predigtort' bezeichnet; Abb. 17.4). 


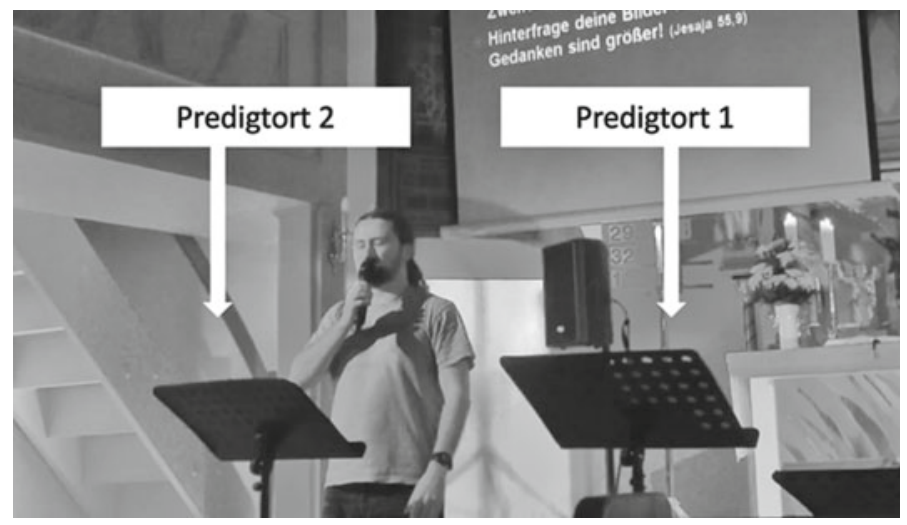

Abb. 17.4 Position am Predigtort

Der Prediger liest in diesem Wortbeitrag den Predigttext nicht einfach vor, sondern verkörpert selbst immer wieder eine in einem biblischen Text beschriebene Person. Er erzählt dabei nicht nur die Geschichte nach, sondern interpretiert sie, füllt Leerstellen und zieht intertextuelle Verweise zu anderen biblischen Texten. 
Beispiel 62: Warum hast du mich verlassen

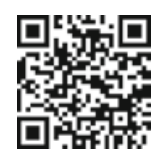

60 P: aber vielleicht im NACHhinein?

\begin{tabular}{|l|l|l|l|}
\hline P1 & 0 & E) \\
\hline$S$ & & \\
\hline & & \\
\hline
\end{tabular}

61 RÜCKblick,

62 wirst du vielleicht SEHen;

63 diese (.) zeIt des ZWEIfels; (-)

64 machen dich staBiler.

65 die lassen deinen glauben nochmal gAnz anders REIfen als-

66 äh-

67 die (.) happy clappy (.) SUperzeiten im christsein. (6.0)

68 zweIfel gehörn zum GLAUben,

69 sieh_s als CHANce?(-)

70 zum WACHsen.

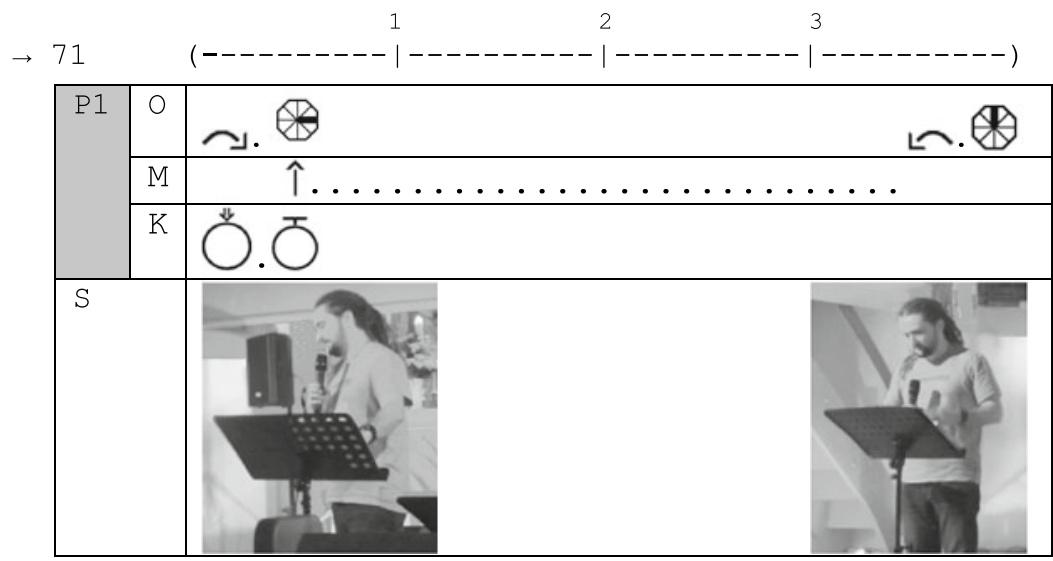


$72{ }^{\circ} \mathrm{hh} \mathrm{hh}{ }^{\circ}(-)$ allmÄchtiger !GOTT!, (--)

73 sieh doch an wie verWIRRT ich bin.

$74{ }^{\circ}$ hh wie !WÜ!tend und ent!TÄUSCHT! ich bin.(--)

$75{ }^{\circ} \mathrm{hh} \mathrm{hh}{ }^{\circ}$

76 ich kann ihnen einfach nIcht GLAUben.

77 (1.5) warum schweIgst du GOTT,

78 (5.0) mein GOTT,

79 mein GOTT;

80 warum hAst DU mich verlassen.

81 (1.0) warum bist du so FERN.=

82 =und hörst meine HILferufe nicht. (-)

$83^{\circ} \mathrm{h}$ jeden tAG (.) RUfe ich zu dir;

84 mein GOTT.

85 doch ANTwortest du nicht.

$86{ }^{\circ}$ hh jEde nacht (.) SCHREIe ich zu dir.

87 doch ich finde keIne RUhe.
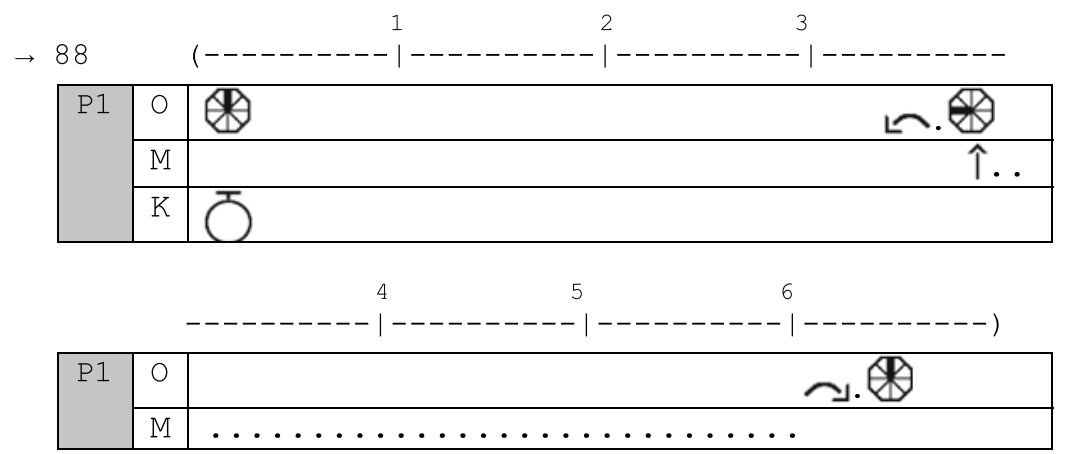

${ }^{\circ}$ hh die bibel ist so ein HERRlich; (.)

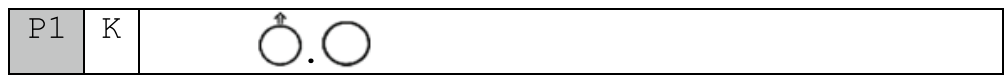

89 EHRliches buch.

90 die nIchts bescHönigt.

$91{ }^{\circ} \mathrm{h}$ schau dir die !GRO! Ben figuren der BIbel an. (-)

92 trotz ihrer zweifel ist GOTT; (-)

93 MIT ihnen,

94 unterWEGS. 
Zunächst nutzt der Prediger zur Visualisierung und Veranschaulichung des Bibeltextes und des Themas „Zweifel“ das Bild eines Baumes und seiner Jahresringe (über Beamer auf einer Leinwand hinter dem Prediger angezeigt) und parallelisiert dieses mit dem Aspekt des schnellen oder langsamen Glaubenswachstums und der damit verbundenen möglichen Zweifel. Im Anschluss daran formuliert er einen Glaubensgrundsatz, den er auch an der Leinwand anzeigt und damit verbunden eine Handlungsaufforderung (kontextualisiert durch den Imperativ; siehe Abschnitt 16.6) an die anwesenden Personen (zweifel gehörn zum GLAUben, sieh_s als CHANce? (-) zum WACHsen, Z.68-70). Er ist dabei körperlich auf die Gemeinde ausgerichtet ( immer wieder der Leinwand zu und setzt damit die Abbildung des Baumes relevant. Sein Kopf ist die meiste Zeit gerade und der Blick in die Gemeinde gerichtet. Schließlich senkt er seinen Kopf ab $\left(\bigcirc^{\Perp}, Z .71\right)$, verändert seine körperliche Ausrichtung ( $\frown$, Z.71) und geht zum anderen Pult ( $\uparrow$, Z.71). Dieser räumliche Wechsel zeigt den Rollenwechsel an, den der Prediger vornimmt. Er verkörpert nun die Figur eines zweifelnden Menschen (Z.72-87). In dieser Rolle nimmt der Prediger seine auf dem Pult liegende Bibel zur Hand und liest daraus einen kurzen Text vor (Z.78-87). Im Gegensatz zur vorherigen Position ist sein Kopf vorwiegend nach unten gerichtet und der Blick nicht dauerhaft auf die Gemeinde orientiert. Im Anschluss daran geht der Prediger wieder zurück zum ersten Predigtort (Z.93) und wechselt gleichzeitig zurück in die Rolle des Predigers. Als dieser kommentiert und interpretiert er nicht nur den vorgelesenen Bibeltext, sondern auch die dargestellten Handlungen und Gedanken der biblischen Person (Z.88-94).

Mehrere Male wechselt der Prediger in seinem Wortbeitrag zwischen diesen unterschiedlichen Rollen. Der Wechsel wird zum einen durch vokale Ressourcen angezeigt: In der Rolle der biblischen Person spricht der Prediger emphatischer, betonter und mit hörbar mehr Behauchung. Er atmet stärker ein und aus und lässt längere Pausen. Auf visueller Ebene zeigt sich der Rollenwechsel u. a. durch ein verändertes Blickverhalten. Während er in der Rolle des Predigers immer wieder direkt in die Gemeinde schaut, tut er dies in der Rolle der biblischen Person nicht. Der Blick bleibt dann auf dem vor ihm liegenden Manuskript oder bewegt sich stärker im Raum, ohne die anwesenden Personen in den Fokus zu nehmen. Auch die Gestik ist in der Rolle der biblischen Figur ausgeprägter. Die deutlichste Kontextualisierung des Rollenwechsels gibt jedoch die Veränderung der personalräumlichen Situation, indem der Prediger den Predigtort wechselt.

Der Dialogpredigtcharakter zeigt sich dann, wenn der Prediger nicht nur indirekt auf die Gedanken der biblischen Person Bezug nimmt, sondern direkt darauf reagiert, wie der nächste Auszug zeigt. 


\section{Beispiel 63: Hineinpassen}
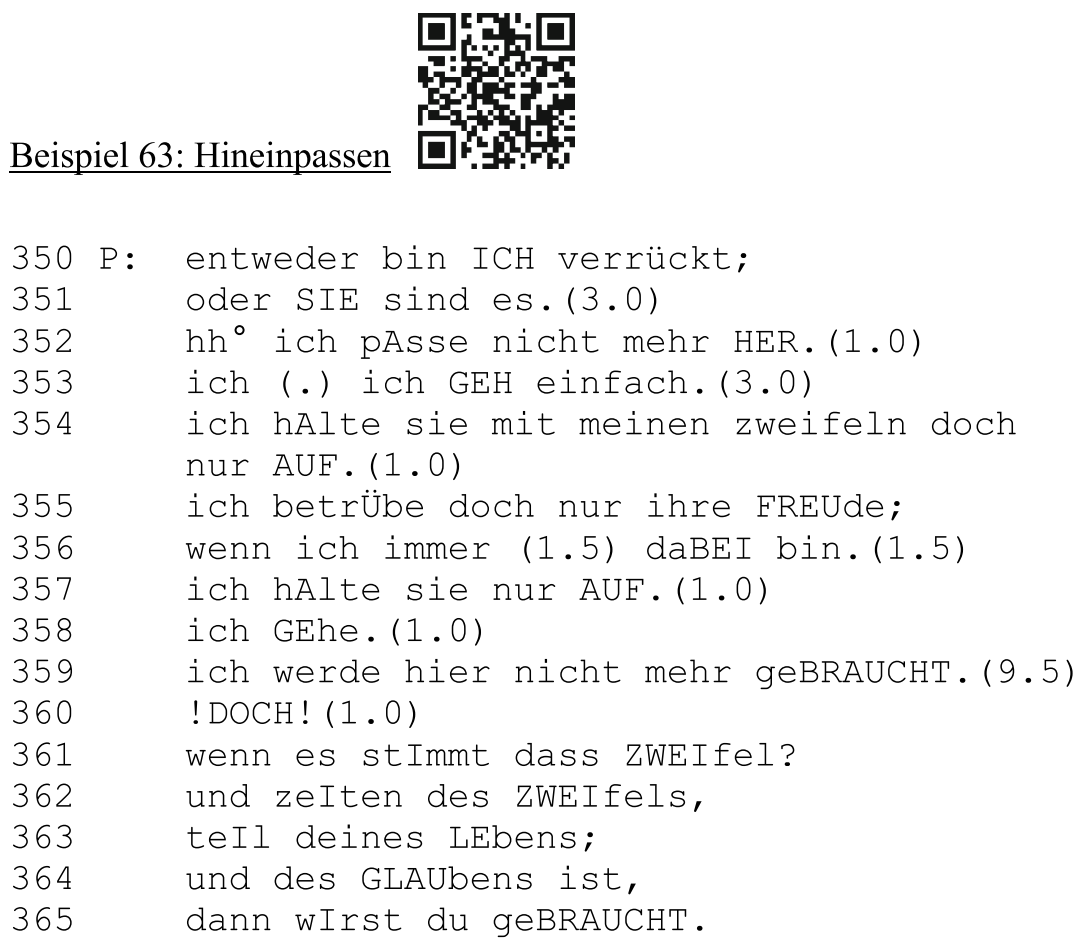

Ähnlich wie in der gezeigten Dialogpredigt, bei der zwei Prediger gemeinsam den Wortbeitrag gestalten und wechselseitig Interrogativsequenzen initiieren (Beispiel 60 und 61), realisiert der Prediger auch in diesem Auszug eine unmittelbare Paarsequenz. Auf die Behauptung bzw. Bewertung, die er in der Rolle der biblischen Person äußert (ich werde hier nicht mehr geBRAUCHT, Z.359), formuliert er nach seinem Ortswechsel (Z.359) in der Rolle als Prediger einen zweiten Paarteil, indem er auf die Behauptung reagiert und eine zweite Bewertung abgibt, die die erste zurückweist (! DOCH !, Z.360). In dieser kurzen Paarsequenz zeigt sich das, was Bachtin als Polyphonie bezeichnet: das gleichberechtigte und unvermischte Nebeneinander unterschiedlicher, wechselseitig aufeinander bezogener Stimmen (vgl. Bachtin 1985:9; siehe auch Benka 2015:19). Die Polyphonie ist ein grundlegendes Gestaltungsprinzip, das Bachtin im Zuge seiner Betrachtung der literarischen Werke Dostojewskis erarbeitet (vgl. Bachtin 1985). Entsprechend komplex und nicht unproblematisch ist die Übertragung auf andere literarische und vor allem nicht-literarische Gattungen. Obgleich sich die 
Polyphonie auch in Dialogen im engen Sinne zeigt, ist sie innerhalb des Konzepts der Dialogizität (siehe Abschnitt 17.1) eher auf der Ebene eines weiten Dialogsverständnisses und dem Dialog als übergeordnetem künstlerischen und formgebenden Gestaltungsprinzips verortet. Zunächst muss die Frage nach der Partizipation und den beteiligten Akteursrollen - bei Bachtin der Autor und der literarische Held - untersucht werden. Diese stehen als unabgeschlossene Personen mit jeweils eigenständigem Bewusstsein einander gegenüber und treten innerhalb eines bestimmten Augenblicks in einen dialogischen Austausch miteinander (vgl. Bachtin 1985:34). Die Polyphonie kann dabei punktuell auftreten, aber auch ein gesamtes Werk umspannend realisiert werden. Die Polyphonie Bachtins kommt gerade dadurch zustande, dass ein Sprecher nicht nur eine Rede neutral wiedergibt, sondern im Moment der Wiedergabe sowohl das Bewusstsein der wiedergegebenen Person als auch sein eigenes Bewusstsein präsent macht und dadurch die beiden Stimmen als eigenständige Bewusstseine nebeneinander stellt und gleichzeitig auf einander Bezug nehmen lässt. Der Prediger in diesem Wortbeitrag kontextualisiert mithilfe der beschriebenen verbalen, vokalen und visuellen Ressourcen und Praktiken, dass es sich jeweils um eine eigene Person (biblische Figur Thomas und Prediger) mit individuellen Ansichten handelt, die gleichberechtigt nebeneinander stehen und im Wortbeitrag in einen Austausch treten. Zunächst ist erkennbar, dass die dargestellte biblische Figur des Zweiflers nicht vom Prediger charakterisiert wird, indem er Kulturwissen oder Personenwissen vermittelt, sondern von der Figur selbst. D. h. die Gemeinde erfährt nicht, wer Thomas ist, sondern wie er sich selbst begreift und wie er auf die Welt blickt. Den anwesenden Personen wird nicht (objektiv) berichtet, welche Erlebnisse der Held, d. h. die biblische Figur, hat, sondern wie er diese deutet und welche Bedeutung er diesen für seine eigene Person zuschreibt (Z.350-359). Bachtin beschreibt diesen Umstand als zentrales Merkmal des Helden in polyphonen Zusammenhängen: „Wir sehen nicht, wer er [der Held; Anm. CD] ist, sondern wie er sich selbst versteht; wir nehmen nicht die Wirklichkeit des Helden ästhetisch wahr, sondern die Art und Weise, wie er sich dieser Wirklichkeit bewusst wird“ (Bachtin 1985:54). Im vorliegenden Beispiel wird das durch die direkte Rede, das Personalpronomen ,ich“ und das szenische Präsens kontextualisiert. In diesem Zusammenhang geht es nach Bachtin bei der Darstellung des Helden nicht um die Vermittlung einer individuellen Biographie und um sozial-charakteristische Elemente, sondern um eine Momentaufnahme einer Person ohne Biographie und objektive soziale Eigenschaften im Moment einer Krise. Diese werden allein durch die subjektive Sicht und Reflexion des Helden selbst rekonstruierbar. Etwas Ähnliches wird in diesem Wortbeitrag erkennbar: Die Figur des Thomas bleibt lange Zeit namenlos und kontextlos. Alles was die anwesenden Personen erfahren, wird durch ihn 
selbst vermittelt. Erst am Ende des Wortbeitrags nennt der Prediger den Namen der biblischen Figur (nicht im Transkript). Diesem Helden mit seinen subjektiven Eindrücken und Empfindungen stehen nun weitere Personen gegenüber, die gleichfalls über individuelle Erfahrungen und Gefühle verfügen. Der Prediger erscheint in diesem Wortbeitrag zwar auch als biographielose Person, wenn er auf seine eigenen Gotteserfahrungen und Zweifel verweist, mehr jedoch - und dies deckt sich wiederum nicht mit dem Polyphoniekonzept Bachtins - als Person mit großem Bibeltextwissen, der nicht nur mehrere biblische Personen benennt, die in ihren Zweifeln biblisch tradiert sind, sondern als übergeordnete Instanz diese aufeinander bezieht und in den größeren thematischen Rahmen des Wortbeitrags einordnet. Die Polyphonie wird zudem dort gebrochen, wo der Prediger auf überzeitliche und überindividuelle Glaubensgewissheiten eingeht und diese in seinem Wortbeitrag aktualisiert. Der Absolutheitsanspruch biblisch tradierter Gewissheiten über Gott und Glauben stehen der Unabgeschlossenheit der biblischen Figur und auch des Predigers nicht gegenüber, sondern überlagern sie. Obwohl in dieser Predigt an unterschiedlichen Stellen dialogische Elemente und sogar polyphone Elemente erkennbar sind, erhöht sich die Dialogizität auf der Ebene der Beteiligungsformate mit den anwesenden Personen nicht.

\subsection{Predigt als dialogische Gattung}

Das Thema der Dialogizität und der Interaktion wurde in diesem Kapitel hinsichtlich der Frage nach dialogischen bzw. interaktiven Momenten in der Predigt und im Wortbeitrag unter dem Stichwort der Beteiligungsformate vertieft. Dabei wurde zunächst zwischen einem weiten und einem engen Dialogbegriff innerhalb der sprachphilosophischen, soziologischen und interaktionalen Forschung unterschieden. Der Durchgang durch das hier untersuchte Korpus christlicher Predigten hat dann gezeigt, dass sowohl Aspekte einer weiten als auch einer engen Dialogizität auf allen drei Gattungsebenen erkennbar werden. In diesem Kapitel werden nun die Praktiken, die in den Kapiteln 13 bis 17 bereits beschrieben wurden, zusammengefasst und innerhalb der vorgestellten Dialogkonzepte eingeordnet.

\section{- Strukturierung des Raumes (siehe Kapitel 14)}

Folgt man der Interaktionsdefinition von Hausendorf, nach der das entscheidende Element für eine Interaktion die wechselseitige Wahrnehmung und die Herstellung von Wahrnehmungswahrnehmung ist, ermöglicht in den hier untersuchten Predigten die Interaktionsarchitektur, d. h. der gebaute und ausgestattete 
Raum, die Herstellung wechselseitiger Wahrnehmung und die Formierung der Interaktionsordnung eines Bühnenformats. Da die Beteiligten der räumlichen Anordnung folgen und sich aufeinander ausrichten, entsteht im Sinne Hausendorfs eine fokussierte Interaktion one-face-to-many-faces. Der Außenstrukturelle Aspekt des materiellen Raumes schafft damit die Herstellung von Interaktivität auf zwischenstruktureller Ebene.

\section{- Kooperative Herstellung des Ereignisses (siehe Kapitel 15)}

Bedingt durch die wechselseitige Wahrnehmbarkeit und die zeitlich-räumlichkörperliche Ko-Präsenz haben die anwesenden Personen die Aufgabe, das Predigtereignis gemeinsam herzustellen und durchzuführen. Obwohl die Predigt ein im Gottesdienst erwartbares Element der Liturgie, d. h. des Gottesdienstablaufs, ist, besteht eine lokal-situative Herstellungsnotwendigkeit, der die anwesenden Personen u. a. mithilfe ihrer körperlichen Ausrichtung nachkommen. Dadurch stellen sie kooperativ und wechselseitig die Predigt als interaktives Ereignis her, aktualisieren und bestätigen die typische Interaktionsordnung und Partizipationsstruktur. Auch darin zeigen sich dialogisch-interaktive Aspekte, die auf eine erfolgreiche Durchführung der kommunikativen Gattung hinwirken. Dabei spielen außenstrukturelle Elemente, wie der Raum und die Kopräsenz, mit binnenstrukturellen Aspekten, wie dem vorhandenen Gattungswissen, zusammen und wirken sich letztlich auf zwischenstruktureller Ebene aus.

\section{- Rezipientenzuschnitt z. B. bei der Wissensvermittlung (siehe Kapitel 16)}

Sowohl im Konzept der Dialogizität nach Bachtin als auch in der Betrachtung von Interaktionen innerhalb der konversationsanalytischen Tradition ist der Rezipientenzuschnitt bzw. die Adressatenorientierung ein zentrales dialogisches Element. In der kommunikativen Gattung der Predigt hat diese Orientierung auf die anwesenden Personen sowohl Auswirkungen auf die Binnenstruktur (z. B. die Art und Weise, wie das Vorhandensein von Wissen zugeschrieben wird und wie darauf aufbauend Bibelwissen, Bibeltextwissen, Religionswissen etc. im Wortbeitrag vermittelt wird) als auch auf die Zwischenstruktur, wenn die Zuschreibungen durch den Prediger in Form von Fragen mit hoher unmittelbarer Antworterwartung geprüft werden. Sowohl in einem weiten als auch in einem engen Dialogverständnis zeigen sich in Bezug auf den Rezipientenzuschnitt und die konkrete Orientierung auf das Gegenüber in der Art und Weise, wie Äußerungen gestaltet werden, dialogische bzw. interaktive Potenziale innerhalb der Predigt und vor allem des Wortbeitrags. 
- Beteiligungsformate (siehe Kapitel 17)

Auf zwischenstruktureller Ebene blockiert die spezifische Interaktionsordnung des Bühnenformats (one-face-to-many-faces) mit ihrer prototypischen Rederechtsverteilung (Bühnenmonolog des Predigers) das turn-taking-System, wie es für dyadische oder auch Mehrpersonen-Interaktionen in der interaktionsanalytischen Forschung herausgearbeitet wurde. So werden potenzielle turnübergaberelevante Orte (TRPs) nicht genutzt und die konditionelle Relevanz z. B. von Interrogativen abgeschwächt bzw. unterdrückt. Dies führt dazu, dass die Prediger eine aktive multimodal realisierte Antwortelizitierung vornehmen müssen, um eine Frage mit hoher unmittelbarer Antworterwartung zu kontextualisieren (eine Ausnahme bilden hier lediglich ritualisierte Paarsequenzen wie die Amen-Sequenz). In dem untersuchten Korpus nutzen die Prediger dazu neun unterschiedliche interaktive Elizitierungspraktiken, die in den meisten Fällen miteinander kombiniert wurden. Am häufigsten zu beobachten sind Interrogative mit mittlerer und hoher Rhetorizität, bei denen die Prediger eine verzögerte Antwort der Gemeinde relevant setzen.

In all der Flexibilität, die vor allem der Wortbeitrag sowohl in Bezug auf die strukturelle Gestaltung als auch in Bezug auf die thematische Entfaltung aufweist, lässt sich mit Blick auf die erkennbaren Beteiligungsformate eine deutliche Verfestigung rekonstruieren. Darüber hinaus wird deutlich, welche Rolle die Gemeinde bei der Ko-Konstruktion des Predigtereignisses als monologische Form spielt, denn es sind hier die Rezipierenden, die die Turnübernahme nicht bzw. nur nach komplexen Aufforderungen realisieren. Dadurch ko-konstruieren sie die monologische Struktur und die damit verbundenen Erwartungen aktiv mit. Auffällig ist auch, dass über Amen-Paarsequenzen hinausgehende Formate des call-and-response nur in Jugendgottesdiensten, alternativen Gottesdienstformen und bei Traugottesdiensten realisiert wurden. Die kommunikative Gattung der Predigt erlaubt es jedoch, die Gattungsgrenzen so weit auszudehnen, dass kurze Sequenzen mit unmittelbarem Wechsel der Interaktionsbeiträge, und damit Dialogizität im engen Sinne, etabliert werden können.

\section{- Rekonstruktiv-prospektiver Charakter (siehe Kapitel 16 und 17)}

In der Dialogkonzeption Bachtins spielt der Anschluss an bereits Geäußertes und der Verweis auf noch nicht Geäußertes und zukünftige Handlungen eine zentrale Rolle. Auf dieser übergeordneten, makrostrukturellen Ebene zeigt sich auch bei Wortbeiträgen christlicher Predigten ein besonderes dialogisches Potenzial, denn gerade dann, wenn die Prediger sich mit biblischen Texten auseinandersetzen, 
tradieren sie nicht nur die Erzählungen und Personen, sondern stellen in vielen Fällen die überzeitliche Gültigkeit der biblischen Aus- und Zusagen sowie die Parallelen mit aktuellen Verhältnissen heraus. Zusätzlich dazu formulieren sie häufig darauf aufbauende Handlungsmöglichkeiten, die zum einen den Gläubigen selbst betreffen und zum anderen in die Gesellschaft hineinwirken können. Der grundsätzlich rekonstruktiv-prospektive Charakter der Wortbeiträge zeigt damit hohe dialogische Potenziale in Bezug auf einen weiten Dialogbegriff.

Das Kapitel hat deutlich gemacht, dass für die Predigt sowohl die Betrachtung eines weiten als auch eines engen Dialogbegriffs relevant sind und dass sich Dialogizität nicht nur in den Vorannahmen des Predigers und im konkreten Rezipientenzuschnitt manifestiert, sondern auch in Beteiligungsformaten, die auf den unmittelbaren Sprecherwechsel ausgerichtet sind. In wie weit man die Gattung der Predigt als dialogische Gattung beschreiben kann, hängt also nicht nur davon $\mathrm{ab}$, ob man einen engen oder einen weiten Dialogbegriff verwendet, sondern auch davon, welchen Aktivitätstyp man im Einzelnen betrachtet. Während die Eröffnung und Beendigung der Predigt einen hohen Grad an Interaktivität (d. h. Dialogizität im engeren Sinne) aufweisen, zeigt der Aktivitätstyp des Wortbeitrags einen hohen Grad an weiter Dialogizität mit verzögerter Antworterwartung und in den meisten Fällen keinen verbalen Interaktionsbeitrag der Gemeinde. Hier dominiert der Prediger mit einem z. T. sehr langen Interaktionsbeitrag das Geschehen (Bühnenmonolog). Dennoch lässt sich die Struktur des Wortbeitrags weit genug ausdehnen, um interaktive Sequenzen zu etablieren und dennoch als Teil der Gattung Predigt mit ihrer spezifischen Interaktionsordnung erkennbar zu sein. Es bedarf in diesem Zusammenhang nicht zwingend neuer Formate wie der Dialogpredigt, um Interaktivität und Beteiligung im Sinne eines engen Dialogbegriffs zu etablieren. Es scheint vielmehr so, als habe die Gattung der Predigt in der Form der Dialogpredigt ihre Grenze erreicht, denn in Nachgesprächen mit den Predigern (die in der vorliegenden Arbeit nicht systematisch durchgeführt und ausgewertet wurden), haben diese berichtet, dass die Dialogpredigt von einigen Rezipierenden nicht als Predigt wahrgenommen wurde. Vielmehr erschien sie einem Interview über religiöse Themen oder einer Podiumsdiskussion näher als dem Wortbeitrag einer Predigt.

Abzuwarten bleibt, ob sich in den nächsten Jahren weitere Beteiligungsformate entwickeln und welchen Einfluss digitale Ressourcen auf die Gestaltung der Predigt haben, und ob interaktive Echtzeitvotings und Live-Feedbacksysteme zukünftig nicht nur im Gottesdienst, sondern auch innerhalb des Wortbeitrags als Beteiligungsressource genutzt werden. Dies muss an dieser Stelle jedoch ein Verweis auf zukünftige Forschungen bleiben. 
Open Access Dieses Kapitel wird unter der Creative Commons Namensnennung 4.0 International Lizenz (http://creativecommons.org/licenses/by/4.0/deed.de) veröffentlicht, welche die Nutzung, Vervielfältigung, Bearbeitung, Verbreitung und Wiedergabe in jeglichem Medium und Format erlaubt, sofern Sie den/die ursprünglichen Autor(en) und die Quelle ordnungsgemäß nennen, einen Link zur Creative Commons Lizenz beifügen und angeben, ob Änderungen vorgenommen wurden.

Die in diesem Kapitel enthaltenen Bilder und sonstiges Drittmaterial unterliegen ebenfalls der genannten Creative Commons Lizenz, sofern sich aus der Abbildungslegende nichts anderes ergibt. Sofern das betreffende Material nicht unter der genannten Creative Commons Lizenz steht und die betreffende Handlung nicht nach gesetzlichen Vorschriften erlaubt ist, ist für die oben aufgeführten Weiterverwendungen des Materials die Einwilligung des jeweiligen Rechteinhabers einzuholen.

(c) 